\title{
Abstracts of the 24th and the 25th Scientific Meeting of the Hong Kong Society of Neurosciences
}

The 24th Scientific Meeting of the Hong Kong Society of Neurosciences (HKSN)

Council 2004

President: David T.W. Yew

Vice-President: Wing-Ho Yung

Secretary: Ken K.L. Yung

Treasurer: Yu Huang

Membership Secretary/Councilor: Chris Wong Councilors: S.O. Chan, X.Q. Yao

International Representative: Y.S Chan

Organizing Committee

H. Benjamin Peng

Karl Tsim

Jun Xia
The 25th Scientific Meeting of the Hong Kong Society of Neurosciences (HKSN)

Council 2005

President: David T.W. Yew

Vice-President: Wing-Ho Yung

Secretary: Ken K.L. Yung

Treasurer: Yu Huang

Membership Secretary/Councilor: Chris Wong

Councilors: S.O. Chan, X.Q. Yao

International Representative: Y.S Chan

Organizing Committee

Xiaoqiang Yao

Wingho Yung 


\section{Contents}

The 24th Scientific Meeting of the Hong Kong Society of Neurosciences

Abstracts of Plenary Lectures .......................... 113

Abstracts of Oral Presentations. . . . . . . . . . . . . . . . . . . . . 114

Abstracts of Poster Presentations ....................... 120

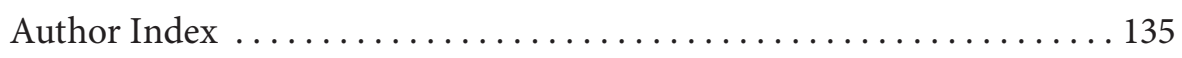

The 25th Scientific Meeting of the Hong Kong Society of Neurosciences

Abstracts of Plenary Lectures ........................... 137

Abstracts of Oral Presentations. . . . . . . . . . . . . . . . . . . 138

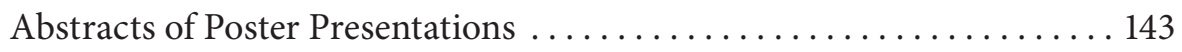

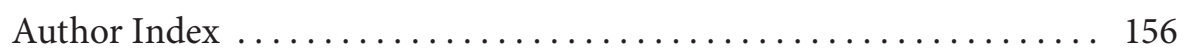

\section{KARGER}

Fax +41613061234

E-Mail karger@karger.ch

www.karger.com
(ㄷ) 2006 S. Karger AG, Basel

$1424-862 X / 06 / 0153-0111 \$ 23.50 / 0$

Accessible online at:

www.karger.com/nsg 


\section{The 24th Scientific Meeting of the Hong Kong Society of Neurosciences}

\section{Plenary Lectures}

PL-1/24

Axonal Regeneration in the Central Nervous System

So, K.-F.

Department of Anatomy, Faculty of Medicine, The University of Hong Kong, Hong Kong, China

Axons in the Central Nervous System (CNS) in adult mammals do not generally regenerate after damage. It is hypothesized that the lack of axonal regeneration is due to both extrinsic and intrinsic factors. The extrinsic factors would include the insufficient supply of trophic factor and/or neurite growth permissive molecules and the presence of inhibitory molecules in the axons. The intrinsic factor could be the decrease in the axonal growth potential in adult mammals. We have used a series of approaches to alter the extrinsic environment and to enhance the growth potentials of adult axons in the optic nerve and spinal cord. The external environment of the CNS axons could be enhanced by providing an environment suitable for axon regeneration, e.g. through the provision of a conduit using peripheral nerve graft for the damaged axons, or Schwann cells or olfactory ensheathing cell transplantation. We could also neutralize the inhibitory molecules using IN-1 or Nogo receptor blocker or to block inhibitory signaling pathways via Rho pathway inhibitor. The prevention of scar tissue formation by Chondroitinase $\mathrm{ABC}$ could also promote axon regeneration in CNS. The intrinsic factors could be modified to enhance regeneration by supplementing appropriate neurotrophic factors e.g. Ciliary neurotrophic factors (CNTF), or by elevating intrinsic regrowth capability, e.g. via the use of cAMP. Our studies suggest that a combined experimental approach is critical in optimizing the regeneration ability of CNS axons in adult mammals.

\author{
PL-2/24 \\ Cyclic GMP and $\mathrm{Ca}^{2+}$ Signaling: Involvement of TRPC \\ and CNG Channels \\ Yao, $X$. \\ Department of Physiology, Chinese University of Hong Kong, \\ Hong Kong, China
}

It is well known that nitric oxide production is stimulated by an increase in cytosolic $\mathrm{Ca}^{2+}$ concentration. Ample amount of evidence now shows that nitric oxide and cGMP themselves can affect $\mathrm{Ca}^{2+}$ influx in neurons in a positive or negative feedback manner. In our study, hippocampal neurons were isolated from 1-day-old Sprague-Dawley rats. Treatment of hippocampal neurons with thapsigargin, which inhibits the endoplasmic reticulum $\mathrm{Ca}^{2+}$-ATPase, induced store-operated $\mathrm{Ca}^{2+}$ influx. Application of cGMP markedly reduced the store-operated $\mathrm{Ca}^{2+}$ influx and the inhibition effect of cGMP was reversed by KT5823, a highly selective blocker for protein kinase G. Taken together, our data suggest that store-operated $\mathrm{Ca}^{2+}$ influx in rat hippocampal neurons is inhibited by cGMP via a protein kinase G-dependent pathway.

Attempts were made to search for molecules that are responsible for the store-operated $\mathrm{Ca}^{2+}$ influx in hippocampal neurons. TRP (transient receptor potential) channels are one of the largest groups of $\mathrm{Ca}^{2+}$-permeable nonselective cation channels. Six TRP subfamilies have been cloned: the canonical TRPC, vanilloid TRPV, melastatin TRPM, mucolpin TRPML, polycystin TRPP and ankyrin transmembrane protein 1 (ANKTM1). Immunohistochemical studies found the expression of TRPC channels in human central nervous system. Therefore, we explored the possibility of whether TRPC channels could be the downstream targets for protein kinase G. Cloned TRPC3 gene was overexpressed in HEK293 cells and the channels were found to mediate store-operated as well as store-independent $\mathrm{Ca}^{2+}$ influx in HEK293 cells. Both store-operated and store-independent $\mathrm{Ca}^{2+}$ influxes (via diacylglycerol) mediated by TRPC3 were inhibited by cGMP. Furthermore, the inhibitory effect of cGMP was reversed by a PKG inhibitor KT5823. Point mutations at two conservative PKG phosphorylation sites markedly reduced the inhibitory effect of cGMP 
on TRPC3, indicating that TRPC3 was a direct target for PKG phosphorylation. CNG (cyclic nucleotide-gated) channels are another group of channels that are widely expressed in central nervous system. CNG channels are directly activated by cyclic nucleotides including cGMP. The expression of CNG1A channels was found in many regions of human brains, notably in hippocampal CA1 and CA3, dentate gyrus, and cerebellar Purkinje cells. In hippocampal neurons isolated from 1-day-old rat, application of cGMP initiated an increase in cytosolic $\mathrm{Ca}^{2+}$ level, which was only observed in the presence of KT5823. The stimulatory effect of cGMP in $\mathrm{Ca}^{2+}$ was inhibited by L-diltiazem, a specific inhibitor for CNG channels, suggesting the involvement of CNG channels. The involvement of CNG became obvious only after the effect of cGMP on TRP channels was abolished. Taken together, there exist two cGMP-sensitive $\mathrm{Ca}^{2+}$ influx pathways in neurons, one (CNG) stimulated by cGMP and the other (TRPC) inhibited by cGMP. Because both CNG channels and TRPC channels mediates $\mathrm{Ca}^{2+}$ influx and because the expression of these channels are found in many brain regions that are known to be important for LTP/LTD, it is likely that they may participate in synaptic plasticity.

\section{Oral Presentations}

\section{OP-1/24 \\ ARMS Interacts with $\alpha$-Syntrophin: Implications for EphA4 Signaling at the Neuromuscular Synapse}

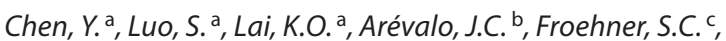
Adams, M.E. ${ }^{c}$, Chao, M.V. ${ }^{b}$, Ip, N.Y. ${ }^{a}$

aDepartment of Biochemistry, the Molecular Neuroscience Center and the Biotechnology Research Institute, Hong Kong University of Science and Technology, Clear Water Bay, Hong Kong, China, and 'bSkirball Institute of Biomolecular Medicine, New York University School of Medicine, New York, N.Y., 'Department of Physiology and Biophysics, University of Washington, Seattle, Wash., USA

ARMS (ankyrin repeat-rich membrane spanning) was initially identified as a substrate for ephrin and neurotrophin receptors and suggested to play important roles in neural development and plasticity. In this study, we showed that ARMS was expressed in developing muscle and became concentrated at the neuromuscular junction during the first postnatal week. Using yeast two-hybrid screening, we identified the PDZ domain protein $\alpha$-syntrophin as a protein that interacts with ARMS in muscle. Immunohistochemical studies revealed a similar expression pattern of syntrophin and ARMS proteins in developing muscle. Interestingly, overexpression of $\alpha$-syntrophin induced ARMS clustering in cultured cells, and this effect is dependent on PDZ domainmediated interactions. Analysis of $\alpha$-syntrophin null mice revealed the disrupted localization of ARMS and EphA4 at the neu- romuscular junction and reduced expression of ARMS in muscle. Moreover, we found that ARMS interacted with EphA4, resulting in an enhanced EphA4-induced tyrosine phosphorylation of Jak/ Stat proteins. Presence of $\alpha$-syntrophin further augmented the induction in a PDZ-dependent manner. Taken together, our findings suggest that ARMS may play a regulatory role in postsynaptic signal transduction through syntrophin-mediated localization of receptor tyrosine kinases such as EphA4.

Acknowledgement: This study was supported by the Research Grants Council of Hong Kong SAR (HKUST 6131/02M) and the Area of Excellence Scheme of the University Grants Committee (AoE/B-15/01).

\section{OP-2/24 \\ Identification of TRKB as a P35-Interacting Protein and a CDK5 Substrate}

Chin, W.H., Ip, N.Y.

Department of Biochemistry, the Biotechnology Research Institute and the Molecular Neuroscience Center, Hong Kong University of Science and Technology, Clear Water Bay,

Hong Kong, China

Cyclin-dependent kinase $5(\mathrm{Cdk} 5)$ is a serine/threonine kinase which is activated upon association with its activators p35 or p39. Cdk5 activity is detected mainly in the nervous system, and is implicated in various cellular processes including neuronal migration, neurite outgrowth, cytoskeleton dynamics, axon guidance and synaptic plasticity. Recent studies suggest that Cdk5 also plays a crucial role in regulating neuronal survival. Since neurotrophin/Trk signaling is similarly implicated in regulating neuronal survival and differentiation, we sought to examine if Cdk5 is involved in Trk signaling. Sequence analysis of Trk receptors reveals that there are potential Cdk5 phosphorylation sites in the juxta-membrane region of Trk receptors. While co-immunoprecipitation assays showed that all members of the Trk family associated with p35, only TrkB and TrkC were demonstrated to be phosphorylated by Cdk5/p25 in vitro. We further examined the potential association between $\mathrm{Cdk} 5$ and $\operatorname{TrkB}$ receptor in vivo. We confirmed that p35 interacted with TrkB in overexpressed COS-7 cells and in rat brain. In addition, we found that the juxtamembrane region of TrkB was phosphorylated by active Cdk5. Site-directed mutagenesis of the potential C $\mathrm{dk} 5$ phosphorylation sites on TrkB resulted in reduced phosphorylation by the Cdk5/ p25 complex. Taken together, our results suggest that TrkB receptor is a p35 interacting protein and a Cdk5 substrate. Studies are in progress to elucidate the functional roles of Cdk5 in TrkB signaling in the nervous system.

Acknowledgement: This study was supported by the Research Grants Council of Hong Kong SAR (HKUST 6091/01M, 6130/ 03M, 2/99C and 3/03C), the Area of Excellence Scheme of the University Grants Committee (AoE/B-15/01). 


\section{OP-3/24 \\ Mitochondrial Clustering at the Vertebrate Euromuscular Junction during Presynaptic Differentiation}

Lee, C.W., Peng, H.B.

Department of Biology, Hong Kong University of Science and Technology, Clear Water Bay, Hong Kong, China

During vertebrate neuromuscular junction (NMJ) development, presynaptic motor axons differentiate into nerve termini enriched in synaptic vesicles (SVs). At the nerve termini, mitochondria are also concentrated, but how mitochondria become localized at these specialized domains is poorly understood. Here, using embryonic Xenopus spinal neuron and muscle cultures, we have investigated the targeting and clustering of mitochondria during nerve terminal differentiation. Labeling with MitoTracker revealed that mitochondria were enriched in naïve neurons at varicosities and growth cones, and FM1-43 uptake experiments showed that these sites contained releasable pools of SVs. In nervemuscle co-cultures, mitochondria and SVs were concentrated at sites where neurites and muscle cells formed NMJs, and mitochondria co-clustered with SVs where neurites were focally stimulated by beads coated with growth factors. At early stages of bead-stimulation, actin-based protrusions developed in neurites near bead contact sites, but these were not detected in cells treated with latrunculin A (Ltn A), an actin polymerization blocker. Moreover, Ltn A inhibited bead-induced mitochondrial and SV clustering, whereas the microtubule disrupting agent nocodazole was ineffective in doing so. Lastly, in contrast to Ltn A which blocked bead-induced clustering of both mitochondria and SVs, the ser/thr phosphatase antagonist okadaic acid inhibited SV clustering but not mitochondrial clustering. Our results suggest that at developing NMJs, synaptogenic stimuli induce the clustering of mitochondria together with SVs at presynaptic terminals in an actin cytoskeleton-dependent manner and involving different intracellular signaling molecules.

Acknowledgement: NIH NS36754, RGC HKUST6107/01M, AoE/B-15/01.

\section{OP-4/24 \\ Pctaire1 Phosphorylates N-Ethylmaleimide Sensitive Fusion Protein and Regulates Constitutive Exocytosis in PC12 Cells}

Liu, Y.X., Cheng, K., Hung, K.W., Fu, A.K.Y., Ip, N.Y.

Department of Biochemistry, the Biotechnology Research Institute and the Molecular Neuroscience Center, Hong Kong University of Science and Technology, Clear Water Bay, Hong Kong, China

Pctaire1, a member of the family of cyclin-dependent kinases, is expressed prominently in terminally differentiated cells. We have previously reported that Pctairel interacts with the Cdk5/ p35 complex in brain and muscle. To elucidate the function of Pctairel, we have identified proteins that associate with Pctaire1 using yeast two-hybrid screen. $\mathrm{N}$-ethylmaleimide sensitive fusion protein (NSF) was one of the positive clones isolated. NSF is a crucial factor in intracellular membrane-fusion events, such as the fusion of synaptic vesicles with the presynaptic membrane during neurotransmission. Binding of NSF to Pctairel can be demonstrated by GST pull-down assay and co-immunoprecipitation experiments. Pctairel was associated with NSF in adult rat brain, and was enriched in the synaptosomal fraction. We found that the D2 domain of NSF, which is required for hexamerization of the NSF subunits, could bind directly to Pctairel and was phosphorylated by Pctaire1. Furthermore, co-expression of NSF and Pctairel kinase dead mutant in COS-7 cells resulted in enhanced oligomerization of NSF. Consistent with this finding, over-expression of the constitutive phosphorylation mutant of NSF reduced the self-association of NSF. To examine the potential roles of Pctairel in regulating exocytosis, the growth hormone $(\mathrm{GH})$ secretion assay in PC12 cells was performed. We showed that over-expression of Pctairel reduced the constitutive GH release compared to that of control while Pctairel kinase dead mutant increased GH release significantly. Moreover, over-expression of NSF phosphorylation deficient mutant enhanced the constitutive $\mathrm{GH}$ release compared to that observed with wild type NSF. Together, our findings suggest that Pctairel activity might regulate constitutive GH release in PC12 cells through the phosphorylation of NSF.

Acknowledgement: This study was supported by the Research Grants Council of Hong Kong SAR (HKUST 6130/03M and $6091 / 01 \mathrm{M})$ and the Area of Excellence Scheme of the University Grants Committee (AoE/B-15/01).

\section{OP-5/24 \\ ANKRA Interacts with p35 and Is a Substrate for Cdk5/p35}

Ng, A.K.Y., Fu, A.K.Y., Ip, N.Y.

Department of Biochemistry, the Biotechnology Research Institute and the Molecular Neuroscience Center, Hong Kong University of Science and Technology, Clear Water Bay, Hong Kong, China

Cdk5 is a serine/threonine kinase that plays a pivotal role in neural development. More than thirty proteins have been identified as the substrates for Cdk5. By phosphorylating these diverse cellular targets, Cdk5 plays a multifunctional role in neurons including neurite outgrowth, axonal guidance, cytoskeleton assembly, membrane transport, synaptic function and dopamine signaling. In addition, recent studies have implicated that Cdk5 is involved in the regulation of gene transcription. For example, our laboratory has reported that a transcription factor, signal transducer and activator of transcription-3, and a transcription regulator, $\mathrm{mSds} 3$, are the substrates for Cdk5. Using yeast two-hybrid screen, we recently identified another protein implicated in the regulation of transcription, named ANKRA (ankyrin-repeat family A protein), as a 335 -interacting protein. We showed that ANKRA associated with p35 based on glutathione S-transferase pull-down analysis as well as co-immunoprecipitation analysis. ANKRA was prominently expressed in brain and remained relatively unchanged during development. In addition, ANKRA protein was detected at abundant level in developing muscle during 
embryonic development and declined thereafter. We demonstrated that ANKRA associated with p35 in brain, and that active Cdk5 could phosphorylate ANKRA in vitro. Taken together, these findings identify ANKRA as a novel substrate of Cdk5 and provide insight into understanding how $\mathrm{Cdk} 5$ regulates gene transcription in the nervous system.

Acknowledgement: This study was supported by the Research Grants Council of Hong Kong SAR (HKUST 6091/01M, 6130/ $03 \mathrm{M}$ and $6119 / 04 \mathrm{M})$ and the Area of Excellence Scheme of the University Grants Committee (AoE/B-15/01).

\section{OP-6/24 \\ A Novel Role of P120 Catenin in Mediating Agrin-Induced Formation of Myopodia during Neuromuscular Synapse Development}

Peng, H.B., Madhavan, R.

Department of Biology, Hong Kong University of Science and Technology, Clear Water Bay, Kowloon, Hong Kong, China

At developing vertebrate neuromuscular junctions (NMJs), muscle cells make initial contacts with motor axons by means of microprocesses, termed myopodia, which are induced by the nerves. In cultured rodent muscle cells, the nerve-secreted, muscle acetylcholine receptor (AChR)-clustering factor agrin also induces myopodia, but how it does so has remained unclear. We report here that in cultured Xenopus embryonic muscle cells, cocultured spinal neurons and bath-applied agrin generated myopodia that preferentially localized near sites of AChR clustering. Myopodia were stained in their entirety by anti-phosphotyrosine antibodies and contacts between myopodia and neighboring muscle cells were strongly labeled by the lectin Vicia villosa agglutinin B4 (VVAB4). VVAB4-positive muscle junctions were enriched in cadherin complex proteins, including p120 catenin (p120ctn), and addition of agrin selectively and reversibly reduced p120ctn's association with cadherin junctions in situ. In accord with these results, agrin-treatment of cultured C2 mouse myotubes transiently increased the tyrosine phosphorylation of p120ctn and decreased its cadherin-interaction in cell extracts. Significantly, forced elevation of p120ctn levels in Xenopus muscle cells induced myopodia in the absence of agrin, an effect that could be further enhanced by agrin-treatment, whereas over-expression of a mutant $120 \mathrm{ctn}$ protein incapable of regulating rho GTPase suppressed agrin-dependent myopodial assembly. Moreover, expression of a different p120ctn mutant protein, lacking multiple src tyrosine kinase phosphorylation sites, generated myopodia independently of agrin, but agrin-treatment failed to enhance this effect. We propose that agrin downstream signaling in muscle modulates, by tyrosine phosphorylation, the cadherinassociation of p120ctn, which, when dissociated from cadherin, acts through rho GTPase to direct the formation of myopodia that help establish incipient NMJs.

Acknowledgement: This work was supported by RGC grant HKUST6101/02M and NIH grant 23583.

\section{OP-7/24 \\ ATP Induces Post-Synaptic Gene Expression in Neuron-Neuron Synapses: The Transcription Regulation of NR2A Subunit}

Siow, N. ${ }^{\mathrm{a}}$, Xie, H. ${ }^{\mathrm{a}}$, Choi, R. ${ }^{\mathrm{a}, \mathrm{b}}$, Barnard, E. ${ }^{\mathrm{b}}$, Tsim, . $^{\mathrm{a}}$

${ }^{a}$ Department of Biology, Hong Kong University of Science and Technology, Hong Kong, China, and ' ${ }^{\text {b Department of }}$

Pharmacology, University of Cambridge, Cambridge, UK

Adenosine $5^{\prime}$-triphosphate (ATP) is an important trophic factor, which is co-stored and co-released at central and peripheral cholinergic and bioaminergic neuronal synapses. Previous studies showed that the synaptic ATP could induce post-synaptic gene transcriptions in muscle $[1,2]$. However, the role of ATP in central nervous system is still not clear. In the brain, excitatory synapses are very important for learning and memory through the process of long-term potentiation. One of the glutamate receptors, $\mathrm{N}$ methyl-D-Aspartate (NMDA) receptor composed of NR1 and NR2 (NR2A, NR2B, NR2C or NR2D) subunits, plays a significant role in this process. Therefore, studying the gene regulation of NMDA receptor subunit is of significance. In the present study, primary culture of rat cortical neurons was used as a model system to study the biological functions of ATP in neuron-neuron synapses. Immunocytofluorescent staining showed that one of the ATP receptor subtypes, $\mathrm{P}_{2} \mathrm{Y}_{1}$ receptor, was co-localized with the post-synaptic marker PSD-95. Activation of $\mathrm{P}_{2} \mathrm{Y}_{1}$ receptor was found to up-regulate NR2A protein expression. The transcriptional regulation of NR2A gene was further studied by using a mouse NR2A promoter tagged with a luciferase reporter gene. Preliminary results showed that application of $\mathrm{P}_{2} \mathrm{Y}_{1}$ receptor agonist could induce a mitogen-activated protein kinase (MAPK) signaling cascade, in which, through the activation of ERK $1 / 2$ and subsequently activate NR2A gene expression. The regulation of acetylcholinesterase (AChE) was also analyzed for comparison. These results suggest that $\mathrm{ATP}$ via its $\mathrm{P} 2 \mathrm{Y}_{1}$ receptor can regulate the NMDA receptor expression, which may contribute to the learning and memory process in our brain.

Acknowledgement: Research Grants Council of Hong Kong (HKUST 6098/02, 6283/03M and 6237/04M); Croucher Foundation.

References

1 Choi R, et al: J Neurosci 2001;23:9224-9234.

2 Choi R, et al: J Neurosci 2003;23:4445-4456. 
OP-8/24

\section{A Camp-Dependent Signaling Directs the Post-Synaptic Expression of COLQ, a Subunit of Collagen-Tailed Form ACHE, at the Vertebrate Neuromuscular Junctions}

Ting, $A{ }^{\mathrm{a}}{ }^{\mathrm{a}}$ Massoulié, J. ${ }^{\mathrm{b}}$, Tsim, $\mathrm{K}^{\mathrm{a}}{ }^{\mathrm{a}}$

aDepartment of Biology, Hong Kong University of Science and Technology, Clear Water Bay, Hong Kong, China, and b Laboratoire de Neurobiologie Moléculaire et Cellulaire, CNRS

UMR 8544, Ecole Normale Supérieure, Paris, France

In vertebrate neuromuscular junction ( $\mathrm{nmj}$ ), the asymmetric acetylcholinesterase is anchored to synaptic basal lamina through a collagen-tailed subunit (ColQ). There are two types of ColQ mRNAs, namely ColQ-1 and ColQ-1a which are different in their first exons. ColQ-1 mRNA is mainly expressed in slow-twitch muscle throughout the whole muscle fiber while ColQ-1a mRNA is expressed in fast-twitch muscle and highly restricted to $\mathrm{nmj}$ regions. The differential expressions of ColQ-1 and ColQ-1a mRNAs in different muscles are regulated by two different promoters, namely pColQ-1 (slow) and pColQ-1a (fast) [1]. However, the molecular mechanisms in regulating their synaptic expressions in different muscles are still not clear. The level of ColQ mRNA in rat muscles dropped dramatically after denervation which suggested that nerve-derived factors and nerve-evoked electrical activity might play a regulatory role(s). The ColQ promoters tagged with a luciferase reporter gene (pColQ-1-Luc and pColQ-1a-Luc) are used as a tool to map out the gene regulations in muscle. A nerve-derived factor, calcitonin gene-related peptide (CGRP), which induced cAMP-dependent signaling pathway in muscle, phosphorylated cAMP-responsive regulatory element binding protein (CREB) and up-regulated the promoter activity of ColQ-1a but not ColQ-1. Application of cAMP potentiated the CREB-mediated ColQ-1a expression. Similar results were obtained by elevation of calcium level in muscle, which activated calcium/calmodulin-dependent kinase (CaMKII) and were found to induce the CREB phosphorylation. In addition, the endogenous level of CREB is much higher in fast muscle (tibialis) than in slow muscle (soleus). These results indicated that CGRP-mediated CAMP-dependent pathway may act as one of crucial regulatory mechanisms to drive the synaptic expression of ColQ-1a in fast muscle.

Acknowledgement: Research Grants Council of Hong Kong (HKUST 6098/02, 6283/03M and 6237/04M).

\section{Reference}

1 Lee H, et al: J Biol Chem 2004;279:27098-27107.
OP-9/24

Expression of NOGO-A in the Chiasm of Mouse Embryos

Wang, J., Chan, S.O.

Department of Anatomy, The Chinese University of Hong Kong, Shatin, N.T., Hong Kong, China

Nogo-A is known to be a myelin-associated protein that inhibits regeneration of central axons. Its roles on development of central pathways, however, are largely unknown. We have investigated Nogo-A expression in the C57 mouse retinofugal pathway, during period of major axon growth at the chiasm. In the retina, Nogo-A was found on the membrane and processes of the radial glial-like cells and not in the ganglion cells and their axons. In the diencephalon, Nogo-A was observed exclusively on the radial glial cells, which are immunopositive to $\mathrm{RC} 2$, at the midline regions of the chiasm. The Nogo-A staining was dramatically reduced at the stalk-chiasm junction, and at the threshold of the optic tract. Labels at the midline revealed a dense ramification of Nogo-A rich glial processes that interact with ingrowing optic axons, which were lacked in those at the optic tract. We concluded that Nogo-A is expressed on the radial glia particularly at the chiasmatic midline, and is probably involved in controls of axon routing, including divergence of optic axons, at the mouse chiasm.

Acknowledgement: Supported partially by a RGC Grant: CUHK4417/03M and a CUHK Direct Grant: 2004.1.051.

\section{OP-10/24 \\ The Early Migration of Vagal Neural Crest Cells to the Gut in Dominant Megacolon Mouse Embryos \\ Wang, L. ${ }^{a}$, Copp, A.J. ${ }^{\text {b }}$ Chan, W.Y. ${ }^{\text {a }}$ \\ aDepartment of Anatomy, Faculty of Medicine, The Chinese University of Hong Kong, Hong Kong, China, and beural \\ Development Unit, Institute of Child Health, London, UK}

The enteric nervous system in vertebrates is derived mainly from vagal neural crest cells at the level of somites 1 to 7 . The vagal neural crest cells detach from the dorsal side of the neural tube and migrate to the gut. Sox 10 , which encodes a transcription factor, is known to play a crucial role in the formation of the enteric nervous system. Mutation of Sox10 in the Dominant megacolon (Dom) mouse leads to intestinal aganglionosis. In order to ascertain whether the intestinal aganglionosis in the Dom mouse is caused by defects in the early migration of neural crest cells, we labelled the vagal neural crest between somites 1 to 7 with WGA$\mathrm{Au}$ at $\mathrm{E}$ 8.5. The labelled embryos were then cultured in vitro for $24 \mathrm{~h}$, and the migratory pathway was reconstructed from serial sections with a computer software. Although neural crest cells from the wild type $(+/+)$, heterozygous $(\mathrm{Dom} /+)$ and homozygous (Dom/Dom) mouse embryos all migrated along the medial pathway and reached the gut mesenchyme at $\mathrm{E} 9.5$, the number of neural crest cells in different regions of the migratory pathway was significantly reduced in homozygous (Dom/Dom) embryos compared with wild type $(+/+)$ embryos. In heterozygous $($ Dom/+) embryos, the number of migrating vagal neural crest cells along 
the migratory pathway was also decreased, but to a lesser extent. Thus in contrast to the previous finding that migration was not affected before the neural crest cells reached the gut mesenchyme, our present study reveals that retarded early migration of vagal neural crest cells from the neural tube to the gut mesenchyme may be a cause of aganglionosis in the gut of Dom mice.

Acknowledgement: The work described here was supported by a grant from the Research Grant Council of the Hong Kong Special Administrative Region (Project No. CUHK 4016/01M).

\section{OP-11/24 \\ Prostaglandin E 2 Activates EP4 Receptor Subtype to Increase Cyclic AMP Production in Rat Dorsal Root Ganglion Cells, in vitro}

Wise, $H$.

Department of Pharmacology, The Chinese University of Hong Kong, Shatin, Hong Kong, China

The hyperalgesic response to prostaglandin $\mathrm{E}_{2}\left(\mathrm{PGE}_{2}\right)$ and prostacyclin mimetics (e.g. cicaprost) is considered to be a cyclic AMP-dependent process occurring in dorsal root ganglion (DRG) cells. However, the ability of $\mathrm{PGE}_{2}$ to increase cyclic AMP levels in isolated adult rat DRG cells is considerably less than that of cicaprost [1]. $\mathrm{PGE}_{2}$ activates four subtypes of $\mathrm{G}$ protein-coupled receptors, known as EP1 (Gq), EP2 (Gs), EP3 (Gi) and EP4 (Gs), while prostacyclin and its mimetics activate the IP receptor which couples primarily to Gs. In an attempt to clarify the relative effects of $\mathrm{PGE}_{2}$ and cicaprost, I have examined a set of EP receptor selective agonists to determine how activation of the four EP receptor subtypes may influence the efficacy of $\mathrm{PGE}_{2}$ for stimulating adenylyl cyclase activity in rat DRG cells. In addition, I have tested prostaglandin $\mathrm{D}_{2}\left(\mathrm{PGD}_{2}\right)$ to confirm the absence of Gs-coupled $\mathrm{DP}$ receptors in these cells.

DRG cells were cultured in 24-well plates, at a density of approximately 7,000 cells/well, for 5 days before assay of $\left[{ }^{3} \mathrm{H}\right]$-cyclic AMP production following prelabelling of cells with $\left[{ }^{3} \mathrm{H}\right]$-adenine [1]. Cicaprost, $\mathrm{PGE}_{2}$ and ONO-AE1-329 (EP4 agonist) increased $\left[{ }^{3} \mathrm{H}\right]$-cyclic AMP production with $\mathrm{pEC}_{50}$ values of $7.42 \pm$ $0.11,6.51 \pm 0.29$ and $7.15 \pm 0.13$, respectively (means $\pm \mathrm{SEM}$, $\mathrm{n}=3$ ). The efficacy of $\mathrm{PGE}_{2}$ and ONO-AE1-329 to increase $\left[{ }^{3} \mathrm{H}\right]$ cyclic AMP production was similar and significantly lower $(\mathrm{p}<$ 0.001 ) than that of cicaprost. Neither $\mathrm{PGD}_{2}$ nor ONO-AE1-259-01 (EP2 agonist) increased adenylyl cyclase activity at concentrations up to $10 \mu \mathrm{M}$. Furthermore, neither sulprostone nor ONOAE-248 (EP3 agonists) inhibited basal or $100 \mathrm{nM}$ cicaprost-stimulated adenylyl cyclase activity. In conclusion, the hyperalgesic effect of $\mathrm{PGE}_{2}$ is likely to be mediated via activation of EP4 receptors in rat DRG and is not affected by co-stimulation of EP3 receptors known to be expressed in these same cells.

Acknowledgement: This work was fully supported by a grant from the Research Grants Council of the Hong Kong Special Administrative Region (HKUST3/03C). The gifts of EP receptor agonists from ONO Pharmaceutical Company Ltd is gratefully acknowledged.

Reference

1 Rowlands DK, et al: Br J Pharmacol 2001;133:13-22.

\section{OP-12/24 \\ Activation of Muscarinic $\mathrm{M}_{4}$ Receptor Augments NGF-Induced Pro-Survival Akt Signaling in PC12 Cells}

Wu, H.T., Wong, Y.H.

Department of Biochemistry, Molecular Neuroscience Center, and Biotechnology Research Institute, Hong Kong University of Science and Technology, Clear Water Bay, Kowloon, Hong Kong, China

Survival or death of neurons during development is mediated by the integration of a diverse array of signal transduction cascades that are controlled by the availability and acquisition of neurotrophic factors and agonists acting at G protein-coupled receptors (GPCRs). Recent studies have demonstrated that GRCRs can modulate signals elicited by receptor tyrosine kinases (RTK) and vice versa. Here, we examined the activity of pro-survival Akt kinase, in response to stimulation by muscarinic acetylcholine receptors ( $\mathrm{mAChRs}$ ) and co-activation with the nerve growth factor (NGF) receptor in PC12 cells endogenously expressing $\mathrm{G}_{\mathrm{i}^{-}}$ coupled $\mathrm{M}_{4} \mathrm{mAChR}$ and $\mathrm{G}_{\mathrm{q}}$-coupled $\mathrm{M}_{1}$ and $\mathrm{M}_{5} \mathrm{mAChRs}$. Western blotting analysis using a phosphospecific Akt antibody revealed a dose- and time-dependent increase in Akt phosphorylation in cells stimulated with $\mathrm{mAChR}$ specific agonist carbachol (CCh). Co-stimulation with CCh and NGF resulted in augmentation of Akt activity in a pertussis toxin (PTX)-sensitive manner, suggesting that $M_{4} \mathrm{mAChR}$, but not $\mathrm{M}_{1}$ and $\mathrm{M}_{5} \mathrm{mA-}$ ChRs, was associated with this synergistic Akt activation. The use

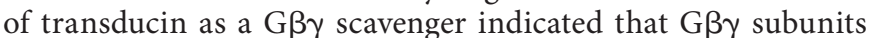
rather than $\mathrm{G} \alpha_{\mathrm{i} / \mathrm{o}}$ acted as the signal transducer. Additional experiments showed that CCh treatment augmented NGF-induced phosphorylation and degradation of the Akt-regulated translation regulator tuberin. This augmentation was also inhibited by PTX pre-treatment or overexpression of transducin. Finally, costimulation of PC12 cells with CCh and NGF resulted in enhancement of cell survival. This is the first study that demonstrated the augmentation effect between $\mathrm{M}_{4} \mathrm{mAChR}$ and NGF receptor, and the regulatory role of $\mathrm{mAChR}$ on tuberin.

Acknowledgement: This work was supported in part by grants from the Research Grants Council of Hong Kong (HKUST 6095/01M and 3/03C), the University Grants Committee (AoE/B15/01), and the Hong Kong Jockey Club.

\section{OP-13/24}

\section{Expression and Action of Secretin in Rat Cerebellar} Deep Nuclei Neurons

Yung, W.H. ${ }^{\text {a }}$, Lee, S.M.Y. ${ }^{\mathrm{b}}$, Chan, Y.S. ${ }^{\mathrm{c}}$, Wang, J.J. ${ }^{\mathrm{d}}$, Chow, B.K.C ${ }^{\mathrm{b}}$

aDepartment of Physiology, The Chinese University of Hong Kong, Hong Kong, ${ }^{b}$ Department of Zoology,

'Department of Physiology, The University of Hong Kong, Hong Kong; ${ }^{\mathrm{d} D e p a r t m e n t}$ of Biological Science and

Technology, Nanjing University, Nanjing, China

We recently reported that secretin and its receptors are expressed in the cerebellum of the rat [1] and human [2]. Electro- 
physiologically, secretin modulates the inhibitory neurotransmission from basket cells to Purkinje neurons. However, despite the fact that Purkinje neurons express secretin receptor mRNA, secretin administration does not evoke any postsynaptic responses in these cells. These observations suggest that Purkinje neurons may synthesize secretin receptors and transport them to nerve terminals in the deep nuclei. To test this hypothesis, we examined the expression of secretin and secretin receptors in the cerebellar deep nuclei of rats and studied the electrophysiological actions of secretin on GABAergic neurotransmission from Purkinje neurons to deep nuclei neurons. By means of in situ hybridization, deep nuclei neurons were found to express both secretin and secretin receptor mRNA. In agreement with this observation, immunohistochemical staining showed strong expression of secretin in the same type of neurons. Furthermore, administration of $30 \mathrm{nM}$ of secretin increased the frequency of TTX-resistant, or miniature, inhibitory postsynaptic currents by $61.6 \%$ in 14 cells $(\mathrm{p}<0.05)$ while the amplitudes were not affected. These data suggest that secretin released by deep nuclei neurons activate presynaptic secretin receptors on the terminals of Purkinje neurons. Therefore, secretin appears to modulate the activity of the cerebellum by acting at multiple levels of inhibitory synapses in the cerebellar circuit.

Acknowledgement: Supported by the National Natural Science Foundation of China and the Research Grants Council of Hong Kong (N_CUHK 427/03).

\section{References}

1 Yung WH, Leung PS, Ng SSM, Zhang J, Chan SCY, Chow BKC: J Neurosci 2001;21:7063-7068

2 Lee SMY, Yung WH, Chen L, Chow BKC: NeuroReport 2005.

\section{OP-14/24 \\ Effect of Calcium on the Expression of Apoptosis-Related Acetylcholinesterase}

\author{
Zhu, H. ${ }^{\text {a }}$, Jin, Q.H. ${ }^{\text {a }}$ Jiang, H. ${ }^{a}$, Wu, W.R. ${ }^{\text {a }}$, Jing, $P .{ }^{a}$, Zhang, B. ${ }^{a}$, \\ Shi, Y.F. ', Zhang, X.J. ${ }^{\text {b }}$ \\ aLaboratory of Molecular Cell Biology, Institute of Biochemistry \\ and Cell Biology, Shanghai Institutes for Biological Sciences, \\ Chinese Academy of Sciences, Graduate School of the Chinese \\ Academy of Sciences, Shanghai, China, and ${ }^{b}$ Department of \\ Molecular Genetics, Microbiology and Immunology, University \\ of Medicine and Dentistry of New Jersey-Robert Wood Johnson \\ Medical School, New Jersey, N.J., USA
}

We have recently reported Acetylcholinesterase (AChE) expression is induced during apoptosis in various cell types. In this study, we reported for the first time the induction of AChE expression during apoptosis is regulated by $\mathrm{Ca}^{2+}$ mobilization. We observed AChE mRNA and protein levels were significantly induced during apoptosis of Hela cells triggered by the calcium ionophores A23187. Chelating intracellular $\mathrm{Ca}^{2+}$ by BAPTA-AM, an intracellular $\mathrm{Ca}^{2+}$ chelator, inhibited AChE expression. At the early stage of apoptosis, A23187 can increase AChE mRNA stability, which was blocked by BAPTA-AM. BAPTA-AM can also inhibit the increase in AChE promoter activity. These results show that cyto- solic $\mathrm{Ca}^{2+}$ plays a key role in the induction of AChE mRNA during apoptosis, through modulating mRNA stability and promoter activity of AChE.

Acknowledgement: This work was supported by the National High Technology '863' Programs of China (Grant No. 2002BA711A07), Grant No. KSCX2-SW-211 from Chinese Academy of Sciences, PKZ2001-11 and 02ZA14118 from Shanghai.

\section{OP-15/24 \\ Identification of NRC-Interacting Factor 1 (NIF-1) as a P35-Interacting Protein}

Zhao, X.-S., Li, Z., Fu, W.-Y., Ip, N.Y.

Department of Biochemistry, Biotechnology Research Institute and Molecular Neuroscience Center, Hong Kong University of Science and Technology, Clear Water Bay, Hong Kong, China

Cyclin-dependent kinase 5 (Cdk5), a serine/threonine kinase that displays kinase activity predominantly in neurons, is activated by two non-cyclin activators, p35 and p39. Previous studies showed that Cdk5 plays an important role in neuronal migration, neurite outgrowth and synaptogenesis in the central nervous system. Interestingly, recent studies implicated the involvement of $\mathrm{Cdk} 5 / \mathrm{p} 35$ in nuclear functions. Several proteins involved in transcriptional regulation including p53, myocyte enhancer factor-2, signal transducer and activator of transcription- 3 as well as $\mathrm{mSds} 3$ were demonstrated to be the substrates for C $\mathrm{dk} 5$. Using yeast twohybrid screening, we have identified NRC-interacting factor 1 (NIF-1) as one of the interacting proteins of p35. NIF-1 can regulate transcriptional activity through its interaction with nuclear hormone receptor transcriptional coactivator (NRC). We demonstrated that NIF-1 associated with $\mathrm{p} 35$ by in vitro pull down assay and in vivo co-immunoprecipitation experiments. This association is specific for p35 as NIF-1 could not interact with p39 when co-expressed in COS-7 cells. Immunocytochemical analysis showed that NIF-1 was exclusively localized to the nuclei when singly transfected in COS7 cells. Interestingly, overexpression of p35 but not p39, regulated the localization of NIF-1 in COS7 cells. These findings suggest that p35 might be involved in transcriptional regulation through its specific interaction with NIF-1 and modulating its subcellular localization.

Acknowledgement: This study was supported by the Research Grants Council of Hong Kong SAR (HKUST 6091/01M, 6130/03M and $6119 / 04 \mathrm{M}$ ) and the Area of Excellence Scheme of the University Grants Committee (AoE/B-15/01). 


\section{Poster Presentations}

\section{P-1/24}

Modulation in Expression of Neurokinin Receptor NK1 in the Striatum of 6-HydroxydopamineLesioned Rats

Chan, W.S. ${ }^{a}$, Chen, L.W. ${ }^{\text {}}$, Chan, Y.S. ${ }^{c}$, Yung, K.K.L. ${ }^{a}$

aDepartment of Biology, Hong Kong Baptist University, Hong Kong, ' Institute of Neurosciences, The Fourth Military University, Xian, 'Department of Physiology, The Hong Kong University, Hong Kong, China

Parkinson's disease (PD) is a serious motor disorder which caused by a degeneration of dopaminergic neurons in the substantia nigra (SN) of the basal ganglia. Neurokinins (NK) are a group of neuropeptides that are affected after and/or involved in the pathogenesis of Parkinson's disease. Objectives of the present study were to investigate the changes in expression of NK1 receptor in different neuronal elements of the striatum after the onset of PD using 6-hydroxydopamine-lesioned rat as an animal model. In lesioned rats, up-regulation of $\mathrm{NK} 1$ proteins was generally observed in the striatum by western blotting and immunofluorescence. In addition, double immunofluorescence revealed that NK1 immunoreactivity was primarily found in perikarya of striatal interneurons, namely the cholinergic, nitric oxide synthasepositive striatal interneurons. Interestingly, after lesion, a marked internalization of NK1 immunoreactivity was found in cholinergic interneurons in the lesioned striatum. The intensity of NK1 immunofluorescence was found to be increased in cholinergic and NOS-immunoreactive striatal interneurons in the lesioned striatum. The present results indicate that expression of NK1 receptor is modulated in the striatum of the lesioned rats. The patterns of expression of NK1 receptor in striatal interneuron subpopulations are also modulated after dopamine denervation. NK1 receptor may therefore involve in the neuroprotection of Parkinson's disease.

Acknowledgement: Support contributed by: Joint Research Scheme, National Natural Science Foundation of China and Research Grants Council of Hong Kong, 30218002 and N_HKBU202/02.

\author{
P-2/24 \\ Gender Differences in Neural Activity Associated \\ with Recognition of Happy and Sad Faces by Human \\ Subjects: An Functional Magnetic Resonance \\ Imaging Study

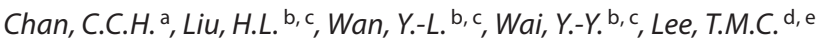 \\ ${ }^{a}$ Applied Cognitive Neuroscience Laboratory, Department of \\ Rehabilitation Sciences, The Hong Kong Polytechnic University, \\ Hong Kong, China; 'b Department of Medical Imaging and \\ Radiological Sciences, Chang Gung University, Taiwan, \\ 'MRI Center, Chang Gung Memorial Hospital, Taiwan (ROC), and \\ dNeuropsychology Laboratory, Department of \\ Psychology, ${ }^{\mathrm{e}}$ Institute of Clinical Neuropsychology, \\ The University of Hong Kong and MacLehose Medical \\ Rehabilitation Centre, Hong Kong, China
}

Do men and women process emotional stimuli differently? This question has been addressed in some prior studies. For example, Kesler/West et al. [1] used functional magnetic resonance imaging (fMRI) to investigate explicit processing of facial emotions, including happiness and sadness. They observed that men showed greater left hemispheric activation when observing sad faces than when observing happy faces. This study explored how the gender of the subjects and of the stimuli affects neural activity associated with emotion recognition of happy or sad expressions using a functional magnetic resonance imaging. The experimental stimuli were 12 photographs of Japanese adults selected from Matsumoto and Ekman's Pictures of Facial Affect. Using a blocked-design paradigm, the neural activity of the 24 volunteers, 12 men and 12 women, was monitored on a $1.5 \mathrm{~T}$ Magnetom Vision MRI scanner (Siemens, Erlangen, Germany) at the Chang Gung Memorial Hospital while they were viewing photos of men or women portraying happy or sad emotions shown through a goggle display system (Resonance Technology Inc., Calif., USA). Our findings support previous reports of gender differences in the neural correlates of emotion recognition, which seems to relate to both the gender of the subjects and the gender of the models portraying the target facial emotions. Our observation of a stronger activation associated with facial emotion recognition in our male subjects, particularly when viewing sad facial emotions, is consistent with our previous finding [2] that gender differences in facial emotion recognition are more noticeable when processing faces portraying sad emotions than when processing faces portraying happy emotions. Relative differences were observed between the male and female subjects in the volume of activation and the lateralization pattern associated with processing emotion recognition when looking at male or female faces. Regarding regions and volumes of activation, both our male and female subjects, when viewing happy emotions portrayed by models of the same gender as themselves, displayed a stronger and a more extensive network of activation. In terms of the lateralization pattern, we observed a general trend of their becoming less left lateralized when our male or female subjects were viewing photos of women portraying either happy or sad emotions than when they were viewing photos of men. Our findings suggest that the laterality of facial emotion processing could be gender, subjects and stimuli, and emotion specific. This observation may fur- 
ther explain the contradictory findings of laterality models of emotion processing reported in the literature. Our findings suggest fundamental gender differences in neural activity associated with processing emotion in male or female faces. Thus, the generalization of the findings in regard to neural activity associated with facial emotion recognition should take gender of the subjects as well as the stimuli into the consideration.

\section{References}

1 Kesler-West M, et al: Cogn Brain Res 2001;11:213-226.

2 Lee TMC, et al: Neurosci Lett 2002;333:13-16.

\section{P-3/24 \\ Mouse Model for Non-Invasive Investigation of Diabetic Neuropathy}

Chen, Y.S., Chung, S.S.M., Chung, S.K.

Institute of Molecular Biology, Faculty of Medicine,

The University of Hong Kong, Hong Kong, China

Diabetic small fiber neuropathy is characterized by hyperalgesia, tactile allodynia and thermal hyperalgesia (loss of sensation). Reduction in small fibers in the skin has been reported in chronic diabetic patients. Those studies in diabetics were mainly performed by skin biopsy analysis following immunostaining with PGP9.5 antibodies. Here the YFP transgenic mice, which express high level of yellowish-green fluorescent protein (YFP) in all motor and sensory neuronal cell bodies, axons and the terminal was used to study diabetic small fiber neuropathy. These mice were induced to become diabetic by streptozotocin injection $(200 \mathrm{mg} / \mathrm{kg} \mathrm{bw})$. In the anesthetised YFP mice, the YFP positive small cutaneous nerve fibers which arose from the large neural plexus underlying the epidermis and ran upwards to the epidermis (i.e. primary small fibers), as well as those arose from the primary small fibers (i.e. secondary small fibers), have been quantitated under the fluorescent stereo-microscope. Density of primary small fibers in the legs was unchanged at 1 and 2 months of diabetes, but decreased at 3 months $(\mathrm{p}<0.001)$ and 6 months $(\mathrm{p}<0.01)$ of diabetes, while there was a trend of decrease in secondary small fibers at 3 months of diabetes, and it was decreased significantly at 6 months of diabetes $(p<0.01)$. Hot plate tests were conducted to determine the heat-induced threshold of the diabetic and non-diabetic YFP mice. The delayed heat sensation in diabetic mice was observed at all stages of diabetes studied, indicating that the functional deficit might precede the structural changes. At the end of the experimental period, 6 months, NCV was measured. Similar to other diabetic mice, the motor $(\mathrm{p}<$ $0.01) /$ sensory $(\mathrm{p}<0.001)$ nerve conduction velocity were also decreased in 6 months diabetic mice. However, there was no correlation between the MNCV/SNCV deficits and the small cutaneous nerve fiber reduction, suggesting that the small fiber deficit may not necessarily be an indicator of large fiber deficit. Here we presented a novel non-invasive method to document the loss of cutaneous nerve fibers in diabetic animal model. We believed that this YFP transgenic mouse model is an invaluable tool for investigating the mechanism of the etiology of diabetic small fiber neuropathy and determining therapeutic efficacy of experimental drugs in chronic diabetic animals.

The 24th Scientific Meeting of the

Hong Kong Society of Neurosciences

\section{P-4/24 \\ Transgenic Mice Over-Expressing Endothelin-1 in Endothelial Cells Have Blood-Retinal Barrier Breakdown and Lower Expression of Glial Fibrillary Acidic Protein}

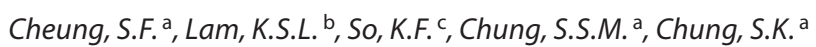

anstitute of Molecular Biology, ${ }^{b}$ Department of Medicine and

'Department of Anatomy, Faculty of Medicine, The University of Hong Kong, Hong Kong, China

Retinopathy, one of the microvascular complications of diabetes, is a major cause of blindness in adults. The breakdown of blood-retinal barrier (BRB) is a pathogenic feature of diabetic retinopathy (DR). The involvement of endothelin-1 (ET-1) in DR has been suggested by up-regulated ET-1 peptide expression in the retinal endothelial cells of diabetic rats. To investigate the contribution of ET-1 in retinal endothelial cells to morphological, biochemical and functional changes in DR, transgenic mice with endothelial ET-1 over-expression driven by mouse tie-(tyrosine kinase)-1 promoter (TET-1 mice) were generated. Semi-quantitative RT-PCR studies demonstrated that total ET-1 mRNA expression in transgenic mouse retina was increased at least 2 -fold. Indeed, immunocytochemical studies showed up-regulation of ET-1 peptide specifically in retinal endothelial cells of TET-1 mice. Moreover, the blood vessel density in the ganglion cell layer of homozygous TET-1 mice was higher than that of non-transgenic mice, indicating that over-expression of ET-1 may lead to neovascularization in retina. On the other hand, the expression of glial fibrillary acidic protein (GFAP) was decreased in optic nerve, astrocytes and Müller cell processes, suggesting that over-expression of ET-1 may down-regulate the expression of GFAP, which is important in the maintenance of BRB. BRB integrity in TET-1 mice was examined by leakage of Evans blue in whole mount retina. Preliminary data showed that there was slightly more focal leakage in retinal blood vessels of TET-1 mice, raising the possibility of ET-1 affecting BRB functions. Our TET-1 mice will be an invaluable model to investigate the contribution of ET-1 in retinal endothelial cells to pathogenic effects of DR.

\section{P-5/24 \\ Differential Expression of Vesicular Glutamate Transporters in Neuronal Elements of the Rat Basal Ganglia}

Chung, E.K.Y., Yung, K.K.L.

Department of Biology, Hong Kong Baptist University, Kowloon Tong, Hong Kong, China

Vesicular glutamate transporters (VGLUT1, T2 and T3) are a group of vesicular transporter proteins that mediate the packing of glutamate neurotransmitter to synaptic vesicles. VGLUTs are known to be differentially expressed by different neuronal elements in the brain. In order to investigate the cellular localization of VGLUT1, T2 and T3 in different neuronal elements in the striatum, double immunofluorescence was employed. Results of the present study revealed that VGLUT1 and VGLUT2 immunoreac- 
tivity was mainly found in the neuropilar elements in the striatum, whereas VLGUT3 immunoreactivity was found in perikarya of striatal neurons. Double labelling revealed that there was a high degree of co-localization between VGLUT1 and VGLUT2 immunoreactivity with synaptophysin immunoreactivity. However, not all of the VGLUT1-immunoreactive elements display VGLUT2 immunoreactivity and vice versa. In addition, VGLUT2 but not VGLUT1 immunoreactivity was found to be highly colocalized with postsynaptic density 95 (PSD95) immunoreactivity. In contrast, VGLUT3 immunoreactivity was observed primarily in perikarya of choline acetyltransferase- and nitric oxide synthase-positive neurons in the striatum. These results indicate that VGLUT1 and T2 proteins are primarily expressed by axonal terminals in the striatum. However, they are likely to be expressed by sub-groups of glutamatergic terminals that are of different origins, in which VGLUT2-expressing terminals may form synaptic connections with PSD95-positive elements, i.e., dendritic spines of medium spiny neurons. These may imply VGLUT2-positive terminals may be of cortical origin. However, the exact origins of these terminals remain to be established. VGLUT3 is only found in cholinergic and nitric oxide synthase-positive striatal interneurons and these may raise a possibility about the roles of glutamate in these neurons.

Acknowledgement: Support contributed by: HKBU2150/03M, Research Grants Council, Hong Kong.

\section{P-6/24}

\section{Early Migration of the Mouse Sacral Neural Crest}

Dong, M. ${ }^{\text {, }}$ Yip, F.P. ${ }^{\text {, }}$ Burns, A.J. ${ }^{\text {b }}$, Chan, W.Y. ${ }^{\text {a }}$

aDepartment of Anatomy, Faculty of Medicine, The Chinese University of Hong Kong, Hong Kong, China, and beural

Development Unit, Institute of Child Health, University College London, UK

Experimental data based largely on findings from avian embryos indicate that enteric ganglia in the hindgut are derived from two sources: the vagal and sacral neural crest. However, in mammals, the contribution of sacral neural crest cells to enteric ganglia and their migratory pathways to the hindgut are still not well understood. In the present study, we employed a combination of techniques including in situ labelling using wheat germ agglutinin gold conjugates and DiI as cell markers, immunohistochemical staining using a specific antibody against the neurotrophin receptor 75 and whole embryo culture to determine the early migration of sacral neural crest cells from the dorsal neural tube to the gut mesenchyme in normal mouse embryos. It was found that most of the sacral neural crest cells posterior to the level of somite 24 migrated along a medial pathway between the somite and the neural tube while some of them took the dorsolateral pathway between the surface ectoderm and the somite. Many of the neural crest cells in the medial pathway formed dorsal root ganglia on two sides of the neural tube. Some neural crest cells continued to migrate ventrally to reach the mesenchymal region around the dorsal aorta on E10.5. By E11.5, the most ventrally located neural crest cells scattered in regions ventral to the dorsal aorta but had not yet entered the gut mesentery or the gut mesenchyme. Our results thus support the notion that sacral neural crest cells colonize the hindgut later than E11.5 and most of them took a medial pathway between the somite and the neural tube.

Acknowledgement: The work described here was supported by a grant from the Research Grants Council of the Hong Kong Special Administrative Region (Project No. CUHK4418/03M).

\section{$\mathrm{P}-7 / 24$ \\ Screening for NMDA Receptor Antagonists Using Traditional Chinese Medicine}

Ip, F.C.F., An, H., Chan, A.W.S., Tong, E.P.S., Hu, S.Y., Wong, Y.H., Ip, N.Y.

Department of Biochemistry, Biotechnology Research Institute and Molecular Neuroscience Center, Hong Kong, University of Science and Technology, Clear Water Bay, Hong Kong, China

Excessive activation of N-methyl-D-aspartate (NMDA) receptor, a major excitatory receptor in the central nervous system (CNS), has been implicated in Alzheimer's disease (AD) as one of the factors that contributes to the acceleration of the disease progression. With its multiple ligand sites and complex receptor activation requirements, NMDA receptor has been a potential target for the treatment of AD. In this study, using rat cortical neuron culture on a high throughput assay platform called Fluorometric Imaging Plate Reader (FLIPR), a catalogue of in-house traditional Chinese medicines (TCM) were screened for potential antagonists of NMDA receptor. With this bioassay model system, pharmacological profiles of known NMDA agonists and antagonists corresponding to the previously published data were observed. A large number of TCM compounds have been tested and several promising candidates were selected for further functional characterization. Survival effects of these compounds on cultured cortical neurons against NMDA insult were examined. In addition, NMDA receptor specific channel activity using whole cell patch clamp was also performed using cultured rat hippocampal neurons. Our findings on the pharmacological profiles of these compounds suggest that they might act as potential NMDA antagonists.

Acknowledgement: This study was supported by the Innovation and Technology Fund established under the Innovation and Technology Commission of the Hong Kong SAR (ITS/226/01) and the Area of Excellence Scheme of the University Grants Committee (AoE/B-15/01).

\section{P-8/24 \\ The Lipid Binding of PICK1 Is Critical for Its Synaptic Targeting and Trafficking of AMPA Receptors}

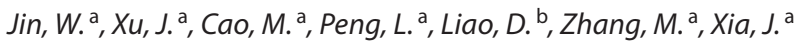

aDepartment of Biochemistry, Hong Kong University of Science and Technology, Clear Water Bay, Kowloon, Hong Kong, China, and ${ }^{\text {bDepartment }}$ of Neuroscience, University of Minnesota, Minneapolis, Minn., USA

The targeting and surface expression of membrane proteins are critical for their functions. PICK1 (protein interacting with C-kinase 1) interacts with the C-termini of many membrane pro- 
teins via its N-terminal PDZ (PSD-95/Dlg/ZO-1) domain and mediate their targeting and surface expression. For example, PICK1 was found to cluster and mediate AMPA (alpha-amino-3-hydroxy-5-methyl-4-isoxazole propionate) receptor trafficking during synaptic plasticity. Recently, PICK1 was predicted to contain a BAR (Bin/amphiphysin/Rvs) domain which has been shown to bind with lipid, sense and produce membrane curvature. Here we show that PICK1 directly binds to lipids, mainly phosphoinositides, via its BAR domain. Lipid binding of PICK1 is required for its synaptic targeting and clustering of AMPA receptors. Wild type PICK1 enhances synaptic targeting of AMPA receptor and this enhancement is depended on PICK1's lipid binding capability. Moreover, lipid binding deficient PICK1 loses its ability to regulate surface expression of AMPA receptors. Taken together, our data indicate that the lipid binding of PICK1's BAR domain is important for its synaptic targeting and AMPA receptors trafficking.

\section{P-9/24 \\ Chondroitin Sulfates Enriched in the Developing Rat Hindbrain Restrict Commissural Projections of Vestibular Neurons}

Kwok, J.C.F. ${ }^{a}$, Lau, W.K. ${ }^{\text {b }}$, Ng, T.K.Y. ${ }^{\text {b }}$, Shum, D.K.Y. ${ }^{a}$, Chan, Y.S. ${ }^{\text {b }}$

Departments of a Biochemistry and bPhysiology, Faculty of

Medicine, The University of Hong Kong, Hong Kong, China

In vitro studies have shown that chondroitin sulfate proteoglycans are inhibitory to axon outgrowth and constitute barriers to pathfinding axons. To assess if chondroitin sulfates (CSs) are involved in limiting axonal projections in the early embryonic hindbrain, chondroitinase $\mathrm{ABC}$ was delivered into the 4 th ventricles of rat embryos (E11.5-E13.5) in culture $\left(24 \mathrm{~h}, 37^{\circ} \mathrm{C}\right)$ to digest away CS moieties in the nearby hindbrain matrix. Controls were treated instead with the PBS-vehicle or the heat-inactivated enzyme. The resulting commissural projections after the treatments were mapped with DiI which was introduced into the vestibular nuclear complex (VNC) near the VIIIth cranial nerve entry zone. At E11.5 $+(1 \mathrm{DIV}), \leq 5$ neurites could be traced extending half of the way towards the midline. With the removal of CSs, a robust outgrowth of axons extended more than half of the way towards the midline. This suggests that CSs limit axonal outgrowth in early embryos. At E12.5 (+1 DIV), the commissural projections assumed fascicles that reached the midline in the controls. In the enzyme-treated embryos, the axons however were unfasciculated as they extended normal to the midline. This suggested that CSs are important in limiting and guiding the course of these pioneering axons. By E13.5 (+1 DIV), enzyme treatment apparently did not affect the pioneer axons that had advanced as thick fascicles normal to the midline. However, later axonal projections from the VNC that took place after the injection of enzyme were defasciculated as they traversed the enzyme-treated matrix. They were diverted from the course of the pioneers at various angles and positions when crossing the midline. This suggests that CSs also limit the course of the later projections which otherwise would be attracted to alternative targets. Recovery of proteoglycans from the early hindbrain and analysis of the CS components found enrichment in 6-sulfated isoforms of chon- droitin as early as E11.5. These results provide in vivo evidence for possible contributions of 6-sulfated chondroitins to limit stray outgrowth and foster axonal fasciculation as vestibular neurons project across the midline towards the contralateral target.

\section{P-10/24 \\ Selective Inhibition of Chondroitin Sulfate to Neurite Growth from Mouse Retina}

Lam, J.S.Y. ${ }^{\text {a }}$ Chan S.O. ${ }^{\text {b }}$

Departments of ${ }^{\mathrm{a} B i o l o g y}$ and ${ }^{\mathrm{b}}$ Anatomy, The Chinese University of Hong Kong, Shatin, Hong Kong, China

In order to determine signaling mechanisms associated with chondroitin sulfate (CS) induced inhibition, we grew explants from ventral temporal (VT) and dorsal nasal (DN) retina of E14 C57 pigmented mouse embryos on laminin, and observed responses of neurites to a CS coated spot. We found CS selectively inhibited neurite growth from VT but not nasal retina at a critical concentration of the coating solution $(10 \mathrm{mg} / \mathrm{ml})$. This inhibition could be abolished by $0.2 \mathrm{U} / \mathrm{ml}$ chondroitinase ABC. Further experiment was done to investigate whether protein kinase $\mathrm{C}$ (PKC) is involved in this inhibitory response. We first characterized expression of various $\mathrm{PKC}$ isoforms in $\mathrm{VT}$ and $\mathrm{DN}$ retinal growth cones. Within the growth cone, PKC- $\alpha$ was predominantly expressed in the periphery and in filopodia, whilst PKC- $\beta 1$ was localized at the core. PKC- $\beta 2$ was found at a lower level and showed a punctuate appearance. Work is still undergoing to examine whether this selective inhibition can be altered by manipulating PKC levels within the growth cone.

Acknowledgement: Supported partially by a RGC Grant: CUHK4417/03M and a CUHK Direct Grant: 2004.1.051.

\section{P-11/24 \\ Changes in Expression of Metabotropic Glutamate Receptors 4 and 7 in the Basal Ganglia of Rats after 6-Hydroxydopamine Lesion}

Rebecca, W.C., Lam, C.H., Yung, L., Yung, K.K.L.

Department of Biology, Hong Kong Baptist University, Kowloon Tong, Hong Kong, China

Parkinson's disease (PD) is a motor disorder caused by a degeneration of dopaminergic neurons in the substantia nigra pars compacta. This degeneration leads to an augmentation of the glutamatergic neurotransmission between different nuclei of the basal ganglia. The augmentation is known to be closely related to the onset of symptoms in PD. Metabotropic glutamate receptors (mGluRs) are G-protein coupled receptors that are known to play important roles in PD. The present study investigated the changes in expression of two Type III mGluRs in an animal model of $\mathrm{PD}$, the 6-hydroxydopamine-lesioned rats, using reverse transcriptase-polymerase chain reaction, western blotting and immunofluorescence. The levels of mGluR4 mRNA and proteins were remarkably increased in the striatum and the substantia nigra of the lesioned rats when compared with the non-lesioned rats. Interestingly, similar levels of mGluR4a proteins were observed be- 
tween the lesioned sides and non-lesioned sides in the lesioned animals. Similarly, up-regulation of mGluR7 mRNAs and immunoreactivity was found in the striatum of the lesioned rats when compared to non-lesioned rats. However, in the substantia nigra, the mGluR7 mRNA and immunoreactivity was found to be downregulated after 6-OHDA lesion. The decrease was primarily found in the lesioned substantia nigra. The present results indicate that there are differential changes of type III mGluRs in the basal ganglia after the onset of PD. The changes may be involved in the neuropathogenesis of PD.

\section{$\mathrm{P}-12 / 24$ \\ Molecular Cloning and Expression of Telomerase Reverse Transcriptase (TERT) in Zebrafish Central Nervous System}

Lau, B.W.M. ${ }^{a}$, Wong, A.O.L. ${ }^{\mathrm{b}}$, Tsao, G.S.W. ${ }^{\mathrm{a}}$, So, K.-F. ${ }^{\text {a }, \text { Yip, H.K.F. }}{ }^{\text {a }}$

Departments of a Anatomy and ${ }^{b}$ Zoology, The University of Hong Kong, Hong Kong, China

Telomerase is a specialized reverse transcriptase that specifically elongates telomeres and thus prevents cellular senescence. The telomerase ribonucleoprotein complex contains a complementary RNA template (TR) and a reverse transcriptase catalytic subunit (TERT), which has been shown to be the key determinant of its enzymatic activity. Based on the amino acid sequence of mouse TERT (mTERT), a zebrafish genomic DNA sequence significantly similar to mTERT has been isolated from zebrafish whole genome shotgun database. Utilizing Rapid Amplification of cDNA Ends (RACE), the full-length zebrafish TERT (zfTERT) cDNA was cloned into a pDNR-CMV mammalian expression vector and its sequence was revealed. After translation, the deduced protein sequence contains 1091 amino-acid residues and a predicted molecular mass of $126 \mathrm{kDa}$. Multiple alignment reveals that the protein sequence bears the conserved motifs and residues found in TERT of other species. However, transfection of pDNRCMV-zfTERT into human fibroblast did not reconstitute telomerase activity. The lack of telomerase activity expression implies that zebrafish TERT cannot utilize human TR in mammalian cells. RT-PCR and functional assay of telomerase activity (TRAP assay) detect TERT mRNA expression and telomerase activity in all zebrafish central nervous system tissues examined, including telencephalon, optic tectum, cerebellum, brain stem, spinal cord and retina. Since continuous neurogenesis can be found in teleost nervous system, the presence of telomerase in these tissues may reflect the neurogenesis potential in zebrafish neural tissues relative to mammalian tissues. This may serve as a comparative model to mammalian central nervous system.

\section{$\mathrm{P}-13 / 24$ \\ Expression of Secretin in the Rat Prenatal and Neonatal Cerebellum}

Lee, S.M.Y. ${ }^{\text {a }}$ Chan, Y.S. ${ }^{\text {b }}$, Wang, J.J. ${ }^{c}$, Chow, B.K.C. ${ }^{\text {, }}$ Yung, W.H. ${ }^{\mathrm{d}}$

Departments of a Zoology, and ${ }^{b}$ Physiology, The University of Hong Kong, Hong Kong, 'Department of Biological Science and Technology, Nanjing University, Nanjing, dDepartment of Physiology, The Chinese University of Hong Kong, Hong Kong, China

The brain-gut peptide secretin has been used to treat subjects suffering from the neurodevelopmental disorder autism despite the controversy on its therapeutic efficacy. Recent evidence indicated that secretin and its receptors are expressed particularly prominently in the cerebellum, an area consistently reported to be affected in autism. This raises the interesting hypothesis that secretin may play a role in the normal development of the cerebellum and perhaps the etiology of autism. As a first step to prove this hypothesis we examined the expression of secretin peptide in the prenatal and neonatal rat cerebella. Standard immunohistochemical technique using antibodies against rat secretin was employed to study the expression of secretin in prenatal rat cerebella at E11, E14, E17, E20 and E22, as well as neonatal rat cerebella at P1, P4, P7, P11 and P14. Immunoreactive cells were visualized by 3,3-diaminobenzide tetrahydrochloride. Specificity of immunostainings was examined by performing controls either in the absence of primary antibody or liquid phase pre-absorption of secretin antiserum with secretin peptide. There were widespread immunopositive signals in neuronal somata in the cerebella at these developmental stages. As early as the prenatal stage at E17, secretin was found to be consistently expressed in the Purkinje cell layer. At prenatal stage E22 and all the neonatal stages being examined in this study, immunoreactivity for secretin was prominently detected in the medial deep nucleus of the developing cerebellum. These results suggest that secretin plays a role in the development of the cerebellum at neonatal and early postnatal stages. Furthermore, during these developmental stages, the Purkinje neuron is a source of secretin.

Acknowledgement: Supported by the National Natural Science Foundation of China and the Research Grants Council of Hong Kong (N_CUHK 427/03).

\section{P-14/24 \\ Role of Endothelial Cell Overexpressed Endothelin-1 (ET-1) in Mouse Model of Ischemic Stroke}

Leung, J.W.C., Lo, A.C.Y., Chung, S.S.M., Chung, S.K.

Institute of Molecular Biology, Faculty of Medicine,

The University of Hong Kong, Hong Kong, China

Endothelin-1 (ET-1) has been implicated in clinical stroke. We have demonstrated ET-1 mRNA expression is induced in astrocytes and endothelial cells after ischemic condition, suggesting that both of these cells synthesize ET-1 under this stress condition. ET-1 protected primary cultured astrocytes from ischemic stress. However, transgenic mice with over-expression of ET-1 in astrocytes displayed more severe neurological deficit and in- 
creased infract volume, suggesting that astrocytic ET-1 have neurotoxic effect on neurons. To further investigate the role of endothelial ET-1 in cerebral ischemic injury, several transgenic mouse lines (TET) were generated by microinjecting the construct, which include ET cDNA with SV40 poly A under tyrosine kinase receptor-specific for endothelial cell (Tie-1) promoter. TET mouse lines were further characterized for ET-1 over-expression. The RT-PCR analysis using the primers specific for tranagene ET-1 showed that transgene ET-1 is only expressed in the brain from TET mice. Total expression of ET-1 mRNA was also increased in brain of transgenic mice when compared to that of non-transgenic mice by semi-quantitative RT-PCR. In situ hybridization and immunocytochemical analyses showed that the increased ET-1 mRNA and peptide expressions are only in endothelial cells of cerebral vessels from the TET mice. ET-1 peptide level was also detected in the endothelial cells of cerebral vessel from TET mice. Under normal condition, no gross morphological change has been found in the brain. However, TET mice showed more severe neurological deficit, larger infarct size and volume after transient middle cerebral artery occlusion (MCAO), suggesting that overexpressing of ET-1 in endothelial cells is deleterious to neuronal survival under ischemic condition. Our present TET model will serve as an ideal model for studying the role of endothelial ET-1 in the pathogenesis of ischemic stroke.

\section{P-15/24 \\ Postnatal Expression of Glutamate Receptor Subunits in Rat Inferior Olivary Neurons Responsive to Horizontal Linear Acceleration}

Li, C., Liu, J.X., Lai, C.H., Chan, Y.S.

Department of Physiology, Faculty of Medicine, The University of Hong Kong, Hong Kong, China

To investigate the developmental profile of ionotropic glutamate receptors in functionally activated otolith neurons within the inferior olive (IO), combined immuno- and hybridization histochemistry experiments were performed in conscious SpragueDawley rats (P9 to adult) that were subjected to sinusoidal linear acceleration along the horizontal plane. Neuronal activation was defined by the expression of Fos protein in cell nuclei. Only a few sporadically scattered Fos-labeled neurons were found in labyrinthectomized and static controls. During postnatal development, $c$-fos expression in subnuclei of the IO (viz. DMCC, IO $\beta$ ) was not observed until P11-13. Evidence of a gravity-related topographic spatial organization was found in these IO subnuclei along its rostrocaudal dimension. In DMCC, neurons responded only to interaural stimulation. In caudal IO $\beta$, though neurons responsive to antero-posterior and interaural stimulations could both be found at a young age, only those responsive to antero-posterior movement persisted in number into the adult. In contrast, rostral IO $\beta$ neurons that were responsive to either direction increased with age, reaching the adult pattern around 1 month-old. In each age group, about $95-98 \%$ of Fos-labeled neurons responsive to horizontal interaural or antero-posterior stimulation also co-expressed NMDA (NR1, NR2A, NR2B) or AMPA (GluR2/3) receptor subunits. While the granule density of NR2B mRNAs decreased from P11, that of both NR1 and NR2A mRNA increased from P11 to P14 and then decreased afterwards. These findings suggest that dynamic changes in the expression of glutamate receptor subunits contribute to the maturation of otolith-related IO neurons in the coding of horizontal head movements.

Acknowledgement: Supported by HK RGC.

\section{P-16/24 \\ Abnormalies of Scotopic Electroretinography in Rats with Laser-Induced Ocular Hypertension \\ Li, R.S. ${ }^{\text {a }}$,Tay, D.K. ${ }^{\text {a }}$, Chan, H.H. ${ }^{\text {b }}$, So, K.F. ${ }^{\text {a }}$ \\ aDepartment of Anatomy, Faulty of Medicine, The University of Hong Kong, Hong Kong, ${ }^{b}$ Department of Optometry and Radiography, Faculty of Health and Social Sciences, \\ The Hong Kong Polytechnic University, Hong Kong, China}

Scotopic threshold response (STR) and negative response (NR) in flash electroretinography (ERG) have been found to be related to the response from inner retina. These are useful indicators to assess the functional changes in inner retina of animal ocular hypertension models which always involve the damage of retinal ganglion cells (RGCs). In the present study, ERG was used to investigate the functional changes of retina in a laser-induced ocular hypertension model.

Ocular hypertension was induced unilaterally using Argon laser photocoagulation of the episcleral veins and limbal veins in Sprague-Dawley adult rats. Intraocular pressure (IOP) was measured with a calibrated tonopen. For studying the number of RGC loss at different time-points, the RGCs were labeled with FluoroGold four days before sacrifice of the animals. ERG was measured in these animals before the laser treatment, at two weeks, four weeks and eight weeks after the laser treatment. The animals were under general anesthesia during all the experimental procedures. There was about 1.6-fold increase of intraocular pressure (IOP) in the experimental eyes after the laser photocoagulation compared to those of the control eyes and the elevated IOP could be maintained at a quite steady level for at least eight weeks. The amplitudes of STR and NR were markedly attenuated together with the progressive loss of RGCs after the induction of ocular hypertension. This indicates that the elevation of IOP in this ocular hypertension model causes functional impairments in inner retina and this result is beneficial to future glaucoma studies using this model.

Acknowledgement: This study was supported by the award from The University of Hong Kong, the donation from the late Mr. And Mrs. Ma Yip Seng, the research grant from the Research Grant Committee of the Hong Kong Special Administrative Region and the research grant (G-T506) from The Hong Kong Polytechnic University. 


\section{P-17/24 \\ Restricted Localization of $\mathrm{P}_{2} \mathrm{Y}_{1}$ Receptor in Cortical Neurons: Functional Role in Small GTPASE Activation}

Ling, K., Kong, L., Tsim, K.

Department of Biology, Hong Kong University of Science and Technology, Clear Water Bay, Hong Kong, China

In vertebrate central nervous system, dendrites are contacted at synaptic terminals where information is passed on via neurotransmitter release. Assembly and modulation of receptors and associated signaling molecules at the post-synaptic membrane are important to determine the type and strength of synapses. In neuronal synapses, adenosine $5^{\prime}$-triphosphate (ATP) is co-stored and co-released with several neurotransmitters in synaptic vesicles. Previous studies demonstrated that ATP activates a subtype of $\mathrm{P} 2 \mathrm{Y}$ receptors, $\mathrm{P} 2 \mathrm{Y}_{1}$ receptor, at vertebrate neuromuscular junctions; it regulates post-synaptic gene expression via mitogen-activated protein kinase pathway [1], and potentiates agrin-induced acetylcholine receptor clusters through the activation of small GTPases, e.g. RhoA, as such to modulate the post-synaptic apparatus of muscle [2]. However, the receptor localization and functional role of ATP as a co-transmitter is not yet determined in neuronal synapses. $\mathrm{P}_{2} \mathrm{Y}_{1}$ receptor is a $\mathrm{G}$-protein-coupled receptor with seven transmembrane domains. At the C-terminal, it contains a potential PDZ binding domain, DTSL. Thus, it could be a possible binding partner of post-synaptic density protein, PSD95. In this study, the localization of $\mathrm{P}_{2} \mathrm{Y}_{1}$ receptor and its potential role in rat cortical neurons were investigated. By immunocytofluorescent staining, $\mathrm{P}_{2} \mathrm{Y}_{1}$ receptors were co-localized with $\mathrm{PSD}$ 95 at punctates along the dendrites. In subcellular level, $\mathrm{P}_{2} \mathrm{Y}_{1}$ receptor protein was co-immunoprecipitated with PSD-95 in adult rat brain extract and in over-expression system in HEK-293T cells. This molecular association was abolished in C-terminal deleted mutant of $\mathrm{P}_{2} \mathrm{Y}_{1}$ receptor that suggested its binding with PSD-95 via DTSL-PDZ interaction. Such restricted localization and organization of the $\mathrm{P}_{2} \mathrm{Y}_{1}$ receptor at the central synapse implies specific signal transduction complexes could be operating during the neurotransmission. In revealing the functional role of $\mathrm{P}_{2} \mathrm{Y}_{1}$ receptor, RhoA was activated when the cultured cortical neuron was challenged with ATP (a general P2 receptor agonist), 2-MeSADP ( $\mathrm{P}_{2} \mathrm{Y}_{1}$-specific agonist) and UTP ( $\mathrm{P}_{2} \mathrm{Y}_{2}$-specific agonist). These results therefore indicated that $\mathrm{P}_{2} \mathrm{Y}_{1}$ receptors are present at post-synaptic apparatus in association with PSD-95 in neuronal synapse. This restricted cellular localization allows ATP and $\mathrm{P}_{2} \mathrm{Y}_{1}$ receptor to activate the downstream signaling cascades RhoA that could possibly modulate the postsynaptic scaffold protein organization in neuron-neuron synapses.

Acknowledgement: Research Grants Council of Hong Kong (HKUST 6098/02, 6283/03M and 6237/04M).

References

1 Choi R, et al: J Neurosci 2003;23:4445-4456.

2 Ling K, et al: J Biol Chem 2004;279:31081-31088.

\section{P-18/24}

\section{Chondroitin Sulfate Proteoglycans in Astrocyte-Schwann Cell Cocultures Limit Neurite Extension and Crossing of Cellular Boundaries}

Liu, H.Y., Shum, D.K.Y.

Department of Biochemistry, Faculty of Medicine,

The University of Hong Kong, Hong Kong, China

Axon regeneration in the injured spinal cord was restricted at the interface between Schwann cell graft and the host astrocytes. Chondroitin sulfate proteoglycans (CSPG) are implicated in the axon-restrictive property of the interface [1]. Astrocytes and Schwann cells were cocultured to mimic the in vivo situation. In the cocultures, we found that: (1) cocultures stained live with the CS56 showed pericellular immunopositivity on Schwann cells; (2) PGs recovered from conditioned medium were digested with chondroitinase and the disaccharide products showed dominance of $\Delta \mathrm{Di} 4 \mathrm{~S}$ over $\Delta \mathrm{Di} 6 \mathrm{~S}$ as assayed with fluorophore-assisted carbohydrate electrophoresis (FACE); (3) RT-PCR for chondroitin 6sulfotransferase (C6ST) and chondroitin 4-sulfotransferase (C4ST) mRNAs showed dominance of C4ST over C6ST; (4) FACE analysis of the pericellular matrix recovered from the cocultures indicated hyaluronan and non-sulfated chondroitin. Taken together, this suggests that CSPGs enriched in 4-sulfated chondroitins were secreted into the medium, but hyaluronan and non-sulfated chondroitins were immobilized at the cell surface. Next, we seeded cortical neurons (E18 rats) on the astrocyte-Schwann cell coculture and studied the consequent neurite growth pattern. We found that: (1) neurons extended neurites along Schwann cell processes, contrasting the multidirectional growth on astrocytes; (2) neurites growing on astrocytes hardly changed course to grow on Schwann cells. Chondroitinase ABC treatment to remove pericellular CS and hyaluronan components indicated neurite growth that could cross from astrocytes to Schwann cells; (3) the average neurite length along Schwann cells was longer in Chondroitinase $\mathrm{ABC}$ treated group than in the non-treated group. The results suggest that immobilized non-sulfated chondroitins and hyaluronan contribute to limiting neurite extension and crossing from astrocyte to Schwann cells when Schwann cells meet astrocytes.

\section{Reference}

1 Chau CH, Shum DK, Li H, et al: FASEB J 2004;18:194-196.

\section{P-19/24 \\ A Comparative Study of the Effects of Daidzein and Genistein on Murine Neuroblastoma Cells \\ Lo, F.H. ${ }^{\text {a }}$, Mak, N.K. ${ }^{\text {b }}$, Leung, K.N. ${ }^{\text {a }}$ \\ aDepartment of Biochemistry, The Chinese University of Hong Kong, Shatin, N.T., Hong Kong, ' Department of Biology, \\ Hong Kong Baptist University, Kowloon, Hong Kong, China}

Daidzein (4',7-dihydroxyisoflavone) and genistein (4',5,7-trihydroxyisoflavone) are two major isoflavones found predominantly in soy beans, as well as in certain traditional Chinese medicinal herbs and tea leaves. Previous studies have shown that soy isoflavones have cancer chemopreventive activity such as reduc- 
ing the rates of breast cancer, prostate cancer and colon cancer in humans. However, the direct anti-tumor activity of soy isoflavones on neuroblastoma cells and their action mechanisms remain poorly understood. In the present study, both daidzein and genistein were found to exert an anti-proliferative effect on the murine neuroblastoma Neuro-2a (BU-1) cells in a time- and dosedependent manner, with an estimated $\mathrm{IC}_{50}$ value of 40 and $50 \mu \mathrm{M}$ respectively at $72 \mathrm{~h}$ of treatment. Trypan blue exclusion test showed that daidzein and genistein, at the concentrations that exerted the growth inhibitory effect, were not cytotoxic to BU-1 cells. In addition, daidzein and genistein induced apoptosis of the BU-1 cells, as evidenced by the formation apoptotic DNA fragments. Moreover, both daidzein and genistein were capable of inducing neuronal differentiation in the BU-1 cells, as the treated cells showed an increase in the length of neurites as detected by light microscopy, and an increase in acetylcholine esterase activity. Confocal microscopy further confirmed the differentiation of the BU-1 cells induced by daidzein and genistein as indicated by an increased expression of the neuronal differentiation marker, the microtubule-associated protein 2 . Flow cytometric analysis indicated that genistein induced a dramatic parallel increase in cell size and granularity after $48 \mathrm{~h}$ of treatment whereas for daidzein treatment, this was less dramatic and required $72 \mathrm{~h}$ of treatment. Furthermore, cell cycle analysis revealed that genistein caused a G2/M phase arrest in the treated BU-1 cells in a time- and dose-dependent manner, while the potency of daidzein to induce cell cycle accumulation at G2/M phase was relatively lower. Our results, when taken together, suggest that both daidzein and genistein exhibit various cellular activities on the murine Neuro-2a BU-1 neuroblastoma cells, ranging from inhibiting cell proliferation, inducing cell cycle redistribution, triggering apoptosis of the cells, to inducing neuronal differentiation to different extent.

\section{P-20/24 \\ Endothelin-1 Overexpression Leads to Blood-Brain Barrier Disruption, More Brain Edema and Increased Aquaporin 4 Expression in Astrocytic Processes after Experimental Stroke}

Lo, A.C.Y., Fung, M.K.L., Yaw, L.P., Chung, S.S.M., Chung, S.K.

Institute of Molecular Biology, The University of Hong Kong, Hong Kong, China

Under normal condition endothelin-1 (ET-1) is expressed by cerebral endothelial cells. However, increased level of ET-1 was observed in both astrocytes and endothelial cells after experimental ischemic stroke and hypoxia/ischemia, suggesting a potential role of astrocytic and endothelial ET-1 in ischemic brain injury. Previously, we reported that transgenic mice over-expressing ET-1 in astrocytes (GET-1 mice) displayed increased cerebral infarct size and more severe neurological deficits upon focal cerebral ischemia induced by middle cerebral artery occlusion (MCAO). However, the mechanism behind astrocytic ET-1 on ischemia-induced brain injury was not clear. Here, we report that GET mice showed lower occludin levels and increased Evans blue extravasation, suggesting increased blood-brain barrier (BBB) breakdown in GET-1 mice after MCAO. GET-1 mice also displayed increased brain swelling and brain water content together with decreased occludin and up-regulated aquaporin 4 expression. These results suggested that increased astrocytic ET-1 resulted in BBB disruption leading to increased formation of brain edema and swelling, infarct and neurological deficits and therefore imposed adverse effects on brain injury after focal cerebral ischemia.

Acknowledgement: Supported by Research Grants Council and Area of Excellence from University Grants Council of Hong Kong (AoE/B-15/01).

\section{P-21/24 \\ HGF Induction of Postsynaptic Specialization in Muscle \\ Madhavan, R., Peng, H.B. \\ Biology Department, Hong Kong University of Science and Technology, Clear Water Bay, Kowloon, Hong Kong, China}

A critical event in the formation of vertebrate neuromuscular junctions (NMJs) is the postsynaptic clustering of acetylcholine receptors (AChRs) in muscle. AChR clustering is dependent upon the activation of the muscle specific tyrosine kinase MuSK, which is part of the functional receptor for agrin, a nerve-derived heparan sulfate proteoglycan (HSPG). At the NMJ, heparan sulfate (HS)-binding growth factors and their receptors are also localized but how they affect agrin/MuSK-signaling and AChR clustering is poorly understood. In this study we found that hepatocyte growth factor (HGF), a HS-binding growth factor, surrounded muscle fibers and localized at NMJs in rat muscle sections. In cultured Xenopus muscle cells, HGF was enriched at spontaneously occurring AChR clusters where HSPGs were also concentrated and, following agrin-stimulation, HGF co-localized with newly formed AChR clusters. HGF presented locally to cultured muscle cells by latex microspheres clustered AChRs and dispersed pre-existing AChR hot spots, and at sites where the HGF-coated beads contacted muscle cells, phosphotyrosine, the activated HGF receptor c-Met, and dystroglycan and syntrophin, two proteins of vertebrate NMJs, also became concentrated. Moreover, this clustering of AChRs and associated proteins in response to HGF beads was found to be dependent on dynamic actin polymerization. Lastly, whereas HGF bath-application alone did not affect AChR clustering, addition of HGF potentiated agrin-induced AChR clustering in muscle cells. Our findings suggest that HGF promotes AChR clustering in muscle and enhances the reliability of postsynaptic signaling during NMJ development.

Acknowledgment: Supported by NIH grant NS23583, RGC grants HKUST 6107/01M and 6280/03M, AoE grant B-15/01 and EHIA grant HIA02/03.SC01. 


\section{P-22/24}

\section{A Proteomics Analysis on SH-SY5Y Cells following Chronic Exposure to Indirubin-3'-Monoxime Treatment}

Mak, S.Y.C. ${ }^{a}$, Ip, R.C.H. ${ }^{a}$, Ip, D.T.M. ${ }^{a}$, Tsim, K.W.K. ${ }^{\mathrm{b}}$, Wan, D.C.C. ${ }^{\mathrm{a}}$

aDepartment of Biochemistry, The Chinese University of Hong Kong, b Department of Biology, Hong Kong University of Science and Technology, Hong Kong, China

Bis-indole indirubin, the active ingredient of the famous Chinese medicinal recipe Danggui Longhui Wan, has been shown to have beneficial effect to treat chronic myelocytic leukemia. Recent research reveals that indirubins are potent inhibitors of cyclin-dependent kinases (CDKs) and glycogen synthase kinase-3 (GSK-3), suggesting that indirubins may also be used to treat Alzheimer's disease and type II diabetes. In order to obtain a global picture of the biochemical changes induced by indirubin, a proteomic analysis on the differentiated human neuroblastoma $\mathrm{SH}$ SY5Y cells following incubation with indirubin- 3 '-monoxime $(100 \mathrm{nM})$ was performed. Total protein lysates of treated and control cells were prepared and subjected to two-dimensional polyacrylamide gel-electrophoresis (2D-PAGE). The protein spots, visualized by silver staining, that were differentially up- or downregulated were excised, in-gel trypsin-digested and then analyzed by matrix-assisted laser desorption/ ionization-time of flightmass spectrometry (MALDI-TOF-MS/MS) for protein identification. Over a hundred proteins were identified and annotated, some of the proteins that were previously shown abnormally expressed in a transgenic model of Alzheimer's disease were found significantly down regulated. This study demonstrates that a systematic analysis of the changes in protein expression profile induced by indirubin may help unveiling novel pathways that account for indirubin-mediated anti-cancer and anti-apoptotic properties.

Acknowledgement: This work was partially supported by grant from the Area of Excellence Scheme established under the University Grants Committee of the Hong Kong SAR (AoE/B15/01) to KWKT and DCCW.

\section{P-23/24}

\section{Expression Profiling of $\mathbf{G} \alpha_{\mathbf{z}}$-Regulated Genes}

Mei, H., Ho, M.K.C., Yung, L.Y., Wong, Y.H.

Department of Biochemistry, the Molecular Neuroscience

Center, and the Biotechnology Research Institute,

Hong Kong University of Science and Technology,

Clear Water Bay, Kowloon, Hong Kong, China

$\mathrm{G} \alpha_{\mathrm{z}}$ is the only $\mathrm{G}_{\mathrm{i}}$-family member which is not a substrate of pertussis toxin and is primarily expressed in neuronal tissues. Although $\mathrm{G} \alpha_{\mathrm{z}}$ has been shown to inhibit adenylyl cyclase and modulate ion channels, its cellular functions remain largely unknown. To investigate the biological relevance of $\mathrm{G} \alpha_{\mathrm{z}}$ signaling independent of possible interference from G $\beta \gamma$ subunits, we have subcloned $\mathrm{G} \alpha_{\mathrm{z}}$ as well as its constitutively active mutant $\left(\mathrm{G} \alpha_{\mathrm{z}} \mathrm{QL}\right)$ into an ecdysone inducible expression vector and introduced the constructs into ECR293 cells (stably expressing the functional ec- dysone receptor). After selection of transfectants with the antibiotic zeocin, expressions of $\mathrm{G} \alpha_{\mathrm{z}}$ and $\mathrm{G} \alpha_{\mathrm{z}} \mathrm{QL}$ were induced by ponasterone A treatment. $\mathrm{G} \alpha_{\mathrm{z}}$ expression was confirmed by immunodetection using a $\mathrm{G}_{\mathrm{z}}$-specific antiserum. Total RNAs were prepared from untreated and ponasterone A-treated samples. Following reverse transcription and labeling, the samples were analyzed with Affymetrix Human Genome U133 Set. Genes differentially regulated upon $\mathrm{G} \alpha_{\mathrm{z}}$ or $\mathrm{G} \alpha_{\mathrm{z}} \mathrm{QL}$ expression were identified by comparative analysis with untreated control cells. A number of databases, including DAVID (Database for Annotation, Visualization and Integrated Discovery) and GeneSpring, were used to analyze the expression profiles. Interestingly, only less than 100 genes showed obvious up- or down-regulation. Several genes of interest were selected for RT-PCR analysis, followed by determination of their protein levels by Western blot analysis. The present study demonstrates that $\mathrm{G} \alpha_{\mathrm{z}}$ may regulate transcriptional activities albeit at a modest level.

Acknowledgement: This work was supported in part by grants from the Research Grants Council of Hong Kong (HKUST 6095/01M, 3/03C), the University Grants Committee (AoE/B15/01), and the Hong Kong Jockey Club.

\section{P-24/24 \\ Expression of Fos Protein in the Medial Geniculate Body of Cochlear-Ablated and Cortical-Activated Rats \\ Sun, X. ${ }^{\text {a, b}}$, Chan, Y.S. ${ }^{a}, H e,{ }^{\text {J }}{ }^{b}$ \\ aDepartment of Physiology, The University of Hong Kong, bepartment of Rehabilitation Sciences, The Hong Kong \\ Polytechnic University, Hong Kong, China}

The time course and extent of the expression of Fos protein in neurons within the medial geniculate body (MGB) were examined after chemical activation of the auditory cortex in cochlearablated Sprague-Dawley rats. Surgical ablation of the bilateral cochlea was performed in ketamine-anesthetized animals which were then allowed to recover for $4 \mathrm{~h}$ (Group I), $24 \mathrm{~h}$ (II), 7 days (III), 14 days (IV), and 30 days (V). After each of these time points, the rats were again anesthetized with ketamine. The exposed auditory cortex on the right side was administered with $\mathrm{GABA}_{\mathrm{A}}$ antagonist biccuculline methobromide $(20 \mathrm{mM})$, which in turn resulted in the activation of cells in the injected site. At $1 \mathrm{~h}$ after injection, the brain was processed for Fos immunostaining. Completeness of cochlea destruction was ascertained by post-mortem examination of the temporal bone. Control experiments were also conducted in cochlear-ablated animals without the injection of biccuculline. Neuronal activation was defined by Fos expression in cell nuclei. In Group-I rats, Fos labeling was mainly confined within the ventral and medial nuclei of the MGB ipsilateral to the activated hemisphere. In Group-II rats, Fos expression was found in the ventral, medial and dorsal nuclei of the MGB ipsilateral to the activated hemisphere. In Group-III rats, Fos expression was mainly located in the dorsal and medial nuclei, with some in the marginal zone of the MGB, but absent in the ventral nucleus of the MGB. In Groups-IV and V rats, the distribution of Fos-labeled neurons in the MGB was similar to that of Group-III rats but the Fos expression was less intense. We demonstrate that corticofugal 
induction of neuronal excitability in the non-lemniscal MGB shows a slower time course than in the lemniscal MGB, suggesting that these two areas of the auditory thalamus are differentially modulated by corticofugal pathways.

\section{$\mathrm{P}-25 / 24$ \\ Activated $\mathbf{G} \alpha_{11}, \mathbf{G} \alpha_{12}$, and $\mathbf{G} \alpha_{13}$ Inhibit Activation of the Pro-Survival AKT Signaling Cascade}

Tam, H.L., Wu, H.T., Wong, Y.H.

Department of Biochemistry, Molecular Neuroscience Center, and Biotechnology Research Institute, Hong Kong University of Science and Technology, Clear Water Bay, Kowloon, Hong Kong, China

The induction of cell survival is a highly regulated process and can be suppressed by a variety of extracellular stimuli. Accumulating evidence indicates that $G$ protein signaling plays an active role in the regulation of cell survival. Our previous study has demonstrated the regulatory effects of $G_{i / o}$ proteins in NGF-induced activation of pro-survival Akt kinase. Here, we explored the role of $G_{11}, G_{12}$, and $G_{13}$ in the regulation of Akt in cultured mammalian cells. In HEK 293 cell transiently transfected with constitutively active $\mathrm{G} \alpha_{11}, \mathrm{G} \alpha_{12}$, and $\mathrm{G} \alpha_{13}$ mutants $\left(\mathrm{G} \alpha_{11} \mathrm{QL}\right.$, $\mathrm{G} \alpha_{12} \mathrm{QL}$, and $\mathrm{G} \alpha_{13} \mathrm{QL}$ respectively), basal phosphorylation of Akt was attenuated as evidenced by western blotting analysis using a phosphospecific Akt antibody. However, the basal Akt phosphorylation level was apparently unaffected by the overexpression of constitutively active $\mathrm{G} \alpha_{\mathrm{s}}$ mutant $\left(\mathrm{G} \alpha_{\mathrm{s}} \mathrm{QL}\right)$. In contrast, expression of $\mathrm{G} \beta_{1} \gamma_{2}$ resulted in an induction of Akt phosphorylation. Additional experiments showed that $\mathrm{G} \alpha_{11} \mathrm{QL}, \mathrm{G} \alpha_{12} \mathrm{QL}$, and $\mathrm{G} \alpha_{13} \mathrm{QL}$, but not $\mathrm{G} \alpha_{\mathrm{s}} \mathrm{QL}$, attenuated phosphorylation of the Akt-regulated translation regulator tuberin. In this study, we have also demonstrated that $\mathrm{G} \alpha_{11} \mathrm{QL}, \mathrm{G} \alpha_{12} \mathrm{QL}$, and $\mathrm{G} \alpha_{13} \mathrm{QL}$ were able to inhibit the epidermal growth factor (EGF)-induced Akt activation and tuberin phosphorylation. Interestingly, $\mathrm{G} \alpha_{11} \mathrm{QL}$ remained capable of inhibiting EGF-induced Akt activation and tuberin phosphorylation in cells pretreated with the phospholipase C (PLC) inhibitor U73122. The inhibitory mechanism of $\mathrm{G} \alpha_{11} \mathrm{QL}$ seems to be independent of PLC activation. Finally, overexpression of the negative mutant of RhoA blocked $\mathrm{G} \alpha_{12}$ QL- and $\mathrm{G} \alpha_{13}$ QL-mediated inhibition, suggesting that activated $\mathrm{G} \alpha_{12}$ and $\mathrm{G} \alpha_{13}$ inhibit Akt signaling via RhoA. Collectively, this study demonstrates the inhibitory effect of activated $\mathrm{G} \alpha_{11}, \mathrm{G} \alpha_{12}$, and $\mathrm{G} \alpha_{13}$ on pro-survival Akt signaling cascade.

Acknowledgement: This work was supported in part by grants from the Research Grants Council of Hong Kong (HKUST 3/03C), the University Grants Committee (AoE/B-15/01), and the Hong Kong Jockey Club.

\section{P-26/24 \\ Chronic Hypoxia Modulates the Function of Melatonin Receptors in the Rat Carotid Body}

Tjong, Y.W. ${ }^{a}$, Chen, Y. ${ }^{a}$, Liong, E.C. ${ }^{\text {b }}$, Tipoe, G.L. ${ }^{\mathrm{b}}$, Fung, M.L. ${ }^{\mathrm{a}}$

Departments of aPhysiology and ${ }^{\mathrm{b}}$ Anatomy, Faculty of Medicine, The University of Hong Kong, Pokfulam, Hong Kong, China

Melatonin modulates the carotid chemoreceptor response to hypoxia and hypercapnic acidosis, and the effect of circadian rhythms on respiratory control is modified by chronic hypoxia. The purpose of this study was to test the hypothesis that chronic hypoxia modulates the function of melatonin receptors in the rat carotid body. To examine the effects of melatonin on the hypoxic or hypercapnic response of the chemosensitive cells, cytosolic calcium $\left(\left[\mathrm{Ca}^{2+}\right]_{\mathrm{i}}\right)$ was measured by spectrofluorometry in fura-2loaded type-I (glomus) cells dissociated from carotid bodies obtained from normoxic $(\mathrm{Nx})$ or chronically hypoxic $(\mathrm{CH})$ rats breathing $10 \%$ oxygen for 4 weeks. Melatonin concentration-dependently enhanced peak $\left[\mathrm{Ca}^{2+}\right]_{\mathrm{i}}$ responses to cyanide or deoxygenated buffer in the $\mathrm{Nx}$ and $\mathrm{CH}$ groups. Yet, melatonin attenuated the peak $\left[\mathrm{Ca}^{2+}\right]_{i}$ response to hypercapnic acidosis in the $\mathrm{Nx}$ whereas it enhanced the $\left[\mathrm{Ca}^{2+}\right]_{\mathrm{i}}$ response in the $\mathrm{CH}$ group. An agonist of melatonin receptors, iodomelatonin also enhanced the $\left[\mathrm{Ca}^{2+}\right]_{\mathrm{i}}$ responses to hypercapnic acidosis or hypoxia in both groups. The melatonin-induced changes in the $\left[\mathrm{Ca}^{2+}\right]_{\mathrm{i}}$ responses were abolished by pretreatment with nonselective $\mathrm{mt}_{1} / \mathrm{MT}_{2}$ antagonist, luzindole, and by $\mathrm{MT}_{2}$ antagonists, 4-phenyl-2-propionamidotetraline or DH97. These findings suggest a functional modulation of melatonin receptors in the glomus cells following chronic hypoxia.

Acknowledgement: This work was supported in part by grants from the Research Grants Council of Hong Kong (7184/01M), the University Grants Committee (10204884).

\section{P-27/24 \\ Stimulation of Mitogen-Activated Protein Kinases by a Human Formylpeptide-Receptor-Like-1}

Kam, A.Y.F., Tse, T.M., New, D.C., Wong, Y.H.

Department of Biochemistry, Molecular Neuroscience Center, and Biotechnology Research Institute, Hong Kong University of Science and Technology, Clear Water Bay, Kowloon, Hong Kong, China

Human formylpeptide-receptor-like-1 (FPRL-1) belongs to a $\mathrm{G}$ protein-coupled formylpeptide receptor family, and has been found to be rather promiscuous due to binding with a variety of agonists such as inflammatory lipoxin A4, amyloidogenic polypeptides and even synthetic peptides. Recently, it has reported that the FPRL- 1 is used by the 42 amino-acid form of $\beta$-amyloidtriggered neuronal cell death [1], thus the receptor may play a potential role in amyloidogenic diseases. However, the molecular mechanism underlying the neurotoxic effect induced by the FPRL-1 is not fully elucidated. The present study we used a highly potent agonist WKYMVM to stimulate the FPRL-1 stably ex- 
pressing in Chinese hamster ovary $(\mathrm{CHO})$ cells, with $\mathrm{pEC}_{50}$ value of XX in the intracellular $\mathrm{Ca}^{2+}$ mobilization assay. Incubation of $\mathrm{CHO}$ cells with WKYMVM induced transient activations of cJun $\mathrm{NH}_{2}$-terminal kinase (JNK) and p38 mitogen-activated protein kinase (p38 MAPK), which are most frequently associated with cellular apoptosis. The maximal activation for both kinases was observed at around 2-5 min. In order to confirm the signaling properties of the FPRL-1-elicited MAPKs activation under more physiological conditions, human U87 astrocytoma cells that endogenously expressed the receptor was also used. Interestingly, WKYMVM-treated U87 only increased the activity of JNK but not p38 MAPK, peaking at $15 \mathrm{~min}$. Moreover, the JNK stimulation in $\mathrm{U} 87$ cells displayed to be more prolonged than that in $\mathrm{CHO}$ cells. Nevertheless, in both CHO and U87 cells, pertussis toxin and an inhibitor for Src family tyrosine kinases clearly abolished the FPRL-1-induced MAPKs activations, suggesting the particpation of $\mathrm{G}_{\mathrm{i}} / \mathrm{G}_{\mathrm{o}}$ proteins and Src family in the signaling cascade. The inhibition of $\mathrm{Ca}^{2+}$-mediated protein kinase $\mathrm{C}$, phospholipase $\mathrm{C} \beta$ and calmodulin-dependent kinase II did not affect the MAPKs stimulation by the FPRL-1. This study provides a basis to further understand the signaling network in the FPRL-1-regulated neuronal toxicity.

Acknowledgement: This work was supported in part by grants from the Research Grants Council of Hong Kong (HKUST 3/03C), the University Grants Committee (AoE/B-15/01), and the Hong Kong Jockey Club.

Reference

1 Ying G, et al: J Immunol 2004;172:7078-7085.

\section{P-28/24 \\ Immunohistochemical Localization of Chondroitin Sulfate Proteoglycans in the Developing Rat Hindbrain \\ Wang, F., Kwok, J.C.F., Shum, D.K.Y. \\ Department of Biochemistry, Faculty of Medicine, \\ The University of Hong Kong, Hong Kong, China}

Our biochemical analysis has shown the occurrence of chondroitin sulfate proteoglycans (CSPGs) in the hindbrain of rat embryos. To localize their expression in the embryos, immunohistochemistry was applied on cryosections of E11.5, E12.5 and E13.5 embryos. Epitopes of CS were detectable in the extra/peri-cellular environment of the neuroepithelium at E11.5 and E12.5. Signals were very weak by E13.5. The results were confirmed by the disappearance of signals following chondroitinase treatment of the sections. Versican-positive signals were pericellular in all three stages. The immunoreactivity was strong towards the ventricular region at E11.5. The signals declined by E12.5 and strong immunoreactivity was found towards the pial surfaces. Neurocan-positive signals appeared to be intracellular and concentrated in a cell layer lining the pial side of the neural tube as early as E12.5. Phosphacan-positive signals were not detectable in all three stages. As hyaluronan binds CSPGs, experiments were also performed to localize hyaluronan in the embryos. The hyaluronan staining pattern resembled that of versican in all three stages, suggesting interaction between versican and hyaluronan in the development of the embryonic hindbrain.

\section{P-29/24 \\ $\mathbf{G}_{14}$-Mediated Stimulation of NFKB by the Type 2 Somatostatin Receptor}

Liu, A.M.L., Wong, Y.H.

Department of Biochemistry, the Molecular Neuroscience Center, and the Biotechnology Research Institute, Hong Kong University of Science and Technology,

Clear Water Bay, Kowloon, Hong Kong, China

Somatostatin is an important neurotransmitter which modulates neuronal firing, release of other neurotransmitters and cognitive processes in the brain. The $\mathrm{G}_{\mathrm{i}}$-linked type 2 somatostatin receptor (SSTR2) is known to regulate multiple signal transduction pathways and modulation of receptor activity may affect the progression of neuroendocrine tumors and pituitary adenomas. We have previously shown that SSTR2 can stimulate phospholipase $C \beta$ via $G \alpha_{14}$, a member of the $G_{q}$ subfamily [1]. Here we delineated the coupling of SSTR 2 and $G \alpha_{14}$ in the stimulation of the transcription factor nuclear factor $\kappa \mathrm{B}(\mathrm{NF} \kappa \mathrm{B})$. In human embryonic kidney 293 cells coexpressing SSTR2 and $\mathrm{G} \alpha_{14}$, somatostatin (SST) induced IкB $\alpha$ kinase (IKK) phosphorylation and NFкBdriven luciferase activity in a time-, dose-dependent and PTX-independent manner. Application of a SSTR2 specific antagonist, PRL-2903, abrogated the IKK/NFKB phosphorylation, confirming the selective activation through SSTR2. G $\beta \gamma$ subunits also regulated IKK/NFKB activation, as indicated by the stimulatory effect of $G \beta_{1} \gamma_{2}$ and the attenuation of SST-induced response by transducin. Using dominant negative mutants and specific kinase inhibitors, phospholipase $\mathrm{C} \beta$, protein kinase $\mathrm{C}$ and calmodulindependent kinase II were shown to participate in the regulation of SST-mediated IKK/NFKB activation. Involvements of c-Src and various intermediates along the extracellular signal-regulated kinase cascade including Ras, Raf- 1 kinase, and MEK1/2 were also validated. Although $\mathrm{G} \alpha_{14}$ is capable of stimulating all three types of mitogen-activated protein kinases, c-Jun N-terminal kinase and p38 MAPK were not required for the SST-mediated responses. These results suggest that the $\mathrm{G}_{14}$-mediated activation of IKK/NFKB by SSTR2 required a convoluted signaling network composed of numerous intermediates.

Acknowledgement: This work was supported in part by grants from the Research Grants Council of Hong Kong (HKUST 3/03C), the University Grants Committee (AoE/B-15/01), and the Hong Kong Jockey Club.

\section{References}

1 Ho MK, et al: Br J Pharmacol 2001;132:1431-1440.

2 Lo RK, et al: Mol Pharmacol 2004;65:1427-1439. 


\section{P-30/24 \\ Transcriptional Regulation of Prima, a Membrane Anchor of Globular Form Ache, in Neuron and Muscle Differentiation}

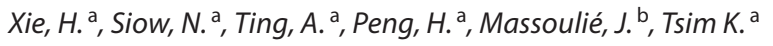

aDepartment of Biology, The Hong Kong University of

Science and Technology, Clear Water Bay, Hong Kong, China;

bLaboratoire de Neurobiologie Moléculaire et Cellulaire,

CNRS UMR 8544, Ecole Normale Supérieure, Paris, France

Acetylcholinesterase (AChE) exists as tetrameric globular $\left(\mathrm{G}_{4}\right)$ form in brain. Proline-Rich Membrane Anchor (PriMA) is able to organize AChE catalytic subunits into tetramers via its Proline-Rich Attachment Domain (PRAD) and anchor the enzyme at the surface of neuron and muscle [1]. To determine the regulation of PRiMA, we isolated a $\sim 2 \mathrm{~kb}$ upstream sequence of the 5' UTR from human PRiMA gene and tagged it with luciferase reporter gene, namely phPRiMA-Luc, which was transfected into cell cultures. The luciferase activity of phPRiMA-Luc increased gradually during differentiation of NG108-15 cells and rat cortical neuron cultures. In contrast, the promoter activity decreased during myogenesis of $\mathrm{C} 2 \mathrm{C} 12$ cells. The promoter activity in neurons and muscle were in line with the expression profiles of PRiMA mRNA in the culture systems by using real time PCR analysis. In cultured neurons, promoter activity of phPRiMA-Luc could be induced by application of $\mathrm{Bt}_{2}$-cAMP, suggesting the involvement of a cAMP-dependent signaling pathway in PRiMA regulation. Moreover, we found that AChE was localized at the lipid raft-enriched membrane microdomain in rat total brain extract, and the immunochemical staining showed that AChE was co-localized with post-synaptic density protein (PSD-95) in cultured cortical neurons. The restricted localization of AChE at the synaptic sites suggested the possible involvement of intracellular binding partner of PRiMA, which may involve in localizing PRiMA and subsequently the $\mathrm{G}_{4} \mathrm{AChE}$ within the synaptic area.

Acknowledgement: Research Grants Council of Hong Kong (HKUST 6098/02, 6283/03M and 6237/04M).

Reference

1 Perrier, A, et al: Neuron 2002;33:275-285.

\section{P-31/24 \\ Depletion of NMDA Receptor Expressions and Dendritic Spines in Hippocampal Cultured Neurons after Low Doses of Dioxin Incubation}

Yeung, C.W., Yung, K.K.L.

Department of Biology and Croucher Institute for Environmental Sciences, Hong Kong Baptist University, Kowloon Tong, Hong Kong, China

One major form of dioxins, namely 2,3,7,8-tetrachlorodibenzo- $\rho$-dioxin (TCDD), is known to be a group of highly persistent and stable compounds which is a major environmental pollutant that imposes serious risks to public health. N-methyl-D-aspartate receptors (NRs) are important molecules that are known to in- volve in the formation of learning and memory in neurons of the brain. In order to investigate the toxic effects of TCDD on the hippocampal neurons, primary cell cultures were employed. After TCDD treatments of sub-lethal doses $(0,0.1,1,4,10$ and $20 \mathrm{pg} /$ $\mathrm{ml}$ ), neurons were seen to survive and with no obvious changes in morphology. Results of both reverse transcriptase-polymerase chain reactions and western blotting experiments indicated that NR1 and NR2B mRNA and protein were found to be decreased in whole hippocampal neurons in a dose dependent manner. The decrease of NR1 and NR2B proteins were found primarily in the membrane extracts of the neurons but not in the cytosol extracts. Immunofluorescence experiments showed that PSD-95 immunoreactivity was depleted after TCDD treatments. These results indicate that the number of dendritic spines on hippocampal neurons was reduced after TCDD treatments also in a dose dependent manner. The present results as a whole indicate that TCDD reduces the expression of NR1 and NR2B proteins in the cell membrane as well as reduces the number of dendritic spines in hippocampal neurons. TCDD toxicity may have a profound effect on learning and memory in the brain.

Acknowledgement: Supported by HKBU2/00C Central Allocation, Research Grants Council, Hong Kong.

\section{P-32/24 \\ Expression of Inhibitor of DNA Binding, ID3, in the Mouse Retina during Postnatal Development}

Yeung, S.C., Yip, H.K.

Department of Anatomy, The University of Hong Kong,

Laboratory Block, Faculty of Medicine, Pokfulam, China

Id3 (inhibitor of DNA binding/differentiation), as well as other Id proteins, was first identified as an inhibitor of differentiation because it was down-regulated during differentiation and upon cell cycle withdrawal, and up-regulated in proliferative and undifferentiated cells, and that overexpression of Id 3 inhibits differentiation. It has recently shown that Id3 expression was found in the dividing mouse neuroblasts during neurogenesis, however, the expression and cell-specific localization of Id3 protein have not been extensively studied in the nervous system, particularly in the retina. In this study, the expression patterns and cell phenotypes of Id 3 were examined in postnatal and in adult mice retina. The expression of Id 3 in mouse retina was observed in the inner retina mainly at postnatal day 0 (P0). At P6, after the laminar organization was formed, expression of Id 3 was confined to the ganglion cell layer and the inner nuclear layer. This spatial expression of Id 3 remained in the adult retina. The Id 3 expressing cells were identified as retinal ganglion cells and amacrine cells by the corresponding cell-specific markers. Furthermore, Id 3 expression was localized in the nuclei of postmitotic neurons in the adult retina. The spatial and temporal expression patterns of Id3 during retinal development, as well as its cellular specificity, provide the fundamental information for the elucidation of its possible role in the retinogenesis.

Acknowledgement: This work is supported by a CRCG grant from the University of Hong Kong. 


\section{P-33/24}

\section{Synergistic Activation of Extracellular Signal- Regulated Kinase by $\mathbf{G}_{\mathrm{i}}$ - and $\mathbf{G}_{\mathrm{q}}$-Coupled Receptors in SK-N-MC Neuroepithelioma Cells}

Yeung, W.W.S., Chan, A.S.L., Wong, Y.H.

Department of Biochemistry, the Molecular Neuroscience Center, and the Biotechnology Research Institute, Hong Kong University of Science and Technology, Clear Water Bay, Kowloon, Hong Kong, China

Mammalian cells often receive multiple extracellular stimuli under physiological conditions, and the various signaling inputs have to be integrated for complex biological responses. $G$ proteincoupled receptors (GPCRs) play a significant role in converting extracellular stimuli into intracellular signals. Several families of GPCRs have been shown to activate extracellular signal-regulated kinase (ERK) in neuronal cells. However, little is known about the signal integration upon co-stimulation of different GPCRs in neuronal cells. In this report, we utilized the SK-N-MC human brain neuroepithelioma cell, which endogenously express different GPCRs of defined coupling specificities, as a neuronal model for studying signal integration of ERKs upon GPCR activation. $\mathrm{G}_{\mathrm{i}}$-coupled neuropeptide $\mathrm{Y}_{1}$ and $\mathrm{G}_{\mathrm{q}}$-coupled muscarinic acetylcholine $M_{1} R$, but not $G_{s}$-coupled dopamine $D_{1}$ receptors are linked to the activation of ERK. The $\mathrm{G}_{\mathrm{i}}$-mediated ERK activation was completely inhibited by PP1, while the $\mathrm{G}_{\mathrm{q}}$-induced response was suppressed by both PP1 and BAPTA-AM. Synergistic ERK activation was obtained by co-stimulating the $\mathrm{G}_{\mathrm{i}^{-}}$and $\mathrm{G}_{\mathrm{q}}$-coupled receptors. The $G_{i} / G_{q}$-induced synergistic ERK activation is PTXsensitive, and appears to be a co-operative effect between $\mathrm{Ca}^{2+}$ and Src family tyrosine kinases. This potentiated ERK activation was associated with a synergistic CREB stimulation. This report demonstrates that signal integration at the level of ERK occurs in neuronal cells upon the simultaneous activation of $\mathrm{G}_{\mathrm{i}^{-}}$and $\mathrm{G}_{\mathrm{q}}$ coupled receptors.

Acknowledgement: This work was supported in part by grants from the Research Grants Council of Hong Kong (HKUST 3/03C), the University Grants Committee (AoE/B-15/01), and the Hong Kong Jockey Club.

\section{P-34/24 \\ Facial Emotion Differentiation: Effects of Participant's Sex, Gender of Poser, and Emotion Type \\ Yip, J.T.H. ${ }^{\text {a }}$ Jing-Lam Ko, J.-L. ${ }^{\text {b }}$, Jack Broerse, J. ${ }^{\text {b }}$ \\ aDivision of Speech and Hearing Sciences, The University of Hong Kong, Hong Kong, China; ${ }^{b}$ Department of Psychology, The University of Queensland, Australia}

The ability to differentiate between different facial emotions was investigated in terms of the effects of participant's sex, gender composition of photograph pairs, and emotion type on accuracy and response times. In Study 1, 30 males and 30 females viewed 240 randomly ordered photograph pairs (conveying same or different facial emotions) based on 12 different photographs taken from Matsumoto and Ekman [1]. Participants were asked to indicate whether they convey the same or different emotion by pressing a mouse button. These photograph pairs consisted of three types of gender compositions (e.g., male-male, female-female, and male-female). In Study 2, 30 males and 30 females viewed 192 randomly ordered photograph pairs consisting of either one of six basic emotions only (happy-happy), or one of the six basic emotions and one neutral photograph only (happy-neutral) in which photographs depicting a particular facial emotion were always paired with their corresponding neutral photograph only. Participants were asked to respond in the exact same manner as in Study 1. In Study 1, females (relative to males) were slower when the gender composition was male-male or female-female and more accurate when the gender composition was male-female. In Study 2, females were slower but more accurate than males in differentiating between facial emotions from their corresponding neutral expressions - except happiness. These findings are congruent with previous claims for female superiority in decoding of facial expressions, though this may be due to their elevated response times. Implications are discussed in terms of current neuropsychological theories of gender and emotion.

\section{Reference}

1 Matsumoto D, Ekman P: Japanese and Caucasian Facial Expressions of Emotion (JACFEE) and Neutral Faces (JACNeuF). SF: Department of Psychiatry, University of California, 1988.

\section{P-35/24 \\ Developmental Expression of Fos Protein in Horizontal Canal-Related Vestibular Nuclear Neurons of Postnatal Rats following Angular Acceleration}

Yiu, C., Lai, C.H., Chan, Y.S.

Department of Physiology, Faculty of Medicine, The University of Hong Kong, Hong Kong, China

To investigate the postnatal distribution of horizontal canalrelated neurons within the vestibular nucleus, conscious young (1-21 days) and adult Sprague-Dawley rats were subjected to constant angular acceleration on the horizontal plane for 60 minutes. This stimulation paradigm, composed of alternate modes of angular acceleration (at $50-200 \% \mathrm{~s}^{2}$ ) in the clockwise (8s) and counterclockwise direction (8s), activates hair cells in both horizontal canals. Neuronal activation within brainstem nuclei was defined by the expression of Fos protein. Labyrinthectomized controls and normal stationary controls showed only a few sporadically scattered Fos-labeled eurons. In P1-4 rats, no Fos-labeled neurons were found in the vestibular nucleus and prepositus hypoglossal nucleus (PrH). In the vestibular nucleus, significant Fos labelling was identified in the medial (MV), spinal (SpV) nuclei and group $\times$ subnucleus as early as P5. From P5 to P14, Fos expression in both the MV and SpV progressively increased, reaching an adult level at P21. In P5-7 rats, Fos-labeled neurons, though few in number, were evenly distributed throughout the entire rostrocaudal length of the MV and SpV. In P21 and adult rats, however, the number of Fos-labeled neurons tended to cluster in the caudal end of the MV and SpV. In the PrH, an area related to ves- 
tibulo-ocular functions, an age-dependent increase in the number of Fos-labeled neurons was observed from P7 onwards. These were mainly distributed in the rostral $\mathrm{PrH}$. The present results provide evidence that functional connectivity between canal receptors and central vestibular neurons is established during the first postnatal week.

Acknowledgement: Supported by HK RGC.

\section{P-36/24}

\section{Protein Kinases as Technological Platforms to Screen Neuroprotective Agents from Chinese Medicine}

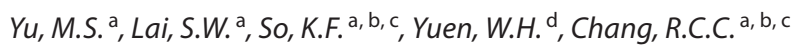

aLaboratory of Neurodegenerative Diseases, Department of Anatomy, ${ }^{b}$ Research Centre of Heart, Brain, Hormone and Healthy Aging, Faculty of Medicine, 'Central Laboratory of Institute of Molecular Technology for Drug Discovery and Synthesis and ${ }^{d}$ Open Laboratory of Chemical Biology of Institute of Molecular Technology for Drug Discovery and Synthesis, The University of Hong Kong, Pokfulam, Hong Kong, China

Alzheimer's disease (AD) is an age-associated neurodegenerative disorder affecting quite a lot of elderly in different countries. Current treatment for AD depends on cholinesterase inhibitor. However, its effectiveness is quite disappointing. Therefore, there is an urgent need to search for alternate treatment and neuroprotection is a possible strategy. One of the critical pathological factors in $\mathrm{AD}$ is the accumulation of beta-amyloid $(\mathrm{A} \beta)$ peptides found in the cortex of $A D$ brain. $A \beta$ peptides have been shown to induce cell death in cultured neurons and are often used as a model toxin to study the pathogenesis of AD. Previous studies have shown that stress kinases (such as PKR, JNK, p38 MAPK and GSK3 $\beta$ ) mediate A $\beta$-triggered neuronal apoptosis. On the other hand, both kinases PDK-1 and Akt in survival signaling pathway can inhibit apoptosis. It is hypothesized that neuroprotection can be achieved by inhibition on pro-apoptotic pathways or activation of survival pathways. By western blot analysis, we found that polysaccharides from Nerium indicum (Oleander) activate the PDK-1Akt survival signaling pathway while the extract from Lycium barbarum (Gou-Qi-Zi) inhibits A $\beta$-triggered PKR and JNK phosphorylation. All these extracts can protect neurons against $A \beta$ toxicity by inhibition on caspase-3 activity. In conclusion, it is possible to make use of protein kinases to screen potential neuroprotective agents from Chinese medicine.

Acknowledgement: This work is supported by Area of Excellence (AoE/P-10/01).

\section{P-37/24 \\ Differential Regulation of Signal Transducers and Activators of Transcription by G-Protein Subunits}

Yuen, J.W.F., Wong, Y.H.

Department of Biochemistry, the Molecular Neuroscience

Center, and the Biotechnology Research Institute,

Hong Kong University of Science and Technology,

Clear Water Bay, Kowloon, Hong Kong, China

Signal transducer and activator of transcription (STAT) proteins are latent transcription factors located in the cytoplasm of resting cells. STATs become activated upon tyrosine phosphorylation at the transactivation domain. To date, seven members of STAT have been identified, many of which are known to be associated with various cellular processes including growth and differentiation. Heterotrimeric guanine nucleotide binding proteins (G proteins) have recently been implicated in the tyrosine phosphorylation and subsequent activation of STAT3. Given that both $\mathrm{G} \alpha$ and $\mathrm{G} \beta \gamma$ subunits are capable of regulating multiple effectors, we examined the activity of STAT in response to stimulation by selected G protein subunits. Human embryonic kidney 293 cells were transiently transfected with various $G$ protein subunits and the cell lysates were then probed with phosphospecific antibodies against different STATs. Expression of GTPase-deficient G $\alpha_{14}$ or $\mathrm{G} \alpha_{16}$, but not their wild-type counterparts, resulted in the phosphorylation of STAT3 at Tyr ${ }^{705}$. STAT3 was also phosphorylated in cells expressing either the $G \beta_{1} \gamma_{2}$ or $G \beta_{2} \gamma_{2}$ complex. However, none of other STAT proteins (STAT1, 2, 4, and 5) examined was phosphorylated under identical experimental conditions, although they can become phosphorylated upon stimulation with cytokines. These findings demonstrated the differential regulatory activity of $\mathrm{G}$ protein subunits on STAT3.

Acknowledgement: This work was supported in part by grants from the Research Grants Council of Hong Kong (HKUST 3/03C), the University Grants Committee (AoE/B-15/01), and the Hong Kong Jockey Club.

\section{P-38/24 \\ Heparanse-Syndecan-3 Interaction in Neurons of the Adult Spinal Cord}

Zhang, Y., Liu, J., Chau, C.H., Shum, D.K.Y.

Department of Biochemistry, Faculty of Medicine,

The University of Hong Kong, Hong Kong, China

Heparan sulfate proteoglycans (HSPGs) are found in the extracellular matrix, on the cell surface and even in intracellular organelles of mammalian neural tissue. The HS moiety can be cleaved endoglycosidically at limited sites by heparanase to yield HS fragments. Most studies of heparanase expression have been related to tissue invasion by tumor cells and inflammatory cells, our study has however been focused on heparanase expression in the normal adult spinal cord. RT-PCR revealed the expression of heparanase mRNA in the spinal cord. In situ hybridization with DIG-labeled anti-sense riboprobe located heparanase mRNA in cells of the spinal cord. Intensely stained signals were found in motor neurons (ventral gray column), interneurons (substantia 
gelatinosa) and tract cells (dorsal gray column). In the white matter, signals were found mainly in glial cell bodies, such as astrocytes. These results were further confirmed immunocytochemically in combination with in situ hybridization. To find interaction of heparanase with HSPG in spinal cord, we explored spinal cord sections with double immunofluorscence for colocalization of heparanase and syndecan-3. Syndecan-3 was found in neuronal cell bodies of the gray matter, similar to heparanase in cellular distribution. In the white matter, although axon tract were syndecan-3-positivity, there was no detectable heparanase immunoreactivity. No syndecan-3 expression was observable in astrocytes. These observations suggest functional significance of interaction of heparanase and syndecan-3 in the neurons within the normal adult spinal cord.

\section{P-39/24 \\ Corticofugal Projection Inhibits the Auditory Thalamus through the Thalamic Reticular Nucleus}

Zhang, Z., He, J.

Department of Rehabilitation Sciences, Hong Kong Polytechnic University, Hung Hom, Kowloon, Hong Kong, China

Electrical stimulation of the auditory cortex causes mainly facilitatory effect on the lemniscal nucleus of the medial geniculate body (MGB) and inhibitory effect on the non-lemniscal nuclei of the MGB $[1,2]$. There are three possible pathways for that corticofugal inhibition: (1) cortex $\rightarrow$ MGB interneurons $\rightarrow$ MGB relay neurons; (2) cortex $\rightarrow$ inferior colliculus $\rightarrow$ MGB (corticocolliculothalamic pathway); (3) cortex $\rightarrow$ thalamic reticular nucleus $\rightarrow$ MGB (corticoreticulothalamic pathway). The first possibility is quite low as we use guinea pig as the animal model in which interneurons count for less than $1 \%$ in the MGB. To further identify the corticofugal inhibitory pathway to the MGB among the latter two possibilities, we compared the neuronal responses of the MGB to electrical stimulation of the auditory cortex between the experimental condition in which the inferior colliculus was dissected and the control condition in which the inferior colliculus was kept intact. Experiments were carried out using in vivo intracellular recording on anaesthetized guinea pig. Our result showed that cortical stimulation under both conditions caused strong inhibitory effects on the MGB neurons. The result suggests that the corticofugal inhibition is likely caused by the corticoreticulothalamic pathway rather than the corticocolliculothalamic pathway.

Acknowledgement: Supported by Competitive Research Grants Commission (PolyU5407/03M).

References

1 Xiong Y, Yu YQ, Chan YS, He J: The Journal of Physiology (London) 2004;560:207-217.

2 Yu YQ, Xiong Y, Chan YS, He J: The Journal of Neuroscience 2004;14: 3060-3069.

\section{P-40/24 \\ Effects of Ginkgo biloba Extract on the Expression of BCL-2 Oncoprotein and Neuronal Nitric Oxide Synthase in the Sensory Cortex of the Senescence Accelerated Mouse}

Yew, D.T., Li, Q., Chan, W.Y.

Department of Anatomy, Faculty of Medicine, The Chinese

University of Hong Kong, Hong Kong, China

One of the most devastating disorders of the old age is deterioration of cognitive and emotional functions, which are related to a relatively large loss of neurons during aging. However, despite the progress made in the understanding of the aging process, the cellular mechanisms underlying this loss of neurons remain largely unclear. In the present study, we focused on (1) the expression of the Bcl-2 oncoprotein, a well-known anti-apoptotic molecule, in the sensory cortex of the aging brain; (2) the production of nitric oxide as reflected by the increase in the expression of the neuronal nitric oxide synthase (nNOS) in the same cortical region; and (3) the effects of Ginkgo biloba extract on the expression of Bcl-2 and nNOS. Senescence accelerated mice-prone strain 8 (SAMP8) was used as the experimental animal because the aging process of this strain is much accelerated and the mice show neuropathological alterations similar to those found in the aging human brain. It was found that at the age of 3 months, a significant level of Bcl-2 oncoprotein expression was detected (30\% of cells expressing the protein), and a relatively low level of nNOS was observed ( $7 \%$ of cells expressing the enzyme). By the age of 9 months, the expression of Bcl-2 was significantly reduced by $73 \%$ while the nNOS level was increased by $57 \%$. However, when the SAMP8 mice were fed with the G. biloba extract from the age of 3 weeks until sacrifice, the reduction in the $\mathrm{Bcl}-2$ expression was almost abolished and the increase in the nNOS level was suppressed at the age of 9 months. Hence, our results appear to suggest that the G. biloba extract may be able to suppress the reduction of $\mathrm{Bcl}-2$ expression and the increase of the nNOS level during aging.

Acknowledgement. The work described here was fully supported by a grant from the Research Grants Council of the Hong Kong Special Administrative Region, China (Project No. CUHK4023/01M). 
Adams, M.E. OP-1/24

An, H. P-7/24

Arévalo, J.C. OP-1/24

Barnard, E. OP-7/24

Burns, A.J. P-6/24

Cao, M. P-8/24

Chan, A.S.L. P-33/24

Chan, A.W.S. P-7/24

Chan, C.C.H. P-2/24

Chan, H.H. P-16/24

Chan, S.O. OP-9/24, P-10/24

Chan, W.S. P-1/24

Chan, W.Y. OP-10/24, P-6/24, $\mathrm{P}-40 / 24$

Chan, Y.S. OP-13/24, P-1/24, P-9/24, P-13/24, P-15/24, P-24/24, P-35/24

Chang, R.C.C. P-36/24

Chao, M.V. OP-1/24

Chau, C.H. P-38/24

Chen, L.W. P-1/24

Chen, Y. OP-1/24, P-26/24

Chen, Y.S. P-3/24

Cheng, K. OP-4/24

Cheung, S.F. P-4/24

Chin, W.H. OP-2/24

Choi, R. OP-7/24

Chow, B.K.C. OP-13/24, $\mathrm{P}-13 / 24$

Chung, E.K.Y. P-5/24

Chung, S.K. P-3/24, P-4/24, P-14/24, P-20/24

Chung, S.S.M. P-3/24, P-4/24, P-14/24, P-20/24

Copp, A.J. OP-10/24

Dong, M. P-6/24

Froehner, S.C. OP-1/24

Fu, A.K.Y. OP-4/24, OP-5/24

Fu,W.-Y. OP-15/24

Fung, M.K.L. P-20/24

Fung, M.L. P-26/24
He, J. P-24/24, P-39/24

Ho, M.K.C. P-23/24

Hu, S.Y. P-7/24

Hung, K.W. OP-4/24

Ip, D.T.M. P-22/24

Ip, F.C.F. P-7/24

Ip, N.Y. OP-1/24, OP-2/24, OP-4/24, OP-5/24, OP-15/24, P-7/24

Ip, R.C.H. P-22/24

Jack Broerse, J. P-34/24

Jiang, H. OP-14/24

Jin, Q.H. OP-14/24

Jin, W. P-8/24

Jing, P. OP-14/24

Jing-Lam Ko, J.-L. P-34/24

Kam, A.Y.F. P-27/24

Kong, L. P-17/24

Kwok, J.C.F. P-9/24, P-28/24

Lai, C.H. P-15/24, P-35/24

Lai, K.O. OP-1/24

Lai, S.W. P-36/24

Lam, C.H. P-11/24

Lam, J.S.Y. P-10/24

Lam, K.S.L. P-4/24

Lau, B.W.M. P-12/24

Lau, W.K. P-9/24

Lee, C.W. OP-3/24

Lee, S.M.Y. OP-13/24, P-13/24

Lee, T.M.C. P-2/24

Leung, J.W.C. P-14/24

Leung, K.N. P-19/24

Li, C. P-15/24

Li, Q. P-40/24

Li, R.S. P-16/24

Li, Z. OP-15/24

Liao, D. P-8/24

Ling, K. P-17/24

Liong, E.C. P-26/24

Liu, A.M.L. P-29/24

Liu, H.L. P-2/24

Liu, H.Y. P-18/24
Liu, J. P-38/24

Liu, J.X. P-15/24

Liu, Y.X. OP-4/24

Lo, A.C.Y. P-14/24, P-20/24

Lo, F.H. P-19/24

Luo, S. OP-1/24

Madhavan, R. OP-6/24, P-21/24

Mak, N.K. P-19/24

Mak, S.Y.C. P-22/24

Massoulié, J. OP-8/24, P-30/24

Mei, H. P-23/24

New, D.C. P-27/24

Ng, A.K.Y. OP-5/24

Ng, T.K.Y. P-9/24

Peng, H. P-30/24

Peng, H.B. OP-3/24, OP-6/24, P-21/24

Peng, L. P-8/24

Rebecca, W.C. P-11/24

Shi, Y.F. OP-14/24

Shum, D.K.Y. P-9/24, P-18/24, P-28/24, P-38/24

Siow, N. OP-7/24, P-30/24

So, K.F. P-4/24, P-16/24, $\mathrm{P}-36 / 24$

So, K.-F. P-12/24, PL-4/24

Sun, X. P-24/24

Tam, H.L. P-25/24

Tay, D.K. P-16/24

Ting, A. OP-8/24, P-30/24

Tipoe, G.L. P-26/24

Tjong, Y.W. P-26/24

Tong, E.P.S. P-7/24

Tsao, G.S.W. P-12/24

Tse, T.M. P-27/24

Tsim, K. OP-7/24, OP-8/24, $\mathrm{P}-17 / 24, \mathrm{P}-30 / 24$

Tsim, K.W.K. P-22/24
Wai, Y.-Y. P-2/24

Wan, D.C.C. P-22/24

Wan, Y.-L. P-2/24

Wang, F. P-28/24

Wang, J. OP-9/24

Wang, J.J. OP-13/24, P-13/24

Wang, L. OP-10/24

Wise, H. OP-11/24

Wong, A.O.L. P-12/24

Wong, Y.H. OP-12/24, P-7/24, P-23/24, P-25/24, P-27/24, P-29/24, P-33/24, P-37/24

Wu, H.T. OP-12/24, P-25/24

Wu, W.R. OP-14/24

Xia, J. P-8/24

Xie, H. OP-7/24, P-30/24

$\mathrm{Xu}, \mathrm{J}$. P-8/24

Yao, X. PL-2/24

Yaw, L.P. P-20/24

Yeung, C.W. P-31/24

Yeung, S.C. P-32/24

Yeung, W.W.S. P-33/24

Yew, D.T. P-40/24

Yip, F.P. P-6/24

Yip, H.K. P-32/24

Yip, H.K.F. P-12/24

Yip, J.T.H. P-34/24

Yiu, C. P-35/24

Yu, M.S. P-36/24

Yuen, J.W.F. P-37/24

Yuen, W.H. P-36/24

Yung, K.K.L. P-1/24, P-5/24, P-11/24, P-31/24

Yung, L. P-11/24

Yung, L.Y. P-23/24

Yung, W.H. OP-13/24, P-13/24

Zhang, B. OP-14/24

Zhang, M. P-8/24

Zhang, X.J. OP-14/24

Zhang, Y. P-38/24

Zhang, Z. P-39/24

Zhao, X.-S. OP-15/24

Zhu, H. OP-14/24 


\section{The 25th Scientific Meeting of the Hong Kong Society of Neurosciences}

\section{Plenary Lectures}

\section{PL-1/25 \\ New Perspectives in G Protein Signaling: Regulation of Protein Kinases and Transcription Factors \\ Wong, Y.H. \\ Department of Biochemistry, the Molecular Neuroscience Center, and the Biotechnology Research Institute, Hong Kong University of Science and Technology, Clear Water Bay, Kowloon, Hong Kong, China}

A vast array of neurotransmitters and neuropeptides act on heptahelical G protein-coupled receptors (GPCRs). Despite of their well-established physiological and clinical roles, the GPCRs are often viewed as molecular switches whose major functions are to regulate intracellular second messengers. The prototypical $G$ proteins $\left(G_{s}, G_{i}\right.$ and $\left.G_{q}\right)$ have long been known to control the intracellular levels of cAMP and $\mathrm{IP}_{3}$ but, with the advent of modern molecular and cell biology tools, it soon became apparent that these $\mathrm{G}$ proteins can regulate complex cellular processes such as mobility, growth, and differentiation. Each of the twenty distinct $\mathrm{G}$ protein $\alpha$-subunits $(\mathrm{G} \alpha)$ has now been shown to interact with multiple effectors, often leading to the activation of protein kinase cascades and transcription factors. Since most GPCRs are capable of interacting with multiple $\mathrm{G}$ proteins, practically all GPCRs can regulate the mitogen-activated protein kinases (MAPKs), thus allowing neurotransmitters and neuropeptides to modulate cell growth and differentiation. Likewise, G protein signaling has been linked to the regulation of transcription factors. For instance, activation of $\mathrm{G}_{\mathrm{i}}$-coupled cannabinoid $\mathrm{CB} 1$ receptors can lead to the stimulation of neurite outgrowth in Neuro2A cells via the signal transducer and activator of transcription 3 (STAT3). In order to fully comprehend the biological functions of the GPCRs, it is important to determine the functional capacity of individual $\mathrm{G} \alpha$ subunits. We have therefore examined the ability of different $\mathrm{G} \alpha$ subunits to regulate protein kinases and transcription factors in the context of their involvement in neuronal survival and differentiation. Constitutively active mutants of various $\mathrm{G} \alpha$ subunits were transiently expressed in HEK 293 and PC12 cells and the activities of target proteins were monitored by immunoblotting and reporter gene assays. The detailed mechanisms by which specific $\mathrm{G} \alpha$ subunits regulate the activities of MAPKs, Akt, STAT3, and nuclear factor- $\mathrm{kB}$ will be discussed. Our results support the idea that different $G$ proteins may employ similar but non-identical pathways to regulate protein kinases and transcription factors, and inhibition of certain key components may produce near 'global shutdown' of $G$ protein signaling at the transcription level.

Acknowledgement: This work was supported in part by grants from the Research Grants Council of Hong Kong (HKUST 3/03C, $6120 / 04 \mathrm{M}$, and 6420/05M), the University Grants Committee (AoE/B-15/01), and the Hong Kong Jockey Club.

\section{PL-2/25 \\ Comparison Study of the Proliferation Ability of Stem Cells under Hypoxic Condition and Its Mechanism}

Zhu, L.-L., Fan, M.

Institute of Basic Medical Science, Beijing, China

Oxygen $\left(\mathrm{O}_{2}\right)$ is vital to nearly all forms of life on earth and it is also an important physiological regulator for the cell function. Hypoxia exists in the developing and adult brain (mean oxygen level is about $3 \%$ in the brain tissue), whereas standard cell culture system generally employs environmental oxygen levels of $20 \%$. This study aims at an examination of the proliferation ability of the different types of adult stem cells exposed to hypoxic condi-

\section{KARGER}

(C) 2006 S. Karger AG, Basel

Fax +41613061234 
tion $\left(3 \% \mathrm{O}_{2}\right)$. We incubate the neural stem cells derived from the embryo rat mescencephalon brain tissue, hMSCs derived from the human bone marrow, myoblast derived from newborn rat and embryo stem cells (ES), P19 cell lines in the hypoxia condition (3\% $\left.\mathrm{O}_{2}\right)$ and normal condition $\left(20 \% \mathrm{O}_{2}\right)$, we found the hypoxia to promote the proliferation of the adult stem cells (NSCs, hMSC and myoblast), but to inhibit the proliferation of ES and P19 cells. To address its mechanism, we further investigated the different gene expression of adult stem cells under the hypoxia condition, and we found that the expression of hif target genes increased although the hif gene expression had no changed. This suggests that hif signaling pathway is involved in the proliferation of adult stem cells under the hypoxia condition. Then, we transfected the neural stem cells with the hif1 and cultured them under the normal condition for 3 days. The result shows that over-expression of hif 1 gene could induce the proliferation of neural stem cells. From above data, we conclude that the proliferation of different types of stem cell are markedly different under hypoxia condition, and HIF signaling pathway might play an important role in the regulation of the adult stem cells.

Acknowledgement: This work was supported by key grant of National Nature Science Foundation of China (30393130).

\section{PL-3/25 \\ Histaminergic Modulation on the Cerebellar Neuronal Activity and Cerebellar Motor Control}

Zhu, J.-N, Song, Y.-N., Li, H.-Z., Shen, B., Tian, L., Wang, J.-J.

School of Life Sciences, Nanjing University, Nanjing, China

Central histaminergic nervous system originates from the tuberomammillary nucleus of the hypothalamus and widely innervates almost the whole brain including the cerebellar cortex and nuclei. Four histamine receptors $\left(\mathrm{H}_{1}-\mathrm{H}_{4}\right)$ have been cloned, and the histamine $\mathrm{H}_{1}, \mathrm{H}_{2}$ and $\mathrm{H}_{3}$ receptors are all expressed in distinctive patterns in the brain. A large number of evidence have demonstrated that the histaminergic system plays a general modulatory role in basic body functions including feeding, arousal, endocrine homeostasis, pain perception and stress, synaptic plasticity and learning, and its dysfunction may be related to some brain diseases (AD, HD, PD and schizophrenia). However, the functional significance of the histaminergic afferent fibers in the cerebellum has remained enigmatic. Using rat brain slice preparations, we investigated the effect of histamine on neuronal activity of the cerebellar Purkinje cells (PC) and interpositus nucleus (IN) neurons. Perfusing slices with histamine produced both in the PC and IN neurons an excitatory response, which was not blocked by low- $\mathrm{Ca}^{2+} /$ high- $\mathrm{Mg}^{2+}$ medium, suggesting a direct postsynaptic action of the amine. Histamine $\mathrm{H}_{2}$ receptor antagonist ranitidine effectively blocked the histamine-induced excitation, but $\mathrm{H}_{1}$ receptor antagonist triprolidine did not. Selective $\mathrm{H}_{2}$ receptor agonist dimaprit mimicked the excitatory effects of histamine on the $\mathrm{PC}$ and IN neurons, while $\mathrm{H}_{1}$ receptor agonists, including 2-pyridylethylamine, 2-thiazolyethylamine and betahistine, did not cause any response. Besides, ranitidine rather than triprolidine effectively antagonized the dimaprit-induced excitations. These results demonstrate that histamine excites the cerebellar PC and IN neurons via $\mathrm{H}_{2}$ receptors. Based on our re- sults of in vitro studies, we further examined histaminergic modulation on the cerebellar motor control in vivo. Histaminergic agents were bilaterally microinjected into the cerebellar IN of male rats, and their effects on motor balance and coordination of the animals performing accelerating rota-rod treadmill and balance beam tasks were observed. Histamine remarkably increased the time that animals balanced steadily on the rota-rod and markedly shortened the duration of passage through the balance beam. Ranitidine considerably decreased the animals' endurance time on rota-rod and noticeably increased the passing time on beam, but triprolidine showed no effect. Furthermore, histamine reversed the inhibitory effects of ranitidine on rats' rota-rod and beam performances. The results demonstrate that histamine enhances rat motor balance and coordination through activation of histamine $\mathrm{H}_{2}$ receptors in the cerebellar IN. In summary, our results provide substantial evidence that histaminergic neurotransmission exists in the cerebellum, and suggest that the hypothalamus may modulate the cerebellar neuronal activity through the hypothalamocerebellar histaminergic projections and subsequently influence the cerebellar function of motor control. Because all cerebellar histaminergic afferent fibers originate from the hypothalamus, a high center for regulating visceral activities, we speculate that the hypothalamocerebellar histaminergic pathway may help the central nervous system to generate integrated and coordinated somatic-visceral responses to the changes of internal and external environments.

Acknowledgement: This work was supported by grants 30070250, 30370462 and the NSFC/RGC Joint Research Scheme 30318004 from the NSFC, RFDP grant 20010284021 from the State Educational Ministry of China and grant BK-97045 and BK2002083 from the Natural Science Foundation of Jiangsu Province.

\section{Oral Presentations}

\section{OP-1/25 \\ Determination of the Pungency and Analgesic Potential of Vanilloids in Suncus murinus (House Musk Shrew)}

Rudd, J.A., Ngan, M.K., Wai, M.K., Wan, C., Yeung, J.H.K.

Department of Pharmacology, Faculty of Medicine, The Chinese University of Hong Kong, Shatin, N.T., Hong Kong, China

There is considerable interest in the development of non-pungent vanilloids as analgesic drugs and for the treatment of a variety of clinical conditions including emesis [1]. In the present studies, we used Suncus murinus, a species of insectivore, to estimate the pungency and analgesic potential of capsaicin (CAPS), resiniferatoxin (RTX) and olvanil (OLV), relative to their action on the emetic reflex. Pungency was assessed using the eye irritancy test where compounds were applied topically [2]. The rank order of potency of the vanilloids to increase blinking relative to their vehicle controls was RTX $>$ OLV $>>$ CAPS (minimum effective doses 
were $0.1,30$ and 3,000 nmol/eye, respectively; $\mathrm{p}<0.05)$. An acetic acid ( $1 \% \mathrm{v} / \mathrm{v}$, i.p.)-induced writhing test was used to assess an analgesic potential [2]. In this test, morphine $5 \mathrm{mg} / \mathrm{kg}$, s.c. (15 min pretreatment) inhibited writhing by $98 \%(\mathrm{p}<0.0001)$. The rank order of inhibitory potency of the vanilloids was RTX $>>$ OLV $>$ CAPS $\left(\right.$ ID $_{50}$ values were $<0.003,0.14$ and $12.6 \mu \mathrm{mol} /$ $\mathrm{kg}$, s.c., respectively). In the analgesia experiments, the vanilloids also induced emesis during the $60 \mathrm{~min}$ pretreatment time. The rank order of potency was RTX $>$ OLV $>>$ CAPS, with significant emesis being seen at $0.3,30$ and $300 \mu \mathrm{mol} / \mathrm{kg}$, respectively $(\mathrm{p}<$ 0.05). In conclusion, the useful analgesic action of CAPS, RTX and OLV occurs at doses below those inducing emesis. However, all 3 vanilloids tested positive in the eye irritancy assay indicating some degree of pungency.

Acknowledgement: This research was supported by a Direct Grant for Research (CUHK 4450052).

\section{References}

1 Rudd JA, Wai MK: Eur J Pharmacol 2001;422:185-195

2 Urban L, et al: Pain 2000;89:65-74.

\section{OP-2/25 \\ Role of Axin in Nerve Growth Factor-Stimulated Neurite Outgrowth}

Ng, Y.P., Lin, S.C., Fu, A.K.Y., Wong, Y.H., Ip, N.Y.

Department of Biochemistry, Biotechnology Research Institute and Molecular Neuroscience Center, Hong Kong University of Science and Technology, Clear Water Bay, Hong Kong, China

Neurotrophins are neurotrophic factors that have well-established roles in neuronal survival and differentiation during development, and in the modulation of synaptic plasticity in differentiated neurons. Functions of neurotrophins are exerted through the activation of Trk receptors, and the subsequent initiation of downstream signaling cascades. Recently, molecules in the canonical Wnt signaling pathway, such as glycogen synthase kinase 3 beta (GSK3 $\beta$ ) and adenomatous polyposis coli (APC), have been demonstrated to modulate neurotrophin-mediated neurite outgrowth. Axin is a multidomain scaffold protein required for the recruitment of APC and $\beta$-catenin to GSK $3 \beta$ in Wnt signaling. Given the recent implication of Wnt signaling in the modulation of neurotrophin functions, it is of interest to examine if Axin may also play a role in neurotrophin-mediated axon outgrowth. We have employed rat pheochromocytoma PC12 cells to determine the functional role of Axin in NGF-induced neuronal differentiation. We found that Axin and its interacting proteins were endogenously expressed in PC12 cells. Furthermore, specific knockdown of Axin by siRNA enhanced phosphorylation of Akt and JNK in PC12 cells. Importantly, reduction of Axin expression was accompanied by a concomitant increase in neurite extension upon treatment of PC12 cells with NGF. Our preliminary results therefore suggest a novel role of Axin in neuronal differentiation through the modulation of neurotrophin signaling.

Acknowledgement: The work is supported in part by the Research Grants Council (HKUST 3/03C) and the Area of Excellence Scheme of the University Grants Committee (AoE/B-15/01).

The 25th Scientific Meeting of the Hong Kong Society of Neurosciences
OP-3/25

\section{Activation of Microglia/Macrophages Determines the Fate of Retinal Ganglion Cell Survival in Rat Chronic Ocular Hypertension Model}

Chiu, K. ${ }^{\text {a, c }}$, Ji, J.Z. ${ }^{a}$, Yu, M.S. ${ }^{\text {a, c }}$, So, K.-F. ${ }^{\text {a-c }}$, Chang, R.C.C. ${ }^{a-c}$

a Laboratory of Neurodeegenerative Diseases, Department of Anatomy, b Research Center of Heart, Brain, Hormone and Healthy Aging, Faculty of Medicine, 'The State Key Laboratory of Brain and Cognitive Sciences, The University of Hong Kong, Pokfulam, Hong Kong, China

Although it has been demonstrated that microglia/macrophages produce neuroprotective effects in acute injury, whether they do the same in chronic neurodegeneration such as glaucoma is largely unknown. Using a laser-induced chronic ocular hypertension $(\mathrm{COH})$ model, we systematically studied the influences of microglia in RGC loss. Adult female SD rats were anesthetized with intra-peritoneal injection of a ketamine/xylazine mixture. Proparacaine hydrochloride was applied to the eyes as topical anesthetics. The limbal vein and the three radial episcleral aqueous humor drainage veins of the right eye were photocoagulated twice with a 7-day interval using an Argon laser. While a small number of microglial cells $\left(10^{3}\right)$ did not produce significant influence, injection of large number of microglial cells $\left(10^{5}\right)$ into the vitreous significantly increased RGC loss. Appropriate quantity $\left(10^{4}\right) \mathrm{mi}-$ croglial cells per intraocular injection markedly reduced RGC loss in the $\mathrm{COH}$ model. Monocyte chemoattractant protein 1 at low concentration (10 and $100 \mathrm{ng}$ ), but not at high concentration (1,000 $\mathrm{ng}$ ), provided significant neuroprotective effect on RGCs, which may attribute to the chemoattractive property on microglia/macrophages to the retina. Immunocytochemical staining on flat mounted retinas displayed high immunoreactivity for ionized calcium binding adapter molecular 1 (Iba1), indicating high number of microglia/macrophages. Potent stimulation of microglia/macrophages by lipopolysaccharide (LPS) significantly increased the death of RGCs in the COH model. Ibal-immunoreactive positive microglia/macrophages in the LPS group were activated with enlarged cell body and thickened short process. These results advance our understanding of the roles of microglia in chronic neurodegeneration. Our results can demonstrate that microglia/macrophages can be either protective or harmful depending on the stimulation in chronic neurological disorder like glaucoma.

Acknowledgement: The study is supported by The American Health Assistant Foundation to R.C.C. Chang and K.-F. So.

\section{OP-4/25 \\ Regulation of ACh Receptor Clustering in Muscle by SIRPa1 and Shp2}

Qian, Y.K., Zhao, X.T., Madhavan, R., Peng, H.B.

Biology Department, Hong Kong University of Science and Technology, Clear Water Bay, Hong Kong, China

At vertebrate neuromuscular junctions (NMJs), nerve-secreted agrin triggers muscle acetylcholine receptor (AChR) aggregation by stimulating the muscle-specific tyrosine kinase MuSK. To 
identify effectors of MuSK signaling, we screened muscle extracts for proteins that showed agrin-dependent changes in tyrosine phosphorylation. Agrin treatment of C2 mouse myotubes increased the tyrosine phosphorylation of signal regulatory protein $\alpha 1$ (SIRP $\alpha 1)$, an activator of the tyrosine phosphatase Shp2, and this was coupled with improved binding of SIRP $\alpha 1$ to Shp2. Whereas ectopic expression of constitutively active Shp2 in myotubes decreased spontaneous and agrin-induced AChR clustering, expression of inactive Shp2 increased AChR clustering, and these opposite effects on AChR clustering were also produced by introduction into myotubes of, respectively, wild-type SIRP $\alpha 1$ and a truncated form of SIRP $\alpha 1$ that does not activate Shp2. Significantly, co-expression of wild-type SIRP $\alpha 1$ with inactive Shp2 or truncated SIRP $\alpha 1$ with active Shp2 reversed the effects of the Shp2 mutants on AChR clustering. These results suggest that SIRP $\alpha 1$ tyrosine phosphorylated downstream from MuSK activates Shp2, which, in turn, suppresses MuSK-dependent AChR clustering. We propose that feedback signaling through SIRP $\alpha 1$ and Shp2 modulates MuSK auto-activation in non-innervated muscle and helps ensure MuSK activation and AChR clustering preferentially beneath nerve contacts at developing NMJs.

Acknowledgement: Grant support: RGC HKUST6280/03M, AoE/B-15/01 and NIH NS23583.

\section{OP-5/25 \\ Neurokinin Receptor One Agonist Septide Offers Neuroprotection on Dopaminergic Neurons}

Chan, W.S. ${ }^{a}$, Chen, L.W. ${ }^{b}$, Y.S. Chan, Y.S. ${ }^{c}$, Yung, K.K.L. ${ }^{a}$

aDepartment of Biology, Hong Kong Baptist University, Hong Kong, ' Institute of Neurosciences, The Fourth Military Med. University, Xi'an, 'Department of Physiology, The University of Hong Kong, Hong Kong, China

Parkinson's disease is a serious motor disorder and it is caused by a degeneration of dopaminergic neurons in the substantia nigra pars compacta. Neurokinins (NK) are a group of neuropeptides that are suggested to be involved in the pathogenesis of Parkinson's disease. Functions of NKs are mediated by NK receptors. Substance P, the natural ligand of NK1 receptor, is found to have neuroprotective effects on dopaminergic neurons. Septide is a selective NK1 receptor agonist. In order to investigate the neuroprotective effect of septide in vitro, septide $(1 \mu \mathrm{M})$ was co-incubated with 6-hydroxydopamine (6-OHDA, $200 \mu \mathrm{M})$ in primary cell cultures of neonatal rat dopaminergic neurons. After $25 \mathrm{~h}$, massive neuronal cell death was observed in those cultures incubated with 6-OHDA, whereas in septide co-incubation cultures most neurons were seen to be intact. By flow cytometric analysis, 17.03 $\pm 2.13 \%$ of tyrosine hydroxylase $(\mathrm{TH})$-immunoreactive neurons were found to survive after co-incubation treatment but only 4.92 $\pm 1.40 \%$ of TH-positive neurons were found to survive after 6 OHDA treatment. In addition, double immunofluorescence revealed that the level of $\mathrm{TH}$ immunoreactivity was also reduced in the surviving neurons after 6-OHDA treatment. No significant reduction of $\mathrm{TH}$ immunoreactivity was found in neurons co-incubated with septide and 6-OHDA. The present results indicate that septide has neuroprotective effects on dopaminergic neurons in culture. In addition, in rat model of Parkinson's disease, neu- roprotective effects on dopaminergic neurons were also observed. Activation of NK1 receptor by septide may have implications in treatment of Parkinson's disease.

Acknowledgement: The present work was supported by Joint Research Scheme, National Natural Science Foundation of China and Research Grants Council of Hong Kong, 30218002 and N_HKBU202/02.

\section{OP-6/25 \\ Calcitonin Gene-Related Peptide Mediates Synaptic Expression of Collagen-Like Subunit (ColQ) of Acetylcholinesterase in Muscle}

Ting, A.K.L. ${ }^{a}$, Choi, R.C.Y. ${ }^{a}$, Lau, F.T.C. ${ }^{a}$, Massoulié, J. ${ }^{\mathrm{b}}$, Tsim, K.W.K. ${ }^{\mathrm{a}}$

aDepartment of Biology and Molecular Neuroscience Center, Hong Kong University of Science and Technology, Clear Water Bay, Hong Kong, China, and ${ }^{\mathrm{b}}$ Laboratoire de Neurobiologie Moléculaire et Cellulaire, Centre National de la Recherche

Scientifique UMR 8544, Ecole Normale Supérieure, Paris, France

In the vertebrate neuromuscular junction (nmj), the asymmetric acetylcholinesterase is anchored to synaptic basal lamina through a collagen-tailed subunit (ColQ). There are two types of ColQ mRNAs, namely ColQ-1 and ColQ-1a, which are different in their first exons. ColQ-1 mRNA is mainly expressed in slowtwitch muscle throughout the entire muscle fiber while ColQ-1a mRNA has a synapse-specific expression pattern in fast-twitch muscle. However, the molecular mechanism in regulating its synaptic expression in muscle is still not clear. The level of ColQ mRNAs in rat muscles dropped dramatically after sciatic nerve denervation, which suggested that nerve-derived factors and nerve-evoked electrical activity might play a regulatory role(s). ColQ promoters tagged with a luciferase reporter gene (pColQ-1Luc and pColQ-1a-Luc) are used as the tools to map out its gene regulations in muscles. Application of CGRP, or its downstream signal $\mathrm{Bt}_{2}$-CAMP, in cultured myotubes induced the transcript expression of ColQ-1a as well as the activity of its promoter pColQ-1a; however, the expressions of ColQ-1 transcript and pColQ-1 did not respond to CGRP or $\mathrm{Bt}_{2}$-cAMP. The CGRP-induced gene activation was blocked by overexpression of a dominant negative mutant of cAMP-responsive element binding protein (CREB). Two cAMP-responsive element (CRE) sites were mapped within pColQ-1a promoter, and the mutation of these 2 CRE sites abolished the response to CGRP or $\mathrm{Bt}_{2}$-cAMP. Parallel to these results, the fast-twitch muscle expressed a significantly higher level of CREB and a strong staining of phosphorylated CREB at its synaptic nuclei. These results indicated that CGRPmediated cAMP-dependent pathway might act as one of crucial regulatory mechanisms to drive the synaptic expression of ColQ in fast muscle. 


\section{OP-7/25 \\ Extracellular Accumulation of Beta-Amyloid Peptides Induces Apoptosis in Cultured Neurons via a Mechanism Independent of Unfolded Protein Responses}

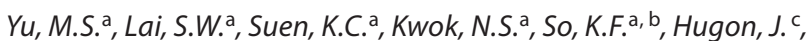
Chang, R.C.C. ${ }^{\mathrm{a}, \mathrm{b}}$

aLaboratory of Neurodegenerative Diseases, Department

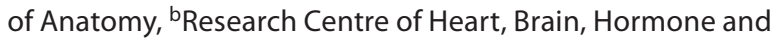
Healthy Aging, Faculty of Medicine, The University of Hong Kong, Hong Kong, China, and 'Department of Neurology, University of Poitiers and Poitiers University Hospital, Poitiers, France

Extracellular accumulation of beta-amyloid $(A \beta)$ peptides in senile plaques is one of the pathological hallmarks in Alzheimer's disease (AD), which can trigger apoptosis. We have previously shown that $A \beta$ triggered calcium release from the ER. Disruption of ER $\mathrm{Ca}^{2+}$ homeostasis has been suggested to cause unfolded protein responses (UPR). While hypothesis has been made about UPR and neurodegeneration in AD, little is known about the effects of extracellular accumulation of $A \beta$ peptides on UPR. In our previous studies, activation of the double-stranded RNA-dependent protein kinase (PKR) has been proved to play important role in $A \beta$-induced apoptosis. Since UPR can be an upstream effector of PKR, our study aims to investigate whether extracellular accumulation of $A \beta$ peptides induces UPR in cultured neurons. Thapsigargin (Tg) and dithiothreitol (DTT) served as UPR inducers. Our results showed that A $\beta$ could not trigger UPR signalings including phosphorylation of PERK, alternative cleavage of xbp-1 mRNA and induction of transcription of xbp-1 and Gadd153. Using fluorescent imaging, neurons treated with $A \beta$ peptides display granulovacuolar structures in the ER, which implies that autophagy might occur in the ER. Taken together, our results suggest that extracellular accumulation of $A \beta$ peptides induces apoptosis via a mechanism independent of UPR.

Acknowledgement: This work is partly supported by HKU Seed Funding for Basic Research (2004-2005), Competitive Earmarked Research Grant award (HKU 7699/05M) from Research Grant Council to RCCC, and PROCORE-France/Hong Kong Joint research Scheme sponsored by Consulate General of France in Hong Kong and Research Grant Council of Hong Kong SAR Government (F-HK21/03T) to R.C.C.C. and J.H.

\section{OP-8/25 \\ Functional Roles of Axin in the Formation of Neuromuscular Junction}

Lu, C.C., Fu, A.K.Y., Ng, Y.P., Lin, S.C., Ip, N.Y.

Department of Biochemistry, Biotechnical Research Institute and Molecular Neuroscience Center, Hong Kong University of Science and Technology, Clear Water Bay, Hong Kong, China

An important event in the formation of neuromuscular junction (NMJ) is the aggregation of acetylcholine receptors (AChRs) in muscle juxtaposed to the presynaptic nerve terminal. Neural agrin, a component of the synaptic basal lamina, induces AChR clustering via the activation of a receptor tyrosine kinase, musclespecific kinase (MuSK). Recently, components of the Wnt signaling pathway, such as Dishevelled (Dsh) and adenomatous polyposis coli (APC), have been implicated in the regulation of AChR clustering. For example, Dsh was observed to interact with MuSK to affect AChR clustering. Similarly, APC was also identified as an AChR-interacting protein, and disruption of the association reduced the number of AChR clusters. These observations raise the possibility that Wnt signaling pathway may be involved in the formation of NMJ. Axis inhibitor (Axin), an interacting partner of both Dsh and APC, has previously been identified as a scaffold protein critical for the degradation of beta-catenin in Wnt signaling. To explore if Axin may also play a role in NMJ formation, we first examined the expression of Axin in cultured C2C12 cells and rat skeletal muscle during development. We found that Axin protein expression could be detected in C2C12 myoblasts and differentiated myotubes. In addition, Northern blot analysis showed that while Axin transcript could be prominently detected in rat skeletal muscle at embryonic day 18 , its expression level decreased during postnatal stages. Interestingly, induction of Axin transcript was observed in muscle following denervation. Furthermore, preliminary result revealed that reduction of Axin led to an increase in the number of AChR clusters. Taken together, our findings suggest that in addition to Dsh and APC, Axin may also play a role in the regulation of NMJ formation/maintenance.

Acknowledgment: This work is supported by the Research Grants Council (HKUST 3/03C) and the Area of Excellence Scheme of the University Grants Committee (AoE/B-15/01).

\section{OP-9/25 \\ Auditory Attention and Its Relation with the Cortocifugal System}

$\mathrm{He}, \mathrm{J}$.

Department of Rehabilitation Sciences, The Hong Kong

Polytechnic University, Hung Hom, Kowloon, Hong Kong, China

Our hearing has the ability to tune our attention to a certain sound/voice while filtering out the unwanted noise. There are several cues which animals and humans use in this tuning processing: the spectrum, the direction, the context of the sound/voice, and the visual information related to the sound/voice. The auditory cortex must be involved in judging the signal from noise and integrating the visual information. On the other hand, it is desirable to place the filter at the auditory pathway as earlier as possible from the point view of information theory. The massive corticofugal projections would answer the above requirements. The major part of corticofugal system in the auditory system is the corticothalamic projections involving the thalamic reticular nucleus. In the present presentation, we are going (1) to review the auditory system: its anatomy and physiology, (2) to zoom up the anatomical structure of the corticofugal system, and (3) finally to focus on our recent studies about the corticofugal modulation using extracelluar recording, intracellular recording, and histochemical techniques.

Acknowledgement: Supported by Hong Kong Research Grants Council grants: CERG PolyU5211/99M, 5407/03M, and 5473/ $04 \mathrm{M}$. 


\section{OP-10/25 \\ Developmental Responsiveness of Vestibular-Related Brainstem Neurons to Horizontal Rotational and Translational Motions}

Yiu, C., Tse, Y.C., Lai, C.H., Chan, Y.S.

Department of Physiology, Faculty of Medicine, The University of Hong Kong, Hong Kong, China

To investigate the distribution of functionally activated vestibular-related brainstem neurons during postnatal development, combined immuno-/hybridization histochemistry for c-fos expression was performed in Sprague-Dawley rats (P1-21; adult). Conscious animals were subjected to rotational or translational stimulus which activates hair cells on the horizontal semicircular canals or utricle, respectively. Neuronal activation within brainstem nuclei was defined by the expression of $c$-fos. Labyrinthectomized controls and normal stationary controls showed only a few sporadically scattered Fos-expressing neurons. During postnatal development, Fos-labeled vestibular nuclear (VN) neurons activated by cycles of constant angular acceleration and deceleration were observed by $\mathrm{P} 4$ while those by sinusoidal translational movement were not identifiable until P7. In both stimulation paradigms, an age-dependent increase in Fos-labeled neurons was observed in the $\mathrm{VN}$ and prepositus hypoglossal nucleus $(\mathrm{PrH})$, the latter being a downstream area related to vestibulo-oculomotor function. In P7-9 rats, Fos-labeled neurons activated by canal or utricle input were evenly distributed throughout the rostro-caudal length of the VN complex (except the dorsal part of lateral VN) as well as groups $\mathrm{x}$ and $\mathrm{y}$. At this age, $\mathrm{PrH}$ neurons were only activated with rotational stimulus and those activated with translational stimulus were not found until P11. In P21 and adult rats, the overlapping distribution of canal- and utricle-related Fos-labeled neurons was limited to the middle part of medial $\mathrm{VN}$ and caudal part of spinal VN. The rostral part of spinal VN was found to be constituted with neurons activated by translational motion. In the medial $\mathrm{VN}$ and $\mathrm{PrH}$, a vast majority of the neurons was activated by rotational stimulus and only a small proportion was by translational stimulus. Taken together, we have demonstrated that canal- and otolith-related brainstem neurons that encode horizontal rotational and translational movements are histologically segregated and exhibit different developmental time frame.

Acknowledgement: Supported by HKRGC.

\section{OP-11/25 \\ Vagal Neural Crest Cell Migration in Dominant Megacolon Mouse Embryos}

Wang, L. ${ }^{\mathrm{a}}$, Copp, A.J. ${ }^{\mathrm{b}}$, Chan, W.Y. ${ }^{\mathrm{a}}$

aDepartment of Anatomy, Faculty of Medicine, The Chinese University of Hong Kong, Hong Kong, China, and beural

Development Unit, Institute of Child Health, London, UK

During embryonic development, vagal neural crest cells emigrate from the neural tube and migrate along definite pathways to the gut to form neurons and glia of the enteric nervous system. The Dominant megacolon (Dom) mouse, which carries a Sox10 mutation, shows aganglionosis (absence of ganglia) in varied lengths of the hindgut. To investigate the cellular mechanism of aganglionosis in the Dom mouse, we first labelled the vagal neural crest of Dom embryos with WGA-Au or DiI at E8.5 and followed the migration of neural crest cells in whole embryo culture prior to their entry into the gut ('pre-enteric' migration) at E9.5. The rostrocaudal migration of neural crest-derived cells in the gut was then traced by examining the expression of enteric neural crest cell markers at various time points from E10.5 to E18.5. It was found that, although pre-enteric neural crest cells migrated along similar pathways in all the genotypes examined, the numbers of pre-enteric neural crest cells in embryos heterozygous $(\mathrm{Dom} /+)$ and homozygous (Dom/Dom) for Dom were significantly smaller than that in wild-type (+/+) embryos. From E10.5 onwards, no neural crest-derived cells were found in the gut of Dom/Dom embryos, and the migration in the Dom/+ gut was retarded from E12.5 onwards. It was also found that while the neural crest cells from the three different genotypes showed similar proliferating ability, the numbers of apoptotic pre-enteric neural crest cells in Dom/+ and Dom/Dom embryos were significantly higher than that of $+/+$ embryos. Our results indicate that excessive cell death, not reduced proliferation, of pre-enteric neural crest cells may be one of the factors responsible for aganglionosis in the hindgut of the Dom mouse.

Acknowledgement: The work described here was supported by a grant from the Research Grants Council of the Hong Kong Special Administrative Region, China (Project No. CUHK 4016/01M).

\section{OP-12/25 \\ Identification of Anaphase Promoting Complex Subunit 2 Isoform as EPHA4 Interacting Protein \\ Hung, K.-W., Shen, Y., Fu, A.K.Y., Ip, N.Y. \\ Department of Biochemistry, Biotechnology Research Institute and Molecular Neuroscience Center, Hong Kong University of Science and Technology, Clear Water Bay, Hong Kong, China}

Eph receptors, the largest family of receptor tyrosine kinases (RTKs), are involved in axon guidance and synapse formation during development. Distinct from other RTKs, Eph receptors are activated by membrane-bound ligands, ephrins. Localization of EphA4 and its ligand ephrin-A2 to the neuromuscular junction (NMJ), together with the observation that activation of EphA4 regulates acetylcholinesterase expression in muscle, suggest that EphA4 receptor is involved in NMJ development and/or maintenance. To further elucidate the downstream signaling of EphA4 receptor at the NMJ, a yeast two-hybrid screen was performed using the cytoplasmic region of EphA4 receptor as bait to identify EphA4 interacting partners in muscle. Unexpectedly, a novel isoform of anaphase promoting complex subunit 2 (APC2), which we named APC2i, was identified as an EphA4-interacting protein. While the functions of APC2i remain to be elucidated, APC2 is involved in cell cycle progression via the regulation of protein degradation, and is recently suggested to play a role in synapse formation/maintenance. To verify the interaction between APC2 $\mathrm{i}$ and EphA4 in vivo, we first examined the expression of APC2i in mouse brain. Using RT-PCR, we found that both APC2 and APC2i transcripts were expressed in mouse adult brain. Furthermore, we observed that EphA4 associated with APC2i or APC2 
when overexpressed in 293T cells. Importantly, overexpression of APC2i resulted in reduced EphA4 protein level, which was reversed by treatment with proteasome inhibitor. Taken together, these findings suggest that APC2i may regulate EphA4 expression by affecting proteasome-dependent degradation of EphA4.

Acknowledgement: This work is supported by the Research Grants Council (HKUST 6131/02M) and the Area of Excellence Scheme of the University Grants Committee (AoE/B-15/01).

\section{Poster Presentations}

\section{P-1/25 \\ Differential Patterns of Developing Vestibular Commissural Projection with Digestion of Chondroitin Sulfates}

Lau, W.K. ${ }^{\text {, }}$ Kwok, J.C.F. ${ }^{\text {, }}$ Ng, T.K.Y. ${ }^{\mathrm{a}}$, Chan, Y.S. ${ }^{\mathrm{a}}$, Shum, D.K.Y. ${ }^{\mathrm{b}}$

aDepartments of Physiology and ${ }^{b}$ Biochemistry, Faculty of Medicine, The University of Hong Kong, Hong Kong, China

Chondroitin sulfate proteoglycans have been attributed with guidance functions in cell migration and process outgrowth. The developing hindbrain was found to be enriched in 6-sulfated isoforms of chondroitin as early as E8.5-9.5 in the mouse; expression levels decreased to undetectable levels in the following two days. To assess if chondroitin sulfates (CS) play a part in determining axonal projections about this period in the early embryonic hindbrain, chondroitinase $\mathrm{ABC}$ (ChABC) was delivered into the 4th ventricles of rat embryos (E11.5-13.5) in culture to digest away CS moieties in the nearby hindbrain matrix. Controls received either vehicle or the heat-inactivated enzyme instead. DiI injection was introduced into the vestibular nuclear complex (VNC) near the VIIIth cranial nerve entry zone to map the commissural projections that developed during the treatments. At E11.5 (+1DIV), few neuritis extended towards the midline in cases of PBS and heatinactivated $\mathrm{Ch} \mathrm{ABC}$. In contrast, with digestion of CSs, robust projections reached the dye-injection site from regions half-way towards the midline. This suggests that CSs limit projection across the hindbrain matrix of early embryos. At E12.5 (+1DIV), the contralateral-projecting axons assumed fascicles bearing tapered terminals that reached the midline in the controls. In the enzymetreated embryos, the axons however remained unfasciculated as they extended normal to the midline. By E13.5(+1DIV), enzyme treatment apparently did not affect the pioneer axons that had advanced normal to the midline and beyond towards the contralateral VNC. However, later axonal outgrowths from the VNC traversed the enzyme-treated matrix as unfasciculated fibres and diverted from the course of the pioneers to cross the midline at various angles and positions along the midline. This suggests that CSs also limit the course of the later projections which otherwise would be attracted to alternative targets. These results provide in vivo evidence for possible contributions of CS to limit stray outgrowth and foster axonal fasciculation as vestibular neurons project across the midline towards the contralateral target.

\section{$\mathrm{P}-2 / 25$ \\ AMPA and NMDA Receptor Properties in Spinal Vestibular Neurons of Developing Rats}

Tse, Y.C. ${ }^{\text {a }}$ Lai, S.K. ${ }^{\mathrm{a}}$ Zhou, H. ${ }^{\mathrm{a}}$, Yung, W.H. ${ }^{\mathrm{b}}$, Chan, Y.S. ${ }^{\mathrm{a}}$

aDepartment of Physiology, The University of Hong Kong,

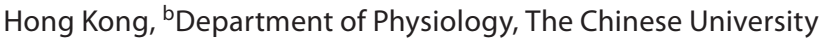
of Hong Kong, Shatin, Hong Kong, China

Ionotropic glutamate receptors (AMPA and NMDA receptors) are important for signal transmission and synaptic plasticity in the vestibular system. However, contribution of the two types of ionotropic glutamate receptors to the coding of vestibular information during development remains unclear. Glutamatergic transmission in the spinal vestibular nucleus was studied in brainstem slices of P1-9 Sprague Dawley rats by whole-cell patchclamp approach. Analysis of miniature excitatory postsynaptic current (mEPSC) showed that both NMDA receptor- and AMPA receptor-mediated currents contributed equally to the mEPSC on or before P7. At P9, however, the AMPA component of the mEPSC became dominant $(\sim 70 \%)$ as compared to the NMDA component. In response to electrical stimulation of the vestibular nerve, the evoked excitatory postsynaptic current (eEPSC) measured from brainstem slices was dominated by NMDA receptor-mediated current ( $\sim 70 \%$ of eEPSC) at P3/5. At P7/P9, the NMDA component decreased to $\sim 55 \%$ while the AMPA component increased to $\sim 45 \%$. At P9, the linear $I-V$ relationship of AMPA receptormediated eEPSC indicated the participation of GluR2 subunits in AMPA receptor. Our findings provide evidence that the functional maturation of spinal vestibular neurons may be related to the developmental profile of AMPA and NMDA receptors within glutamatergic synapses.

Acknowledgement: Supported by HKRGC.

\section{P-3/25 \\ Regulation of STAT3 Phosphorylation BY $\mathbf{~ G} \alpha_{\mathbf{s}}$ Lo, R.K.H. ${ }^{a}$, Liu, A.M.F. ${ }^{a}$, Wise, H. ${ }^{\text {b }}$,Wong, Y.H. ${ }^{a}$ \\ aDepartment of Biochemistry, the Molecular Neuroscience Center, and the Biotechnology Research Institute, Hong Kong University of Science and Technology,

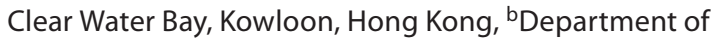 Pharmacology, The Chinese University of Hong Kong, Shatin, Hong Kong, China}

Signal transducer and activator of transcription 3 (STAT3) has been shown to play a role in neuronal differentiation and STAT3 activation by $\mathrm{G}$ protein-coupled receptors (GPCRs) is beginning to be appreciated. Given that a large number of GPCRs such as the $\beta_{2}$-adrenergic and dopamine $D_{2}$ receptors employ $G_{s}$ for signal transduction, we asked if $\mathrm{G}_{\mathrm{s}}$ signaling can indeed lead to the phosphorylation and activation of STAT3. To address this issue, a constitutively active mutant of $\mathrm{G} \alpha_{\mathrm{s}}\left(\mathrm{G} \alpha_{\mathrm{s}} \mathrm{QL}\right)$ was transiently expressed in HEK 293 cells and the phosphorylation status of STAT3 was determined with phospho-specific antibodies. Overexpression of G $\alpha_{s}$ QL significantly induced both $\mathrm{Tyr}^{705}$ and $\mathrm{Ser}^{727}$ STAT3 phosphorylations as compared to $\mathrm{G} \alpha_{\mathrm{s}}$ or vector control. Inhibiting the 
downstream effector of $\mathrm{G} \alpha_{s}$, protein kinase A (PKA), by H-89 or Rp-cAMP dramatically decreased the G $\alpha_{s}$ QL-induced STAT3 activations. Similarly, suppression of phosphatidylinositol-3-kinase (PI3K) activity reduced the STAT3 phosphorylations. For Janus kinases (JAKs) and c-Src, application of AG490 or WHI-P131 (inhibitors for JAK2 and JAK3 respectively) completely abolished the $\mathrm{G} \alpha_{s} \mathrm{QL}$-induced STAT3 phosphorylations while the inhibition of c-Src by PP1 or PP2 was only sensitive in attenuating the Ser ${ }^{727}$ STAT3 phosphorylation, but not phosphorylation at $\mathrm{Tyr}^{705}$. This interesting finding was also observed for the extracellular signalregulated kinase (ERK) cascade; inhibition of MEK1/2 only eliminated the $\mathrm{G} \alpha_{\mathrm{s}} \mathrm{QL}$-induced $\mathrm{Ser}^{727}$ phosphorylation with $\mathrm{Tyr}^{705}$ phosphorylation being unaffected. Inhibitor of c-jun $\mathrm{N}$-terminal kinase (JNK) again completely abrogated the STAT3 stimulations at both phosphorylation sites. In addition to STAT3 phosphorylations, the transcriptional activation of STAT3 was examined using a STAT3-driven luciferase reporter. Correspondingly, G $\alpha_{s} \mathrm{QL}$ dramatically enhanced STAT3-driven luciferase expression. Blockade of PKA, PI3K, JNK or JAKs significantly attenuated $\mathrm{G} \alpha_{\mathrm{s}} \mathrm{QL}-$ mediated luciferase activations. Interestingly, c-Src and MEK1/2 inhibitions only partially reduced the $G \alpha_{s} \mathrm{QL}$-induced luciferase expressions as these inhibitions only disturbed the $\mathrm{Ser}^{727}$ STAT3 phosphorylation, which is important in the enhancement of STAT3-related gene transcription. Collectively, these studies reveal the ability of $\mathrm{G} \alpha_{\mathrm{s}}$ to stimulate STAT3 phosphorylations as well as transcriptional activity through multiple intermediates.

Acknowledgement: This work was supported in part by grants from the Research Grants Council of Hong Kong (HKUST 3/03C and HKUST 6120/04M), the University Grants Committee (AoE/ B-15/01), and the Hong Kong Jockey Club.

\section{$\mathrm{P}-4 / 25$ \\ Action of the GLP-1 Receptor Agonist, Exendin-4, on the Suncus murinus (House Musk Shrew) Isolated Ileum \\ Chan, S.S.W. ${ }^{a}, H e$, J. ${ }^{b}$, Lin, G. ${ }^{a}$, Rudd, J.A. ${ }^{a}$, Yamamoto, K. $^{\mathrm{c}}$ \\ ${ }^{a}$ Department of Pharmacology, The Chinese University of Hong Kong, Shatin, Hong Kong, bepartment of Rehabilitation Sciences, Hong Kong Polytechnic University, Kowloon, Hong Kong, China, and 'Department of Medical Physics and \\ Engineering, Osaka University, Japan}

Glucagon-like peptide-1 (GLP-1) receptor agonists are being currently explored for the treatment of obesity and diabetes in humans but are associated with nausea at high doses. There are some studies showing GLP-1 agonists modulate gastrointestinal motility but the mechanism is essentially unknown [1]. In the present studies, we investigate the action of exendin-4 on the Suncus murinus isolated ileum and determine if the mechanism of action involves the enteric nervous system. Segments of Suncus ileum were dissected and placed in an organ bath containing Krebs solution at $37^{\circ} \mathrm{C}$ and gassed with $95 \% \mathrm{O}_{2} / 5 \% \mathrm{CO}_{2}$. Agonists were added to the bath using a 3-10-min dosing schedule. In some experiments, antagonists were added to the organ bath $20 \mathrm{~min}$ prior to the addition of agonists. Nicotine (0.3-300 $\mu \mathrm{M})$ and ex- endin-4 (1-300 nM) induced concentration-related contractions of the ileum yielding $\mathrm{pEC}_{50}$ values of $5.3 \pm 0.3$ and $8.5 \pm 0.3$, respectively. Tetrodotoxin $(1 \mu \mathrm{M})$ significantly antagonized the contractile action of nicotine $(5 \mu \mathrm{M})$ and exendin-4 (10 nM), but not acetylcholine $(0.5 \mu \mathrm{M})$, whereas atropine $(1 \mu \mathrm{M})$ blocked the action of all 3 agonists; hexamethonium $(500 \mu \mathrm{M})$ only reduced the action of nicotine. In conclusion, the action of exendin- 4 to contract the ileum probably involves the enteric nervous system and a release of acetylcholine to activate muscarinic receptors.

Reference

1 Nauck MA, et al: Reg Peptides 2005;128:135-148.

\section{P-5/25 \\ Comparison of the Activity of Supstance P and Vanilloids to Induce Plasma Extravasation in Suncus murinus (House Musk Shrew)}

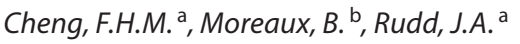 \\ aDepartment of Pharmacology, The Chinese University of \\ Hong Kong, Shatin, N.T., Hong Kong, China, and ${ }^{\text {b} D e p a r t m e n t ~}$ \\ of Gastrointestinal Emerging Diseases, Johnson and Johnson \\ Pharmaceutical Research and Development, a Division of \\ Janssen Pharmaceutica, Beerse, Belgium
}

Vanilloids have been used to release substance P (SP) from sensory nerves as an indirect means of activating tachykinin $\mathrm{NK}_{1}$ receptors on blood vessels to cause plasma extravasation [1]. In the present studies, therefore, we compared the actions of capsaicin (CAPS), resiniferatoxin (RTX) and SP to induce plasma extravasation in the brain and peripheral tissues of Suncus murinus, a species used to detect the anti-emetic activity of tachykinin $\mathrm{NK}_{1}$ receptor antagonists. Studies also examined the potency of the $\mathrm{NK}_{1}$ receptor antagonists, R116301 and R115614 [2], to inhibit the druginduced plasma extravasation. Animals were anaesthetized and Evan's blue dye $(31 \mu \mathrm{mol} / \mathrm{kg}$, i.v. $)$ was then administered $5 \mathrm{~min}$ prior to CAPS $(0-1.3 \mu \mathrm{mol} / \mathrm{kg})$, RTX $(0-48 \mathrm{nmol} / \mathrm{kg})$, or SP $(0-60 \mathrm{nmol} / \mathrm{kg}) .5 \mathrm{~min}$ later, animals were killed and the brain, kidney, lung, spleen, bladder and trachea were removed and plasma extravasation determined as previously described [3]. SP induced dose-dependent plasma extravasation in the bladder $(\mathrm{p}<$ $0.05)$ and the trachea $(\mathrm{p}<0.05)$, but no significant plasma extravasation was seen in the other tissues ( $p>0.05)$. CAPS and RTX, on the other hand, did not induce plasma extravasation ( $\mathrm{p}>0.05)$. A 30-min pretreatment with R116301 (0-1.5 $\mu \mathrm{mol} / \mathrm{kg}$, i.v.) and $\mathrm{R} 115614(0-2 \mu \mathrm{mol} / \mathrm{kg}$, i.v.) reduced significantly SP (20 nmol/ $\mathrm{kg}$ )-induced plasma extravasation in the bladder; $\mathrm{ID}_{50}$ values were 1.2 (95\% CI: $0.6-3.2)$ and $1.8 \mu \mathrm{mol} / \mathrm{kg}$ (95\% CI: 0.9-5.9), respectively. There was also a trend for both compounds to reduce extravasation in the trachea $(\mathrm{p}>0.05)$. In conclusion, vanilloids are not suitable to use in Suncus murinus to induce plasma extravasation. However, the SP-induced plasma extravasation assay is useful to estimate the in vivo potency of $\mathrm{NK}_{1}$ receptor antagonists.

\section{References}

1 Hutter MM, et al: Pancreas 2005;30:260-265.

2 Megens AA, et al: J Pharm Exp Ther 2002;302:696-709.

3 Bonnet J, et al: Eur J Pharmacol 1996;310:37-46. 


\section{P-6/25}

\section{Regulation of P2Y1 Receptor: Signal Transduction,} Dimerization, Desensitization and Internalization

\author{
Choi, R.C.Y. ${ }^{\mathrm{a}, \mathrm{b}}$, Wong, C.S.S. ${ }^{\mathrm{b}}$, Barnard, E.A. ${ }^{\mathrm{b}}$, Tsim, K.W.K. ${ }^{\text {a }}$
}

aDepartment of Biology and Molecular Neuroscience Center, Hong Kong University of Science and Technology, Clear Water

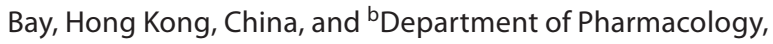
University of Cambridge, Cambridge, UK

Extracellular adenosine triphosphate (ATP) is identified as a new class of neurotransmitter in the last decade. It is co-stored with the classical neurotransmitters in certain cholinergic, adrenergic, glutaminergic and GABA-ergic neurons, and co-released upon neuronal stimulation. One subclass of ATP receptors is the metabotropic $\mathrm{P} 2 \mathrm{Y}$ receptors (G-protein-coupled receptors). Among all of the $\mathrm{P} 2 \mathrm{Y}$ receptors, $\mathrm{P}_{2} \mathrm{Y}_{1}$ receptor is presented in neuromuscular junctions and is shown to stimulate acetylcholine receptor and acetylcholinesterase expression via the coupling to $\mathrm{G}_{\mathrm{q} / 11}$ protein and phospholipase $\mathrm{C}$ for intracellular $\mathrm{Ca}^{2+}$ mobilization. Therefore, it is essential to determine the regulation of $\mathrm{P} 2 \mathrm{Y}_{1}$ receptor upon ligand activation. In this study, human $\mathrm{P}_{2} \mathrm{Y}_{1}$ receptors were tagged with Myc epitope for recognition, and two C-terminal truncations were made to determine the role of intracellular C-terminus. Results showed that all the constructs were properly expressed at the membrane region of the transfected HEK293 cells. In $\mathrm{Ca}^{2+}$ mobilization after receptor activation, the truncated receptor showed a slight reduction of ligand potency and efficacy. Followed by the receptor activation, the wild-type and truncated $\mathrm{P}_{2} \mathrm{Y}_{1}$ receptors were shown to be desensitised. In addition, $\mathrm{P} 2 \mathrm{Y}_{1}$ receptor was induced to form homodimer upon agonist activation, while the two truncated receptors were not able to form dimer. Finally, receptor internalisation was observed in prolong treatment of agonist in wild-type $\mathrm{P}_{2} \mathrm{Y}_{1}$ receptor but not in the two truncated receptors. Based on these results, we conclude that the C-terminal tail of $\mathrm{P}_{2} \mathrm{Y}_{1}$ receptor is not involved in its signal transduction and desensitisation, but this tail carries the essential determinants of its homo-dimerisation and of its agonist-driven internalisation.

Acknowledgement: Supported by HKUST 6283/03M, 6237/ 04M, 6404/05M and 3/03C.

\section{$\mathrm{P}-7 / 25$ \\ Cytoprotective Effects of Lycium barbarum on Cultured Neurons Against Reducing Stress on the Endoplasmic Reticulum}

Yu, M.-S. ${ }^{\text {a }}{ }^{c}$, Ho, Y.-S. ${ }^{a}$, So, K.-F. ${ }^{\text {a-c }}$, Yuen, W.-H. ${ }^{\text {d }}$, Chang, R.C.-C. ${ }^{\text {a-c }}$

aLaboratory of Neurodegenerative Diseases, Department of

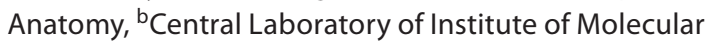
Technology of Drug Discovery and Synthesis, 'Research Centre of Heart, Brain, Hormone and Healthy Aging, 'Open Laboratory of Institute of Molecular Technology of Drug Discovery and Synthesis, The University of Hong Kong, Pokfulum, Hong Kong, China

Lycium barbarum is a commonly used Chinese medicinal herb for nourishment of the eyes, liver and kidney. Studies have shown that extracts from L. barbarum process anti-aging and cytoprotective activities. Its extracts have been demonstrated to exhibit anti-oxidative effects in which oxidative stress is considered to contribute to aging processes. Many studies, therefore, explain the protective effects of $L$. barbarum as a result of its anti-oxidative activities. In this study, we demonstrated that L. barbarum is not solely an anti-oxidant. We used dithiothreitol (DTT) as reducing agent to trigger reducing stress in primary cultured neurons and in human neuroblastoma SH-SY5Y cell line. We found that extracts of $L$. barbarum (LBG) exerted cytoprotective effects on both types of cells by lowering the DTT-induced LDH release and activation of caspase-3. DTT is a well-known endoplasmic reticulum (ER)-stress inducer and can cause PKR-like ER kinase (PERK) activation. We found that LBG significantly attenuated the level of DTT-induced phosphor-PERK in primary neuronal cultures. Taken together, our study shows that L. barbarum can exhibit cytoprotective effects against reducing stress on the ER and is therefore not simply an antioxidant.

Acknowledgement: This work is partly supported by HKU Strategic Research Theme on Healthy Aging, and HKU Seed Funding for Basic Research (2004-2005) to R.C.C.C.

\section{P-8/25 \\ Neuroprotective Effect of Lycium barbarum in Rat Chronic Ocular Hypertension Model via Immunomodulation of Macrophages/Microglia

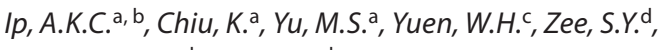 Chang, R.C.C. ${ }^{\mathrm{a}, \mathrm{b}}$, So, K.-F., b

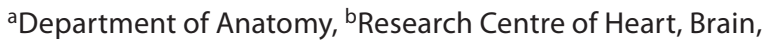 Hormone and Healthy Aging, Faculty of Medicine, 'Department of Chemistry, ${ }^{d}$ Department of Botany, The University of Hong Kong, Pokfulam Hong Kong, China}

Glaucoma is a neurodegenerative eye disease, characterized by retinal ganglion cell (RGC) death and elevated intra-ocular pressure (IOP). We have previously demonstrated that Lycium barbarum reduces RGC death in animals with elevated IOP. Also, there is a correlation between L. barbarum-induced neuroprotection and activation of microglia. In this study, we aim to further investigate the biological mechanisms of its neuroprotective ef- 
fects via modulating of immunocompetent cells both in vivo and in vitro. Permission to use adult female Sprague-Dawley rats was granted by Ethical Committee in The University of Hong Kong. Rats were fed daily with different concentrations of crude extract of $L$. barbarum for a total of either 21 or 35 days. On day 7 after commencement of feeding, chronic ocular hypertension $(\mathrm{COH})$ was induced on right eyes of all animals under anesthesia with ketamine and xylazine. The number of RGCs was examined by retrograde transport of Fluoro-gold via superior colliculi and the results were compared between the two eyes of the same animal. Immunocytochemistry was also conducted. Two murine cell lines, RAW264.7 for macrophages and BV2 for microglia, were employed for in vitro study. Cultured cells were exposed to different concentrations of L. barbarum. Culture medium was then collected at different time-points. Nitrite level representing nitric oxide in collected culture medium was determined by Griess's method. The results showed that the neuroprotective effect of $L$. barbarum remained up to 4 weeks after first laser treatment. Also, rats fed with the crude extract of L. barbarum showed an increase of Ibal immunoreactivity in the retina. However, most of microglia in the retina were in semi-activated state with thick processes and large cell body. Assay of nitrite demonstrated that there was insignificant amount of nitric oxide production in both murine cells lines at different concentrations of L. barbarum. In conclusion, L. barbarum protected rat RGCs in COH model, via modulation of microglia. Also, direct incubation of the extract with macrophages/microglia in vitro did not elicit classical activation of these cells. These results suggested that L. barbarum could be a potential protective agent for glaucoma.

Acknowledgement: The study is supported by The Glaucoma Foundation (USA) for K.F.S. and R.C.C.C. A.K.C.I. and K.C. are supported by graduate studentship from The University of Hong Kong.

\section{$\mathrm{P}-9 / 25$ \\ Activation of the Human FPRL-1 Receptor Promotes $\mathrm{Ca}^{2+}$ Mobilization and Stimulates Mitogen-Activated Protein Kinases in U87 Astrocytoma Cells}

Kwan, D.H.T., Kam, A.Y.F., Wong, Y.H.

Department of Biochemistry, the Molecular Neuroscience Center, and the Biotechnology Research Institute, Hong Kong University of Science and Technology,

Clear Water Bay, Kowloon, Hong Kong, China

The human formyl-peptide receptor like 1 (FPRL-1) is a variant of the $\mathrm{G}_{\mathrm{i}}$-coupled formyly-peptide receptor. Functional FPRL1 is endogenously expressed in the U87 astrocytoma cell line [1] and there is accumulating evidence to suggest that FPRL-1 may be involved in neuroinflammation associated with the pathogenesis of Alzheimer's disease. In this study, we examined the ability of FPRL-1 to mobilize intracellular $\mathrm{Ca}^{2+}$ and regulate mitogenactivated protein kinases in U87 astrocytoma cells as well as Chinese hamster ovary (CHO) cells stably expressing FPRL-1. TrpLys-Tyr-Met-Val-Met (WKYMVM), a specific agonist for FPRL1, can stimulate $\mathrm{Ca}^{2+}$ mobilization in both U87 and FPRL-1/CHO cells with $\mathrm{EC}_{50}$ values around $16.3 \mu \mathrm{M}$ and $70.9 \mathrm{nM}$, respectively. $\mathrm{Ca}^{2+}$ mobilization in both cell lines were completely inhibited by pretreating the cells with pertussis toxin, indicating the involvement of $\mathrm{G}_{\mathrm{i}}$ proteins. WRW4, a selective antagonist of FPRL-1, can inhibit the $\mathrm{Ca}^{2+}$ mobilization stimulated by WLYMVM. To investigate the downstream signaling pathways involved, phospholipase $C \beta$ inhibitor $\mathrm{U} 73122$ and $\mathrm{IP}_{3}$ receptor antagonist $2 \mathrm{APB}$ were employed. Only 2-APB was found to abolish the WKYMVMstimulated $\mathrm{Ca}^{2+}$ increase. Immunoblotting analysis showed that WKYMVM can activate the mitogen-activated protein kinase (MAPK) pathway. Whereas addition of WKYMVM peptide led to JNK, ERK and P38 phosphorylations in FPRL-1/CHO cells, the agonist only induced phosphorylation of JNK and ERK in U87 cells. Phosphorlaytions of JNK and ERK in both cell types were not affected by the treatment with BAPTA, a calcium chelator. In conclusion, stimulation of $\mathrm{G}_{\mathrm{i}}$-coupled FPRL-1 can lead to calcium mobilization and the differentiation activation of MAPK pathways in transfected CHO cells and U87 cells.

Acknowledgement: This work was supported in part by grants from the Research Grants Council of Hong Kong (HKUST 3/03C), the University Grants Committee (AoE/B-15/01), and the Hong Kong Jockey Club.

Reference

1 Le Y, et al: J Neuroimmunol 2000;111:102-108.

\section{P-10/25 \\ Potential Neuroprotective Agent from Botanical Extract: An Experience of Using Verbena officinalis against $\boldsymbol{\beta}$-Amyloid Peptide Neurotoxicity}

Lai, S.W. ${ }^{a}$, Yu, M.-S. ${ }^{\text {, }}$ Yuen, W.-H. ${ }^{\text {, }}$, Zee, S.-Y. ${ }^{c}$, So, K.-F. ${ }^{\text {a, b }}$, Chang, R.C.-C. ${ }^{\mathrm{a}, \mathrm{b}}$

aLaboratory of Neurodegenerative Diseases, Department of Anatomy, ${ }^{b}$ Central Laboratory of the Institute of Molecular Technology for Drugs Discovery and Synthesis, 'Department of Botany, dDepartment of Chemistry, The University of Hong Kong, Pokfulam, Hong Kong, China

Increasing lines of evidence have demonstrated the potential of using botanical extract to prevent neurodegenerative diseases. Verbena officinalis Linn. (Verbenaceae) is a perennial plant which has been used as herbal medicine or health supplement in both Western and Eastern countries for centuries. It has been used to treat acute dysentery, enteritis, amenorrhea and depression. In addition, aqueous extract of $V$. officinalis has been shown to exhibit sedative effects in an animal model. Since it has a wide array of biological effects, we hypothesized that $V$. officinalis can exert cytoprotective effects in central nervous system. Lactate dehydrogenase $(\mathrm{LDH})$ assay was used as index of cytotoxicity for various toxins/stresses. Prior to the exposure of $\beta$-amyloid (A $\beta$ ) peptide and reducing agent dithiothreitol, treatment of aqueous extracts of $V$. officinalis significantly attenuated their toxicity determined by $\mathrm{LDH}$ assay. As extracellular accumulation of $\mathrm{A} \beta$ peptide has been considered to be an important pathological factor in Alzheimer's disease (AD), we have further explored the neuroprotection of $V$. officinalis aqueous extracts against $A \beta$. Treatment of $V$. officinalis aqueous extracts attenuated A $\beta$-triggered DEVDand VDVAD-cleavage activities in dose-dependent manner. Furthermore, $V$. officinalis attenuated $A \beta$-triggered apoptosis con- 
firmed by DAPI staining. According to our previous findings, $A \beta$ peptide can activate the stress kinases, including double-stranded RNA-dependent protein kinase (PKR) and c-Jun N-terminal kinase (JNK). Our present results showed that $V$. officinalis attenuated the phosphorylation of both PKR and JNK in A $\beta$-treated neurons by Western blot analysis. Taken together, we have proved our hypothesis by showing the novel neuroprotective effects of $V$. officinalis. As $V$. officinalis has long been used for many years to be a folk medicine, our study may provide a potential lead as a neuroprotective agent against neuronal loss in AD.

Acknowledgement: S.W.L. and M.S.Y. are supported by postgraduate studentship from The University of Hong Kong. The study is partially supported by HKU Seed Funding for Basic Research (2004 \& 2005) and HKU University Strategic Theme Research on Healthy Aging to R.C.C.C.

\section{P-11/25 \\ Regulation of Collagen-Like Subunit (ColQ) of Acetylcholinesterase by Muscular Activity in Muscle}

Lau, F.T.C. ${ }^{a}$, Ting, A.K.L. ${ }^{a}$, Massoulié, J. ${ }^{\mathrm{b}}$, Tsim, K.W.K. $^{\mathrm{a}}$

aDepartment of Biology and Molecular Neuroscience Center, The Hong Kong University of Science and Technology, Clear Water Bay, Hong Kong, China, and baboratoire de Neurobiologie Moléculaire et Cellulaire, Centre National de la Recherche Scientifique UMR 8544, Ecole Normale Supérieure, Paris, France

Vertebrate neuromuscular junction (nmj) contains high concentration of acetylcholine receptor (AChR) and acetylcholinesterase (AChE). Within the nmj, there is a synaptic basal lamina that allows the anchoring of asymmetric AChE through the presence of a collagenous protein (ColQ). There are two ColQ transcripts, namely ColQ-1 and ColQ-1a, which are driven by 2 distinct promoters, pColQ-1 and pColQ-1a, respectively. ColQ-1 mRNA is more abundant in slow-twitch muscle and uniformly expressed throughout the entire muscle fiber, whereas ColQ-1a mRNA is expressed in fast-twitch muscle with a synapse-specific pattern. These differential regulations are thought to be mediated by muscular activity and nerve-derived factors. Muscular activity was found to suppress the AChR gene expression via a calciumdependent signaling pathway. Inhibition of muscle contraction by tetrodotoxin (TTX) inhibits the asymmetric AChE in cultured myotubes. In this study, we would like to investigate the effect of muscular activity on ColQ gene regulation in muscle by using real-time PCR analysis and promoter-luciferase reporter. Primary chick muscle culture and mouse $\mathrm{C} 2 \mathrm{C} 12$ muscle cell line were treated with acetylcholine (ACh), carbachol and calcium ionophore A23187 to mimic the effect of muscular activity. The level of ColQ mRNAs and the transcriptional activity of promoters were increased after the treatment, while the induction effects of carbachol was blocked by TTX. To investigate the possible downstream mechanisms, the phosphorylation of several signaling molecules triggered by muscular activity was analysed. These results support the notion that ColQ expressions could be up-regulated by muscular activity.

Acknowledgement: Supported by HKUST 6283/03M, 6237/ 04M, 6404/05M and 3/03C.

The 25th Scientific Meeting of the

Hong Kong Society of Neurosciences

\section{P-12/25 \\ NGF-Induced Neuronal Differentiation of PC12 Cells: Delineation of Signaling Molecules and Mapping of Pathways}

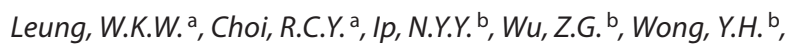
Cheung, P.T. ${ }^{\mathrm{C}}$, Tsim, K.W.K. ${ }^{\mathrm{a}}$

aDepartment of Biology and Molecular Neuroscience Center, ${ }^{b}$ Department of Biochemistry, Biotechnology Research Institute, and Molecular Neuroscience Center, Hong Kong University of Science and Technology, Clear Water Bay, Hong Kong, 'Department of Paediatrics, Queen Mary Hospital, The University of Hong Kong, China

In human brain, proper development and precise neuronal connection are required to form a functional brain. Neuronal survival and differentiation are the vital processes to govern the fate of different types of neurons via different neurotrophic factors, such as nerve-growth factor (NGF), brain-derived neurotrophic factor (BDNF), ciliary neurotrophic factor (CNTF), neurotrophin-3/4 (NT-3/4), etc. These trophic factors are secreted by target cells to support the growth, axonal gudiance and differentiation of neurons. Understanding of the neuronal differentiation induced by those trophic factors is important to determine the underlying molecular mechanisms, which is essential for drug targeting and therapy of certain neurodegenerative diseases. Based on this rationale, we attempted to investigate the change of gene expression upon NGF-induced neuronal differentiation in culture model called rat pheochromocytoma PC12 cells. After NGFtreatment for $12 \mathrm{~h}$, mRNAs were collected and used to perform microarray gene analysis to determine the change of gene expressions. Four different groups of up-regulated genes were chosen for further verification using reverse-transcription polymerization chain reaction (RT-PCR). Results showed that the mRNA of those chosen genes were up-regulated by NGF treatment. At this stage, the functions of all these genes involved in NGF-induced neuronal differentiation are not known yet.

Acknowledgement: Supported by 3/03C.

\section{P-13/25 \\ Change in Perineuronal Net of Rat Vestibular Nuclear Neurons in Development and in Injury}

Ma, C.W. ${ }^{\text {a }}$ Lai, C.H. ${ }^{\text {a }}$, Shum, D.K.Y. ${ }^{\text {b }}$, Chan, Y.S. ${ }^{\text {a }}$

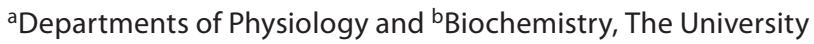
of Hong Kong, Hong Kong, China

Perineuronal net $(\mathrm{PN})$ is a lattice-like extracellular matrix surrounding neurons. With the use of the lectin Wisteria floribunda agglutinin as a cytochemical marker, we studied the expression patterns of $\mathrm{PN}$ within the vestibular nuclei in normal postnatal rats (P1 to adult) as well as in adult rats at 5 to 11 days after unilateral labyrinthectomy (UL). In uninjured rats, $\mathrm{PN}$ was detectable by P3 in the vestibular nucleus as fuzziness about neuronal cell bodies. From P9 onwards, the fuzzy PN was progressively consolidated into a network organization. The fuzziness was no longer observable after P12. During postnatal development, the 
number of cell bodies indicating $\mathrm{PN}$ was found to increase, reaching adult level by P21. In unilateral labyrinthectometomized rats, the $\mathrm{PN}$ on the labyrinth-intact side remained similar to uninjured age-matched rats. On the lesioned side at 5 days after UL, the PN recapitulated the fuzziness of early postnatal stages of uninjured rats. By 11 days after UL, the PN resumed the network pattern. Taken together, our findings suggest that the PN plays a crucial role in modulating the pericellular environment of vestibular nuclear neurons both during postnatal development of normal rats as well as in adult rats following destruction of the ipsilateral inner ear.

\section{P-14/25 \\ Overexpression of $\mathbf{G} \alpha_{z}$ Inhibits Muscle Differentiation}

Mei, H., Wu, Z., Ip, N.Y., Wong, Y.H.

Department of Biochemistry, the Molecular Neuroscience Center, and the Biotechnology Research Institute, Hong Kong University of Science and Technology,

Clear Water Bay, Kowloon, Hong Kong, China

$\mathrm{G} \alpha_{\mathrm{z}}$ is primarily expressed in neuronal tissues and it is the only member within the $\mathrm{G} \alpha_{\mathrm{i}}$ subfamily which is not a substrate of pertussis toxin. Despite of the fact that $\mathrm{G} \alpha_{\mathrm{z}}$ can functionally interact with $\mathrm{G}_{\mathrm{i}}$-coupled receptors, its precise role in neurons has yet to be defined. Interestingly, $\mathrm{G} \alpha_{\mathrm{z}}$ has been found to be endogenously expressed in the mouse $\mathrm{C} 2 \mathrm{C} 12$ myoblast cell line. Again, the exact function of $\mathrm{G} \alpha_{\mathrm{z}}$ in myoblasts is unknown. In the present study we explored the possible involvement of $\mathrm{G} \alpha_{\mathrm{z}}$ signaling in muscle differentiation. $\mathrm{C} 2 \mathrm{C} 12$ cells stably expressing $\mathrm{G} \alpha_{\mathrm{z}}$ exhibited impaired ability to differentiate when compared with control cells. A luciferase reporter gene with myogenin promoter was used to monitor muscle differentiation-dependent signals. The luciferase signal was inhibited upon overexpression of $\mathrm{G} \alpha_{\mathrm{z}}$ in a dose-dependent manner. As a further evidence of the inhibition effect, Western blot analysis showed that myogenin expression was reduced in cells overexpressing $\mathrm{G}_{\mathrm{z}}$. In an attempt to identify the downstream partners of $\mathrm{G} \alpha_{\mathrm{z}}$, microarray analysis was performed on inducible ECR293/G $\alpha_{\mathrm{z}}$ and ECR293/G $\alpha_{\mathrm{z}} \mathrm{QL}$ cells; these cell lines expressed the wild-type and constitutively active mutant of $G \alpha_{z}$ upon induction by ponasteron A. Using GeneSprings for data filtering, a number of genes were shown to be differentially regulated by $\mathrm{G} \alpha_{\mathrm{z}}$; some of the identified genes appeared to have direct relationships with muscle differentiation.

Acknowledgement: This work was supported in part by grants from the Research Grants Council of Hong Kong (HKUST 3/03C and HKUST 6420/05M), the University Grants Committee (AoE/ B-15/01), and the Hong Kong Jockey Club.

\section{P-15/25 \\ Regulation of NR2A, a Subunit of $\mathbf{N}$-Methyl- D-Aspartate Receptor, by a cAMP-Dependent Signaling Pathway in Neuronal Cultures}

Siow, N.L., Choi, R.C.Y., Xie, H.Q.H., Tsim, K.W.K.

Department of Biology and Molecular Neuroscience Center, Hong Kong University of Science and Technology,

Clear Water Bay, Hong Kong, China

Cyclic AMP-dependent pathway including intracellular cAMP, protein kinase A (PKA) and the cAMP response element binding protein (CREB) has been known to link with the establishment of long-term memory and cell survival via gene transcription. N-methyl-D-aspartate receptors (NMDARs) are known to be a key player in such processes. Previous study has shown that gene expression of NMRAR subunit 1 (NR1) could be up-regulated by a PKA-dependent pathway. Therefore, it could be worth to investigate whether the gene expressions of other NMDAR subunits could also be regulated by a cAMP-dependent signaling pathway. NG108-15 neuroblastoma cell line and primary culture of rat cortical neurons were used to study the gene expression of NR2A (one of the NR2 subunits) via the regulation of a cAMPdependent pathway. The endogenous NR2A protein was up-regulated upon treatment of $\mathrm{Bt}_{2}$-cAMP and forskolin. To further investigate the molecular mechanism of cAMP in regulating transcriptional activity of NR2A, a mouse NR2A promoter $(\sim 1 \mathrm{~kb})$ was cloned and tagged with a luciferase reporter gene. The promoter activity was also up-regulated upon the treatments of $\mathrm{Bt}_{2}$ cAMP and forskolin. DNA footprinting was performed on the NR2A promoter, and three CRE sites were mapped. The authenticities of these CRE sites were confirmed by gel mobility shift assay. In addition, mutations of these CRE sites were performed to test the effect on CAMP-induced NR2A regulation. The results suggested that gene expression of NR2A could be up-regulated by a cAMP-dependent pathway in neuron cultures.

Acknowledgement: Supported by HKUST 6283/03M, 6237/ 04M, 6404/05M and 3/03C.

\section{P-16/25 \\ Regulation of Canonical Transient Receptor Potential Isoform 6 (TRPC6) by Protein Kinase G}

Wong, C.O., Huang, Y., Yao, $X$.

Department of Physiology, The Chinese University of Hong Kong, Shatin, N.T., Hong Kong, China

Transient receptor potential (TRP) channels are non-selective cation channels widely expressed in the nervous system [1]. They play a role as cellular sensor in response to stimuli including temperature, mechanical stress and inflammatory agents [2]. Since its first discovery in Drosophila in 1977, at least 28 TRP channels have been classified in humans. Nevertheless, little is known concerning the regulatory mechanism of these TRP channels. Protein phosphorylation has long been regarded as one of the major ways in protein regulation. In recent years, several kinases have been reported as participating in TRP channel regulation. Among them, protein kinase $\mathrm{G}(\mathrm{PKG})$ has been found to be directly phos- 
phorylating TRPC3, thereby resulting in channel inactivation [3]. In the present study, the involvement of $\mathrm{PKG}$ in the regulation of TRPC6, a TRPC isoform with high sequence homology to TRPC3 [4], is studied. PKG and TRPC6 genes were co-transfected into HEK293 cells. By means of fluorescence $\mathrm{Ca}^{2+}$ measurement, fluorescence signal given by $\mathrm{Ca}^{2+}$ influx with/without the treatment of PKG-inhibitor was recorded. Magnitude of the signal from the TRPC6-non-transfected cells was compared with that from the PKG-TRPC6-cotransfected cells. Results indicate that TRPC6 is inactivated in PKG-transfected HEK293, and the activity restores in the presence of PKG inhibitor.

Acknowledgement: The project is supported by RGC grant (CUHK4366/04M).

\section{References}

1 Moran MM, et al: Curr Opin Neurobiol 2004;14:362-369.

2 Clapham DE: Nature 2003;426(6966):517-524.

3 Kwan HY, et al: Proc Natl Acad Sci USA 2004;101:2625-2630.

4 Vazquez G, et al: Biochim Biophys Acta 2004;1742:21-36.

\section{P-17/25}

\section{Role of Calmodulin-Dependent Kinase II in Nerve} Growth Factor-Induced Differentiation of PC12 Cells

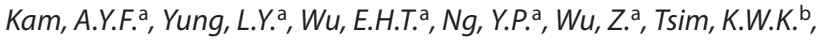
Wise, H. ${ }^{c}$, Ip, N.Y. ${ }^{\text {a }}$, Wong, Y.H. ${ }^{a}$

Departments of ${ }^{a}$ Biochemistry and ${ }^{b}$ Biology, Molecular Neuroscience Center, and Biotechnology Research Institute, Hong Kong University of Science and Technology, Clear Water Bay, Kowloon, Hong Kong, 'Department of Pharmacology, The Chinese University of Hong Kong,

Shatin, Hong Kong, China

Neuronal differentiation is a complex process which requires the precise orchestration of numerous players. In order to gain insight into the molecular mechanisms underlying nerve growth factor (NGF)-induced neuronal differentiation, our team has conducted a microarray analysis of NGF-treated PC12 cells, and selected several differentially regulated genes for functional analysis. In particular, we noticed that a number of up-regulated genes are associated with the $\mathrm{Ca}^{2+}$-dependent signaling pathways. They include the $\mathrm{G}_{\mathrm{q}}$-coupled bradykinin $\mathrm{B}_{2}$ receptor, protein kinase $\mathrm{C} \alpha$, and calmodulin-dependent kinase II $\beta$ (CaMKII). To confirm their involvement in NGF-induced differentiation of PC12 cells, we monitored the changes in intracellular inositol-trisphosphate $\left(\mathrm{IP}_{3}\right)$ and $\mathrm{Ca}^{2+}$ in the absence or presence of specific inhibitors or activators. Following NGF treatment for $24 \mathrm{~h}$, bradykinin was able to produce a more robust stimulation of $\mathrm{IP}_{3}$ formation and $\mathrm{Ca}^{2+}$ mobilization. Moreover, NGF-induced neurite outgrowth and expression of neurofilament in PC12 cells were significantly suppressed in the presence of KN-62, a CaMKII inhibitor. In contrast, KN-92 (the inactive analogue of KN-62) was totally ineffective in suppressing the NGF-induced responses. These studies suggest a role for $\mathrm{Ca}^{2+}$-dependent signaling in NGF-induced neuronal differentiation.

Acknowledgement: This work was supported in part by grants from the Research Grants Council of Hong Kong (HKUST 3/03C), the University Grants Committee (AoE/B-15/01), and the Hong Kong Jockey Club.

The 25th Scientific Meeting of the Hong Kong Society of Neurosciences

\section{P-18/25}

\section{Role of PRiMA in Regulating Globular Form of Acetylcholinesterase: The Possible Role of AChE Oligomerization}

\author{
Xie, H.Q.H. ${ }^{a}$, Choi, R.C.Y. ${ }^{\text {, }}$ Siow, N.L. ${ }^{a}$, Peng, H.B. ${ }^{a}$, Massoulié, J. ${ }^{b}$ \\ Tsim, K.W.K. ${ }^{\mathrm{a}}$ \\ aDepartment of Biology and Molecular Neuroscience Center, \\ Hong Kong University of Science and Technology, \\ Clear Water Bay, Hong Kong, China, and ${ }^{\mathrm{b}}$ Laboratoire de \\ Neurobiologie Cellulaire et Moléculaire, CNRS UMR 8544, \\ Ecole Normale Supérieure, Paris, France
}

Acetylcholinesterase plays an important role in controlling cholinergic neurotransmission. AChE T-subunit $\left(\mathrm{AChE}_{\mathrm{T}}\right)$, expressing in vertebrate muscle and neuron, possesses distinct oligomerization patterns in different tissues. Globular tetrameric form of $\mathrm{AChE}_{\mathrm{T}}\left(\mathrm{G}_{4}\right)$ is predominantly expressed in the brain, while asymmetric form of $\mathrm{AChE}_{\mathrm{T}}\left(\mathrm{A}_{12}\right)$ is the major functional form of AChE in neuromuscular junction. Proline-Rich Membrane Anchor (PRiMA) and ColQ (Collagen-tailed subunit) are able to organize AChE catalytic subunits into tetramers and asymmetric form, respectively, via their Proline-Rich Attachment Domain (PRAD) and anchor the enzyme at the cell surface and basal laminar. Previous study shows that interaction between PRAD of ColQ and $\mathrm{AChE}_{\mathrm{T}} \mathrm{C}$-terminal can facilitate the stability of AChE. To determine the role of PRiMA in regulating AChE, we over expressed PRiMA with $\mathrm{AChE}_{\mathrm{T}}$ in NG108-15 neuroblastoma cells. It was found that the expression of PRiMA could induce the assembly of exogenous $\mathrm{AChE}_{\mathrm{T}}$ into tetramers $\mathrm{G} 4$ enzyme. Interestingly, the total enzymatic activity of $\mathrm{AChE}_{\mathrm{T}}$ was also increased by the presence of PRiMA, which was mainly due to the elevation of $\mathrm{G}_{4} \mathrm{AChE}$ activity. Similar results were observed in mouse $\mathrm{C} 2 \mathrm{C} 12$ muscle cells. These evidences suggest that PRiMA is a critical and essential factor for directing the assembly of $\mathrm{G}_{4}$ AChE. Apart from its primarily role, PRiMA could also modulate the enzymatic activity via interaction of the PRAD and $\mathrm{AChE}_{\mathrm{T}}$.

Acknowledgement: Supported by HKUST 6283/03M, 6237/ 04M, 6404/05M and 3/03C.

\section{P-19/25 \\ The Effect of NGF-Induced Differentiation on the Expression of Prostanoid Receptor in PC12 Cells \\ Yung, H.S. ${ }^{a}$, Wong, Y.H. ${ }^{\text {b }}$, Wise, $H_{.}{ }^{\text {a }}$ \\ aDepartment of Pharmacology, The Chinese University of Hong Kong, Hong Kong, and ' Department of Biochemistry, University of Science and Technology, Hong Kong, China}

The expression of cyclooxygenase- 1 has been reported to be increased in rat pheochromocytoma (PC12) cells following differentiation by nerve growth factor (NGF) [1]. Therefore, we have determined if the process of neuronal differentiation has any effect on the expression of the five members of the prostanoid receptor family by assaying responses to prostaglandin $\mathrm{D}_{2}$ (DP agonist), prostaglandin $\mathrm{E}_{2}$ (EP agonist), prostaglandin $\mathrm{F}_{2 \alpha}$ (FP ago- 
nist), cicaprost (IP agonist), U46619 (TP agonist), and sulprostone $\left(\mathrm{EP}_{3} / \mathrm{EP}_{1}\right.$ agonist $)$. Undifferentiated $\mathrm{PC} 12$ cells $\left(3 \times 10^{5}\right.$ cells/ well) and NGF-differentiated PC12 cells (50 ng/ml for $32 \mathrm{~h}$ ) were prelabelled with $\left[{ }^{3} \mathrm{H}\right]$-adenine or $\left[{ }^{3} \mathrm{H}\right]$-inositol for the assay of $\left[{ }^{3} \mathrm{H}\right]$-cAMP and $\left[{ }^{3} \mathrm{H}\right]$-inositol phosphate $\left(\left[{ }^{3} \mathrm{H}\right]-\mathrm{IP}\right)$ production, respectively [2] $(n=3)$. None of the agonists tested $(1 \mu M)$ produced any change in $\left[{ }^{3} \mathrm{H}\right]$-IP production, although bradykinin $(10 \mu \mathrm{M})$ significantly increased $\left[{ }^{3} \mathrm{H}\right]-\mathrm{IP}$ production in both cell groups $(\mathrm{p}<0.01)$. In the undifferentiated PC12 cells, both prostaglandin $\mathrm{D}_{2}(\mathrm{p}<0.01)$ and $\mathrm{U} 46619(\mathrm{p}<0.05)$ increased $\left[{ }^{3} \mathrm{H}\right]$-cAMP, while prostaglandin $\mathrm{E}_{2}$, prostaglandin $\mathrm{F}_{2 \alpha}$ and sulprostone significantly inhibited forskolin $(1 \mu \mathrm{M})$-stimulated $\left[{ }^{3} \mathrm{H}\right]$-cAMP production $(\mathrm{p}<0.01)$. No statistically significant changes were observed in NGF-differentiated PC12 cells, where the magnitude of the responses were decreased. In conclusion, PC12 cells express Gscoupled DP and the Gi-coupled $\mathrm{EP}_{3}$ receptors, but do not express Gs-coupled IP receptors. FP and TP receptors, which primarily couple to Gq-proteins, appear to couple to Gi- and Gs-proteins, respectively, in PC12 cells, and the expression of all these receptors appears to decrease in the early stages of neuronal differentiation.

Acknowledgement: This work was fully supported by a grant from the Research Grants Council of the Hong Kong Special Administrative Region (HKUST3/03C).

\section{References}

1 Kaplan MD, et al: J Biol Chem 1997;272:18534-18537.

2 Chow KB, et al: Br J Pharmacol 2001;134:1375-1384.

\section{P-20/25 \\ Explant Cultures of Embryonic Rat Dorsal Root Ganglia Exhibit Heparanase Expression in Migrating Cells}

Zhang, Y., Shum, D.K.Y.

Department of Biochemistry, Faculty of Medicine, The University of Hong Kong, Hong Kong, China

Mammalian heparanase is an endo- $\beta$-D-glucuronidase that cleaves heparan sulfate moieties of proteoglycans at limited sites. Its enzymatic activity is strongly implicated in the regulation of cell growth, migration and differentiation of tumor cells, endothelial cells and inflammatory cells [1]. The findings of the differences in cellular expression of heparanase in normal adult spinal cord [2] open a new area for us to explore the functions of heparanase in cell migration, during neural development and regulation of cellular environments in adult neural tissue. Here, we provide in vitro evidence that heparanase expression correlates with cell migration as revealed by model cultures of embryonic rat dorsal root ganglia (DRG). Cells migrating away and cells about to exit the DRG core showed strong expression of heparanase protein and mRNA, while those cells remaining sessile in the DRG center showed low ISH signals. The upregulated expression of heparanase protein and endoglucuronidase activity in explant cultures compared with neat explants suggest heparanase functions as an active enzyme to facilitate the cellular emigration from the dorsal root ganglia in vitro.
Acknowledgement: This work is supported by CRCG, The University of Hong Kong, grants 10204997\&10205634 to D.K.Y.S.

\section{References}

1 Vlodavsky I, et al: Nat Med 1999; 5: 793-802.

2 Zhang Y, et al: J Comp Neurol 2005.

\section{$\mathrm{P}-21 / 25$ \\ A Flavonol Glycoside, Isolated from Roots of Panax notoginseng, Protects the $\beta$-Amyloid-Induced Neurotoxicity in Cultured PC12 Cells}

\author{
Zhu, J.T.T., Leung, W.K.W., Cheung, J.K.H., Zhao, K.J., Dong, T.T.X., \\ Tsim, K.W.K. \\ Department of Biology and Molecular Neuroscience Center, \\ Hong Kong University of Science and Technology, \\ Clear Water Bay, Hong Kong, China
}

Panax notoginseng (Radix Notoginseng, Sanqi) is a wellknown traditional Chinese medicine, which has been reported to have many pharmacological activities and clinical effects. The main active constituents of $P$. notoginseng are saponins, flavonoids, dencichine and polysaccharides. Among flavonoids, a major flavonol glycoside, which accounts $\sim 60 \%$ of total flavonoids, was isolated and purified from water extract of the roots of $P$. notoginseng by various chromatographic methods for the first time. The structure of the flavonol glycoside was identified as quercetin $3-\mathrm{O}-\beta$-D-xylopyranosyl- $\beta$-D-galactopyranoside by NMR, UV and IR spectrum. The pre-treatment of quercetin 3-O- $\beta$-D-xylopyranosyl- $\beta$-D-galactopyranoside prevented the $\beta$-amyloid-induced or the serum deprivation-induced cell death in a dose-dependent manner in cultured pheochromocytoma PC12 cells. Treatment of this flavonol glycoside protected over $90 \%$ of cells against the neurotoxicity. On the other hand, the flavonol glycoside could also reduce the intracellular release of lactate dehydrogenase (LDH) and calcium surge from damage cultured PC12 cells which was used as indicator of cell death. In addition, the flavonol glycoside contained strong anti-oxidation activity, which therefore might explain its neuroprotective activity. In conclusion, we found a new active constituent in P. notoginseng, which has an in vitro function in protecting neuronal cells.

Acknowledgement: Supported by HKUST 6283/03M, 6237/ 04M, 6404/05M and 3/03C. 


\section{P-22/25 \\ Neuroprotection by Novel Anti-Alzheimer's Dimer bis(7)-Tacrine via Blockade of NMDA Receptor and Selective Inhibition of Neuronal Nitric Oxide Synthase}

Li, W. ${ }^{a}$, Lee, N.T.K. ${ }^{\text {, }}$ Xue, J. ${ }^{\text {b }}$, Kan, K.K.W. ${ }^{\text {a }}$ Fu, H. ${ }^{\text {a }, ~ L a m, ~ C . S . C . ~}{ }^{a}$,

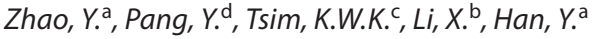

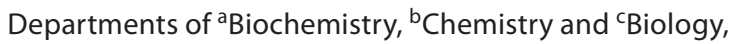
Hong Kong University of Science and Technology, Hong Kong, China, and dMayo Foundation for Medical Education and Research, Rochester, Minn., USA

The excessive activation of nitric oxide synthase (NOS)/NO pathway has been proposed to be commonly attributed to the neuropathology in various neurodegenerative disorders. In this study, it was found that bis(7)-tacrine, a newly developed acetylcholinesterase inhibitor, prevented neuronal injuries caused by various stimuli in vitro and in vivo, which were mediated by NO pathway. In primary cultured neurons, compared with MK-801 ( $\mathrm{IC}_{50}$ $0.018 \mu \mathrm{M})$ and memantine $\left(\mathrm{IC}_{50} 2.1 \mu \mathrm{M}\right)$, bis(7)-tacrine ( $\mathrm{IC}_{50}$ $0.025 \mu \mathrm{M})$ elicited the dose- and time-dependent reduction of excitotoxicity and NO release caused by glutamate. Using patchclamp and ligand binding assays, it were shown that the $\mathrm{IC}_{50}$ of bis(7)-tacrine, MK-801 and memantine to inhibit currents triggered by NMDA were 2.5, 0.053 and $3.7 \mu \mathrm{M}$, and their Ki competed with $\left[{ }^{3} \mathrm{H}\right] \mathrm{MK}-801$ were $0.70,0.035$ and $0.79 \mu \mathrm{M}$, respectively. Furthermore, at effective neuroprotective concentrations bis(7)-tacrine substantially reversed the overactivation of neuronal NOS caused by glutamate without interfering with its basal activity. The dimer was confirmed to competitively inhibit both purified neuronal and inducible NOS with $\mathrm{IC}_{50}$ at 0.52 and $1.7 \mu \mathrm{M}$. Together, these results suggest that bis(7)-tacrine exerts the neuroprotective properties by synergistically inhibiting NOS activity via both indirect and direct pathways.

Acknowledgement: Supported by grants from the Research Grant Committee of Hong Kong: HKUST6120/02M, 6133/03M; N-HKUST001/00, 643/99; AOE/b15/01, P_10/01.

\section{P-23/25 \\ Identification of Critical Early Genes Involved in Nerve Growth Factor-Induced PC12 Differentiation}

Xiao, F. ${ }^{\mathrm{a}}$, Ng, Y.P. ${ }^{\mathrm{a}}$, Tsim, K.W.K. ${ }^{\mathrm{b}}$, Wise, H. ${ }^{\mathrm{c}}$, Wong, Y.H. ${ }^{\mathrm{a}}$, Ip, N.Y. ${ }^{\mathrm{a}}$, Wu, Z. ${ }^{a}$

Department of a Biochemistry and ${ }^{b}$ Biology, Hong Kong University of Science and Technology, Hong Kong, 'Department of Pharmacology, The Chinese University of Hong Kong, China

Nerve growth factor (NGF) is a critical neurotrophic factor indispensable for neuronal cell survival and differentiation. Stimulation of PC12 cells by NGF induces neurite-like extensions and expression of many neuronal markers and has been widely used as a cell culture model to study NGF-induced neuronal differentiation and survival. In the past decade, many intracellular signaling pathways including the mitogen-activated protein kinase pathways and the phosphatidylinositol 3-kinase/Akt pathway have been known to be activated by NGF and significantly contribute to NGF-induced cell survival and differentiation. However, the critical downstream target genes involved in the NGF action remain largely unknown. In the current project, we employed the microarray method to characterize the whole-genome gene expression profiles in response to NGF treatment. We paid particular attention to the genes affected by NGF at an early time point $(12 \mathrm{~h})$, well before the late phenotypic changes induced by NGF when many structural genes (e.g., neurofilament) are highly induced. We hope to identify key regulators modulated by NGF at the initial phase which may in turn affect expression profiles of other genes at the late stages. Duplicate samples (non-treated control sample and the test sample treated with NGF for $12 \mathrm{~h}$ ) were used for RNA extraction and subjected to microarray analysis (Affymetrics Chip). Bioinformatic tools were extensively used to process the raw data. Three criteria were used (raw signal strength, fold changes, and statistical significance) to select a list of genes for subsequent verification using semi-quantitative RT-PCR. We were able to confirm that the expression of many of the selected genes indeed undergoes significant changes upon NGF treatment. We are currently in the process of evaluating the role of these gene products in NGF-induced PC12 differentiation.

Acknowledgement: This project was supported by grants from the Research Grants Council of Hong Kong (HKUST 3/03C), the University Grants Committee (AoE/B-15/01) and the Innovation and Technology Commission (ITS/226/01).

\section{P-24/25 \\ The Early Migration of Sacral Neural Crest Cells in the Mouse Embryo \\ Chan, A.K. ${ }^{\mathrm{a}}$, Burn, A.J. ${ }^{\mathrm{b}}$, Chan, W.Y. ${ }^{\mathrm{a}}$ \\ aDepartment of Anatomy, Faculty of Medicine, The Chinese University of Hong Kong, Hong Kong, China, and ${ }^{\mathrm{b}}$ Neural \\ Development Unit, Institute of Child Health, London, UK}

Neurons and glial cells that make up the enteric nervous system are derived from neural crest cells (NCCs) at the vagal and sacral regions. While the contribution and the migratory pathway of the former to the enteric nervous system have been extensively studied, the information on the sacral NCCs is scarce, especially in rodents. To determine the migratory pathway of sacral NCCs from the neural tube to the developing gastrointestinal tract, mouse embryos at E9.5 were isolated, and pre-migratory neural crest cells at the sacral region adjacent to the 24th to 28th somite were labelled by injecting an exogenous cell marker, namely wheat germ agglutinin gold conjugates (WGA-Au), into the lumen of the neural tube. The labelled embryos were then cultured in vitro and the migratory pattern was determined by examining the spatiotemporal distribution of labelled cells at different somite stages. At the 27-28 somite stage, sacral NCCs had already started their emigration from the neural crest region adjacent to the 24th and 25 th somite. Labelled migrating cells were mainly found on the dorsal side of the neural tube. At the 29-30 somite stage, more NCCs emigrated from the neural tube and the crest region with NCC emigration extends more caudally to the region adjacent to the 27th somite. By the 31-32 somite stage, the sacral region extending from the 24th to 28th somite showed NCC emigration 
from the neural tube. Labelled cells were scattered dorsoventrally from the dorsal neural tube to the mesenchymal region between the somite and the neural tube. At the 35-36 somite stage, cell emigration from the neural crest continued and more labelled cells were found in the mesenchyme. However, no labelled cells were found in the gut mesenchyme. The present study demonstrates that neural crest cells at the sacral region have begun their migration at the $27-28$ somite stage and that they migrate along the pathway between the somite and the neural tube. Our results are also in line with the notion that sacral NCCs in rodents reach the gut mesenchyme at a stage more advanced than the 36-somite stages.

Acknowledgements: The work described here was supported by a grant from the Research Grants Council of the Hong Kong Special Administrative Region, China (Project No. CUHK 4418/ 03M).

\section{$\mathrm{P}-25 / 25$ \\ DOC-2/Dab2 Is Expressed in the Human Fetal Brain and Mouse Embryos}

Chan, A.K. ${ }^{a}$, Cheung, K.K. ${ }^{\mathrm{b}}$, Mok, S.C. ${ }^{\mathrm{c}}$, Yew, D.T. ${ }^{\mathrm{a}}$, Chan, W.Y. ${ }^{\mathrm{a}}$

aDepartment of Anatomy, Faculty of Medicine, The Chinese University of Hong Kong, China, b Harvey Laboratory,

Victor Chang Cardiac Research Institute, Sydney, Australia, and

'Laboratory of Gynecologic Oncology, Brigham and Women's

Hospital, Harvard Medical School, Boston, Mass., USA

The signal transduction adaptor protein DOC-2/Dab2 is one of the two mammalian orthologs of the Drosophila Disabled. It has been implicated in signal transduction by mitogens, TGF $\beta$ and Ras-related activation of protein kinases. The protein also regulates functions of the visceral endoderm in early mouse embryos. To further determine the roles of the protein in development, we examined the spatio-temporal expression of the protein in the human fetal neocortex and hippocampus (12 to 32 gestational weeks) and in mouse embryos (E8.5 to E16.5) using an immunohistochemical method and a specific antibody to DOC-2/ Dab2 proteins. The protein expression was detected in all layers of the human fetal hippocampus throughout gestation. In the neocortex, the marginal zone, the upper cortical plate and the subcortical layer of the temporal cortex (Brodmann's area 41), the sensory cortex (area 1) and the occipital cortex (area 17) were immunoreactive at all the gestational ages examined, but the frontal cortex (area 10) and the motor cortex (area 4) were largely negative except that their marginal zone and the subcortical layer were immunoreactive. In mouse embryos, the protein was mainly expressed in the cranial and truncal mesenchyme and the developing heart at early organogenesis (E8.5). The protein started to appear in the cranial neural tube one day later and the cranial and truncal mesenchyme remained positive at mid-gestation. In addition, the vertebral column and the gut submucosa also became positive. The expression in the heart was gradually restricted to the trabeculae and valves. At late gestation, many brain regions and connective tissues of several developing structures including gut showed the protein expression. In the heart, the expression was localized to the valves. Our results demonstrate a specific spatial and temporal expression pattern of DOC-2/Dab2 protein in the developing brain and many other embryonic structures, implicating that the protein plays important roles in development.

Acknowledgement: The study on human fetuses had been approved by the Clinical Research Ethics Committee, Faculty of Medicine, The Chinese University of Hong Kong. The work described here was supported by a grant from the Research Grants Council of the Hong Kong Special Administrative Region, China (Project No. CUHK4262/04M).

\section{P-26/25 \\ Mitochondrial Function Regulates Actin-Mediated Presynaptic Development \\ Lee, C.W., Peng, H.B. \\ Department of Biology, Hong Kong University of Science and Technology, Clear Water Bay, Kowloon, Hong Kong, China}

Mitochondria are highly enriched in the presynaptic nerve terminal at the vertebrate neuromuscular junctions. Our previous studies showed the clustering of mitochondria with higher membrane potential $\left(\Psi_{\mathrm{m}}\right)$ at the presynaptic regions, but the exact functions of these localized synaptic mitochondria remain unclear. In this study, we investigated the correlation between the mitochondrial $\Psi_{\mathrm{m}}$ and the development of synaptic specializations during synaptogenesis. Labeling the Xenopus spinal neurons with a mitochondrial $\Psi_{\mathrm{m}}$-sensitive probe JC-1 revealed that the mitochondrial $\Psi_{\mathrm{m}}$ could be reversibly manipulated either by a mitochondrial activity enhancer creatine or by a protonophore FCCP. Synapsin immunostaining on the naïve neurons indicated that the number and area of the preexisting synaptic vesicle (SV) clusters were positively correlated to the mitochondrial $\Psi_{\mathrm{m}}$, suggesting a potential regulatory role of mitochondrial activity in synaptogenesis. Upon presynaptic induction by growth factorcoated beads, we found newly polymerized filamentous $(F)$-actin scaffolds, as visualized by fluorescent phalloidin after masking the preexisting F-actin with jasplakinolide, at the bead-neurite contact regions in control, but not in FCCP-treated cultures. To further examine the specific role of mitochondria in actin polymerization, we showed that a mitochondrial ATP synthase inhibitor oligomycin, but not a mitochondrial $\mathrm{Na}^{+} / \mathrm{Ca}^{2+}$ exchanger inhibitor CGP-37157, was able to suppress the local polymerization of F-actin and the subsequent clustering of SVs and mitochondria induced by beads. Taken together, our results suggest that the local concentration of mitochondria at the nascent nerve terminal may serve as a local ATP source for the construction of actin cytoskeletal scaffold, which may further facilitate the clustering of mitochondria and SVs during the presynaptic development.

Acknowledgement: NIH NS36754, RGC HKUST6107/01M, AoE/B-15/01. 


\section{P-27/25 \\ Intermittent Hypoxia Time-Dependently Reduces Large-Conductance Calcium-Activated Potassium Channel Activities via Redox Mechanism in Rat Hippocampal CA1 Pyramidal Neurons}

Tjong, Y.W., Fung, M.L.

Department of Physiology, Faculty of Medicine, The University of Hong Kong, Pokfulam, Hong Kong, China

Intermittent hypoxia $(\mathrm{IH})$ is defined as repeat episodes of hypoxia interlace with episodes of normoxia, which is associated with obstructive sleep apnea (OSA). It was found that IH modulates the neuronal excitability and hippocampal functions. Large conductance calcium-activated potassium (BKca) channel is activated by membrane potential, together with a rise in intracellular calcium, that maintain the resting state of neuronal cells. Recent studies reported that the BKca channel activities increased after ischemic exposure but decreased in chronic hypoxia in rat hippocampal CA1 pyramidal neurons. The effect of IH on the BKca channel activity is not yet known. The aim of the present study is to investigate the change of BKca channel activity during the time course of $\mathrm{IH}$ and the underlying cellular pathways. We hypothesized that $\mathrm{IH}$ induces a time-dependent change in BKca channel activities in rat hippocoampal CA1 neurons. Young male Sprague-Dawley rats (21 days old, 60-70 g) were exposed to IH (inspired oxygen levels cyclic between 5 and $21 \%$ at 60 cycles $/ \mathrm{min}$ for $8 \mathrm{~h}$ /day for 7 days) or to normoxia $(\mathrm{N})$ as a control (in room air). Patch clamping studies with the excised inside-out configuration were performed on freshly dissociated hippocampal CA1 neurons from the $\mathrm{IH}$ or $\mathrm{N}$ rats. The mean slope conductance in 3-day IH (IH3), IH7 and IH10 group had no differences and was not different from the $\mathrm{N}$ group. The open probability of BKca channel activity reduced during the time course of $\mathrm{IH}$ treatment. At $+40 \mathrm{mV}$ holding potential, the open probability of BKca channel lowered in the IH3 comparing with the N group and markedly decreased following 7-day and 10-day IH exposure. The mean open time of BKca channel decreased with a prolongation of the mean closed time and the changes were positively correlated to the duration of $\mathrm{IH}$ exposure. These results suggest that $\mathrm{IH}$ induces time-dependent changes in BKca channel activity in hippocampal CA1 neurons.

Furthermore, the decreased BKca channel activity in the IH7 group was recovered by an oxidizing agent 5,5'-dithio-bis(2-nitrobenzoic acid) (1 mM) but not by reducing agent dithiothreitol (1 $\mathrm{mM})$, suggesting an involvement of redox mechanism in modulation of BKca channel in IH. In summary, IH time-dependently attenuates hippocampal BKca channel activities via redox modulation, which may lead to neuronal hyperexcitability in the pathophysiological development of OSA.

Acknowledgement: This study was supported by research grants from Research Grants Council, HKSAR, and the University Research Council of The University of Hong Kong.

\section{P-28/25 \\ Heat Shock Protein 27 Expresssion in Retinal Ganglion Cells Is Independent of Distance of Axotomy in Hamster}

Wong, W.K., Cho, E.Y.P.

The Chinese University of Hong Kong, Hong Kong, China

It is uncertain whether heat shock protein 27 (HSP27) plays a role in neuronal survival after injury. Previously, we have shown that in hamster retina, a small proportion of retinal ganglion cells (RGCs) expressed HSP27 in the early phase (2 weeks) post-axotomy. It is known that a closer distance of optic nerve transection (ONT) would increase the cell death of RGCs, hence, we want to address whether the expression of HSP27 in RGCs correlate with the change of axotomy distance and the survival of RGCs after axotomy. The optic nerve was cut in adult golden hamsters at different distances: 1, 2 and $4 \mathrm{~mm}$. After 3, 7 and 14 days post-axotomy, the retinas were taken out and double-stained with anti$\beta I I I-t u b u l i n$ (clone TuJ1) and anti-HSP27 antibodies. The number of TuJ1-positive RGCs which represented the total number of RGCs and HSP27-positive RGCs were quantified in the same retina at each post-axotomy time point and for each distance of axotomy. At 1- and 2-mm ONT, there was a significant drop in the number of TuJ1-positive RGCs continuously from normal to 14 days, whereas at $4 \mathrm{~mm} \mathrm{ONT}$, this decrease was seen only 7 days to 14 days. On the other hand, at each time point, differences in TuJ1surviving RGCs were observed at different distances of axotomy, in which a closer distance induced a greater cell death. In contrast to the change in number of surviving RGCs at different axotomy distances, the number of HSP27-positive RGCs remained fairly constant. From 3 days post-axotomy, a small proportion of RGCs expressed HSP27 for all 3 distances, which it sustained at 7 days after ONT cut. However, at 14 days ONT, only a few HSP27-RGCs remained in all 3 groups. This indicates although the survival of RGCs varies with distance of axotomy, the expression of HSP27 does not correlate with the distance of ONT nor the survival of RGCs. This suggests that the signal which induces HSP27 expression may be separate from the one that influences RGC cell death.

\section{P-29/25 \\ A Neuromuscular Junction-Like Calcium Release Mechanism in a Unicellular Organism

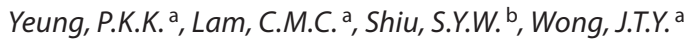 \\ aBiology Department, Hong Kong University of Science and Technology, ${ }^{\text {b}}$ Physiology Department, Hong Kong University, Hong Kong, China}

When a myocyte is depolarized by an action potential, calcium ions enter the cell through L-type calcium channels located on the sarcolemma. This calcium, or the physical interaction between the activated L-type calcium channel, triggers a subsequent release of calcium that is stored in the sarcoplasmic reticulum (SR) through calcium-release channels ryanodine receptors. Crypthecodium cohnii is an unicellular dinoflagellate (phyloge- 
netically related to malarial parasite) with cortical multi-membranous structures apparently similar to the SR. In the present study, both fluorescence-conjugated ryanodine and dihydropyridine gave positive labellings on the cortical area of dinoflagellate cells in where the chlortetracycline-stained calcium stores were located. Either mechanical stimulations or potassium ions could induce membrane potential changes and calcium mobilizations. In addition, cytosolic calcium mobilizations induced by L-type calcium channel agonist (Bay $\mathrm{K}$ ) was inhibited by ryanodine receptor antagonist (dantrolene). When the membrane potentials were disrupted by sodium ionophore, both mechanically-induced cytosolic calcium mobilizations and membrane potential changes were reduced. This indicated that the dihydropyridine receptor-like protein was upstream of the ryanodine receptor-like channel. Accumulated data, therefore, are consistent with a neuromuscular type excitation-contraction coupling-like mechanism in the dinoflagellates.

Acknowledgement: Part of this research was supported by HKUST's EHIA05/06.SC04 in Molecular Medicine awarded to J.T.Y.W. and S.Y.W.S).

\section{P-30/25 \\ Expression of TRPC3 Channels in Human Cerebrum and the Interacting Phosphorylation-Mediated Inactivation Mechanisms for the TRPC3 Channel}

Kwan, H.-Y., Yip, H., Huang, Y., Yao, X.

Department of Physiology, The Chinese University of Hong Kong, Hong Kong, China

Canonical Transient Receptor Potential 3 (TRPC3) channel is an isoform of the TRPC family. It is a $\mathrm{Ca}^{2+}$-permeable channel and is activated downstream of phospholipase C (PLC). We, as well as other studies, showed that it is expressed in hippocampus, posterior pituitary, thalamic areas, medulla, spinal cord, human cerebral artery and human cerebral cortical neurons [1-3]. In the present study, we explored the relationship between the PKC and PKG inactivation mechanisms of TRPC3 channel. HEK cells were used as an expression model. We transfected HEK cells with a PKG-expressing construct and a TRPC3-expressing construct. Addition of 1-oleoyl-2-acetyl-sn-glycerol (OAG), a membranepermeant analog of diacylglycerol (DAG), elicited a TRPC3-mediated $\left[\mathrm{Ca}^{2+}\right]_{\mathrm{i}}$ rise in these cells. This OAG-induced rise in $\left[\mathrm{Ca}^{2+}\right]_{\mathrm{i}}$ could be inhibited by phorbol 12-myristate 13 -acetate (PMA), an agonist for PKC, in a dose-dependent manner. 8-Br-cGMP (2 $\mathrm{mM})$, an activator of PKG, could also inhibit the OAG-induced $\left[\mathrm{Ca}^{2+}\right]_{\mathrm{i}}$ rise; this inhibition was reversed by a PKG blocker, KT5823 (1 $\mu \mathrm{M})$. With standard VASP Ser239 phosphorylation experiment, it showed that PKC could stimulate the activity of PKG, suggesting an interaction between the PKC- and PKG-mediated inhibitory pathways on TRPC3. Further studies have shown that point mutations at the two PKG phosphorylation sites (T11 and S263) of TRPC3 [4] markedly reduced the PMA inhibition. Moreover, inhibition of PKG activity by KT5823 (1 $\mu \mathrm{M})$ also greatly reduced the PMA inhibition on the channel. In conclusion, the data presented here support the hypothesis that there are two interacting phosphorylation-mediated inactivation mechanisms for the TRPC3 channel. Besides directly inhibiting the channel, PKC can also activate PKG, which in turn phosphorylates TRPC3 and inhibits the channel.

Acknowledgement: The project is supported by RGC grant (CUHK4366/04M).

\section{References}

1 Riccio A, et al: Brain Res Mol Brain Res 2002;109:95-104.

2 Mizuno N, et al: Mol Brain Res 1999;64:41-51.

3 Yip H, et al: Histochem Cell Biol 2004;122:553-561.

4 Kwan H, et al: PNAS 2004;101:2625-2630.

\section{P-31/25 \\ Modulation in Gene Expression of NMDA \\ Receptor One Reduces Motor Symptoms of 6-Hydroxydopamine-Lesioned Rat}

Leung, T.C.H., Lam, R.W.C., Yung, K.K.L.

Department of Biology, Hong Kong Baptist University Kowloon Tong, Hong Kong, China

Parkinson's disease is a common motor disorder and it is caused by a degeneration of dopaminergic neurons in the substantia nigra. After dopamine denervation, an over-activity of glutamatergic pathways has been found and the over-activity is implicated in the neuropathology of Parkinson's disease. Our previous study (Lai et al., Neurochem. Int. 45, 11-22, 2004) have found that application of an antisense oligodeoxynucleotide specific for N-methyl-D-aspartate receptor one (NR1) have successfully knockdown the expression of NR1 gene expression in the striatum of 6-hydroxydopamine-lesioned rats. Reduction in motor symptoms in the lesioned rats has then been found. In the present study, modulation of gene expression of NR1 was re-addressed using a small interfering RNA (siRNA) specific for NR1. In PC12 cells, reductions of NR1 proteins after a single application of NR1 siRNA were found by Western blotting experiments. In addition, after one single application of NR1 siRNA in the striatum of the lesioned rats, a significant reduction in apomorphineinduced rotation was found. Interestingly, no changes in the levels of NR1 proteins were found between the lesioned and non-lesioned striatal tissues. The levels of NR1 immunofluorescence were not modified after the siRNA application. The mechanisms of the reduction in motor symptoms in the rat model of Parkinson's disease by NR1 specific siRNA therefore wait for further investigation.

Acknowledgement: The present work was supported by Faculty Research Grant, FRG/04-05/II-27, Hong Kong Baptist University. 


\section{P-32/25 \\ A Role of Phospholipase $\mathrm{C}$ and $\mathrm{PI}_{3}$-Kinase in the Regulation of TRPV4 Channels}

Kwan, H.Y. ${ }^{\mathrm{a}}$, Janssens, $A .{ }^{\mathrm{b}},{ }, Y a o, X^{\mathrm{a}}{ }^{\mathrm{a}}$, Nilius, $B .{ }^{\mathrm{b}}$

aDepartment of Physiology, Chinese University of Hong Kong,

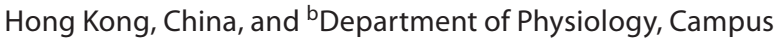

Gasthuisberg, KU Leuven, Belgium

TRPV4 is a member of the Vanilloid Transient Receptor Potential (TRPV) channel family. It is an outward rectifying cationic channel activated by hypotonicity-induced cell swelling [1] and warm temperature $\left(\geq 25^{\circ} \mathrm{C}\right)[2,3]$. Its expression in dorsal root ganglia neurons, the hippocampus neurons and the osmosensory cells of the brain's circumventricular organs $[4,5]$ strongly suggests its contribution to the regulation of the core body temperature and osmosensing functions. In this report, we study a $\mathrm{Ca}^{2+}$-independent gating mechanism on TRPV4 channel. Murine TRPV4 was cloned in an expression plasmid coupled by green fluorescent proteins and an IRES sequence. This construct was transiently transfected to HEK 293 cells. A specific TRPV4 agonist [6], $4 \alpha$-PDD $(1 \mu \mathrm{M})$, activated the TRPV4 currents. Activation of this channel also induced a rise in $\left[\mathrm{Ca}^{2+}\right]_{\mathrm{i}}$ in these cells. Application of a phospholipase C (PLC) inhibitor U73122 (1 $\mu \mathrm{M})$ in the bathing solution in patch clamp study reduced the $4 \alpha$ PDD-activated current. Wortmannin $(50 \mu \mathrm{M})$, an inhibitor for phosphatidylinositol 3-kinase, increased the $4 \alpha$-PDD-activated current significantly when the chemical is applied in the pipette solution. In confocal study, pre-incubation of the cells with $\mathrm{U} 73122(10 \mu \mathrm{M})$ for $10 \mathrm{~min}$ also reduced the $4 \alpha$-PDD-induced rise in $\left[\mathrm{Ca}^{2+}\right]_{\mathrm{i}}$, whereas an inactive analogue U73343 had no inhibitory effect. In conclusion, the data presented here suggest that the inhibition of PLC reduces the channel activity; while inhibition of phosphatidylinositol 3-kinase and phosphatidylinositol 4-kinase enhances the channel activity.

Acknowledgement: The project is supported by RGC grant (CUHK4366/04M).

\section{References}

1 Liedtke W, et al: Cell 2000;103:525-535.

2 Watanabe H, et al: JBC 2002;277:47044-47051.

3 Voets T, et al: Nature 2004;430:748-754.

4 Guler AD, et al: J Neurosci 2002;22:6408-6414.

5 Liedtke W, et al: PNAS 2003;100:13698-13703.

6 Watanabe H, et al: JBC 2002;277:13569-13577.

\section{P-33/25 \\ Dedifferentiation of Adult Human Myoblasts Induced by CNTF in vitro}

Chen, $X .^{a, b}$, Fan, $M{ }^{a}$

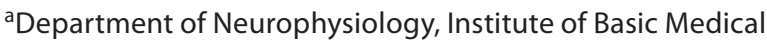
Sciences, Beijing, 'baboratory of Nerves and Muscles,

Astronaut Research and Training Center of China, Beijing, China

Ciliary neurotrophic factor (CNTF) belongs to the interleukin (IL)-6 family cytokines (IL-6, IL-11, LIF, oncostatin M (OSM), cardiotrophin-1 (CT-1), cardiotrophin-like cytokine (CLC)). Cellular responses to CNTF and IL-6-type cytokines are elicited by different multiunit receptor complexes (CNTFR $\alpha$, gp130, LIFR). Binding of CNTF to the CNTFR $\alpha$ induces a heterodimer of the signal transducing $\beta$-receptors gp130 and LIFR, which triggers intracellular signaling cascades. The variety of CNTFR complexes, however, funnels into activation of an only limited number of intracellular signaling cascades mainly including the JAK-STAT and ERK-MAPK or p44/p42 MAPK pathways, while the latter has been implicated in regulating myoblast differentiation in vitro, but its functions seem to be controversial with either a positive or a negative role in myogenesis. Furthermore, although CNTF can cause activation of p44/p42 MAPK in neural cells and adipocytes, whether CNTF may activate p44/p42 MAPK in skeletal myoblasts is still unclear. The expression of CNTF is restricted to Schwann cells in the peripheral and astrocytes in the central nervous system. Recent studies indicated that CNTF receptor (CNTFR) localized predominantly within neural tissue has relatively high expression in skeletal muscle, and in denervated skeletal muscle CNTF exerts myotrophic effects and the expression of CNTF $\alpha$ receptor $(\mathrm{CNTFR} \alpha)$ significantly also increases. However, the direct effect of CNTF on skeletal myoblasts is not yet well understood. Here, we investigated the direct effect of CNTF on skeletal myoblasts of adult human. Surprisingly, we found that CNTF induced the myogenic lineage-committed myoblasts at a clonal level to dedifferentiate into multipotent progenitor cells - they not only could proliferate for over 20 passages with the expression absence of myogenic specific factors Myf5 and MyoD, but they were also capable of differentiating into new phenotypes, mainly neurons, glial cells, smooth muscle cells, and adipocytes. These 'progenitor cells' retained their myogenic memory and were capable of redifferentiating into myotubes. Furthermore, CNTF could activate the p44/p42 MAPK and downregulate the expression of myogenic regulatory factors (MRFs). Finally, PD98059, a specific inhibitor of $\mathrm{p} 44 / \mathrm{p} 42$ MAPK pathway, was able to abolish the effects of CNTF on both myoblast fate and MRF expression. Our results demonstrate the myogenic lineage-committed human myoblasts can dedifferentiate at a clonal level and CNTF is a novel regulator of skeletal myoblast dedifferentiation via $\mathrm{p} 44 /$ p42 MAPK pathway. 
Barnard, E.A. P-6/25

Burn, A.J. P-24/25

Chan, A.K. P-24/25, P-25/25

Chan, S.S.W. P-4/25

Chan, W.S. OP-5/25

Chan, W.Y. OP-11/25, P-24/25, P-25/25

Chan, Y.S. OP-5/25, OP-10/25, P-1/25, $\mathrm{P}-2 / 25, \mathrm{P}-13 / 25$

Chang, R.C.C. OP-3/25, OP-7/25

Chang, R.C.-C. P-7/25, P-10/25

Chen, L.W. OP-5/25

Chen, X. P-33/25

Cheng, F.H.M. P-5/25

Cheng, R.C.C. P-8/25

Cheung, J.K.H. P-21/25

Cheung, K.K. P-25/25

Cheung, P.T. P-12/25

Chiu, K. OP-3/25, P-8/25

Cho, E.Y.P. P-28/25

Choi, R.C.Y. OP-6/25, P-6/25, P-12/25, P-15/25, P-18/25

Copp, A.J. OP-11/25

Dong, T.T.X. P-21/25

Fan, M. P-33/25, PL-2/25

Fu, A.K.Y. OP-2/25, OP-8/25, OP- $12 / 25$

Fu, H. P-22/25

Fung, M.L. P-27/25

Han, Y. P-22/25

He, J. OP-9/25, P-4/25

Ho, Y.-S. P-7/25

Huang, Y. P-16/25, P-30/25

Hugon, J. OP-7/25

Hung, K.-W. OP-12/25

Ip, A.K.C. P-8/25

Ip, N.Y. OP-2/25, OP-8/25, OP-12/25,

$\mathrm{P}-12 / 25, \mathrm{P}-14 / 25, \mathrm{P}-17 / 25, \mathrm{P}-23 / 25$

Janssens, A. P-32/25

Ji, J.Z. OP-3/25

Kam, A.Y.F. P-9/25, P-17/25

Kan, K.K.W. P-22/25

Kwan, D.H.T. P-9/25

Kwan, H.-Y. P-30/25, P-32/25

Kwok, J.C.F. P-1/25

Kwok, N.S. OP-7/25

Lai, C.H. OP-10/25, P-13/25

Lai, S.K. P-2/25
Lai, S.W. OP-7/25, P-10/25

Lam, C.M.C. P-29/25

Lam, C.S.C. P-22/25

Lam, R.W.C. P-31/25

Lau, F.T.C. OP-6/25, P-11/25

Lau, W.K. P-1/25

Lee, C.W. P-26/25

Lee, N.T.K. P-22/25

Leung, T.C.H. P-31/25

Leung, W.K.W. P-12/25, P-21/25

Li, H.-Z. PL-3/25

Li, W. P-22/25

Li, X. P- $22 / 25$

Lin, G. P-4/25

Lin, S.C. OP- $2 / 25$, OP- $8 / 25$

Liu, A.M.F. P-3/25

Lo, R.K.H. P-3/25

$\mathrm{Lu}$, C.C. OP- $8 / 25$

Ma, C.W. P-13/25

Madhavan, R. OP-4/25

Massoulié, J. OP-6/25, P-11/25, P-18/25

Mei, H. P-14/25

Mok, S.C. P-25/25

Moreaux, B. P-5/25

Ng, T.K.Y. P-1/25

Ng, Y.P. OP-2/25, OP-8/25, P-17/25, $\mathrm{P}-23 / 25$

Ngan, M.K. OP-1/25

Nilius, B. P-32/25

Pang, Y. P-22/25

Peng, H.B. OP-4/25, P-18/25, P-26/25

Qian, Y.K. OP-4/25

Rudd, J.A. OP-1/25, P-4/25, P-5/25

Shen, B. PL-3/25

Shen, Y. OP-12/25

Shiu, S.Y.W. P-29/25

Shum, D.K.Y. P-1/25, P-13/25, P-20/25

Siow, N.L. P-15/25, P-18/25

So, K.-F. OP-3/25, OP-7/25, P-7/25, $\mathrm{P}-8 / 25, \mathrm{P}-10 / 25$

Song, Y.-N. PL-3/25

Suen, K.C. OP-7/25

Tian, L. PL-3/25

Ting, A.K.L. OP-6/25, P-11/25

Tjong, Y.W. P-27/25

Tse, Y.C. OP-10/25, P-2/25
Tsim, K.W.K. OP-6/25, P-6/25, P-11/25, P-12/25, P-15/25, P-17/25, P-18/25, $\mathrm{P}-21 / 25, \mathrm{P}-22 / 25, \mathrm{P}-23 / 25$

Wai, M.K. OP-1/25

Wan, C. OP-1/25

Wang, J.-J. PL-3/25

Wang, L. OP-11/25

Wise, H. P-3/25, P-17/25, P-19/25, P-23/25

Wong, C.O. P-16/25

Wong, C.S.S. P-6/25

Wong, J.T.Y. P-29/25

Wong, W.K. P-28/25

Wong, Y.H. OP-2/25, P-3/25, P-9/25, P-12/25, P-14/25, P-17/25, P-19/25, P-23/25, PL-1/25

Wu, E.H.T. P-17/25

Wu, Z.G. P-12/25, P-14/25, P-17/25, P-23/25

Xiao, F. P-23/25

Xie, H.Q.H. P-15/25, P-18/25

Xue, J. P-22/25

Yamamoto, K. P-4/25

Yao, X. P-16/25, P-30/25, P-32/25

Yeung, J.H.K. OP-1/25

Yeung, P.K.K. P-29/25

Yew, D.T. P-25/25

Yip, H. P-30/25

Yiu, C. OP-10/25

Yu, M.S. OP-3/25, OP-7/25, P-7/25, $\mathrm{P}-8 / 25, \mathrm{P}-10 / 25$

Yuen, W.-H. P-7/25, P-8/25, P-10/25

Yung, H.S. P-19/25

Yung, K.K.L. OP-5/25, P-31/25

Yung, L.Y. P-17/25

Yung, W.H. P-2/25

Zee, S.-Y. P-8/25, P-10/25

Zhang, Y. P-20/25

Zhao, K.J. P-21/25

Zhao, X.T. OP-4/25

Zhao, Y. P-22/25

Zhou, H. P-2/25

Zhu, J.-N. PL-2/25

Zhu, J.T.T. P-21/25

Zhu, L.-L. PL-2/25

\section{KARGER}

๑ 2006 S. Karger AG, Basel

Fax +41 613061234

E-Mail karger@karger.ch

www.karger.com 